\title{
PHYTOPLANCTON ET PRODUCTIVITÉ PRIMAIRE DE QUELQUES LACS D'ALTITUDE DANS LES PYRÉNEEES
}

\author{
par J. CapblancQ ${ }^{1}$.
}

\section{SOMMAIRE}

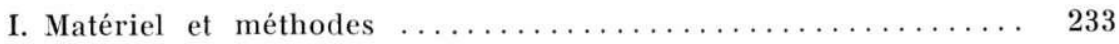

1. Techniques de terrain $\ldots \ldots \ldots \ldots \ldots \ldots \ldots \ldots \ldots \ldots \ldots \ldots \ldots \ldots \ldots$

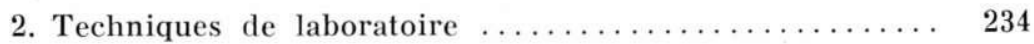

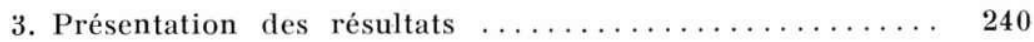

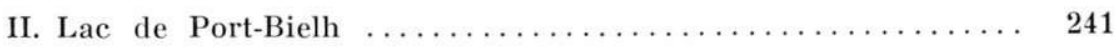

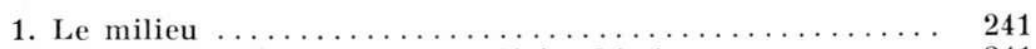

1.1. Température et propriétés chimiques ........ 241

1.2. Lumière .......................... 248

1.3. Zooplancton $\ldots \ldots \ldots \ldots \ldots \ldots \ldots \ldots \ldots \ldots \ldots \ldots$

2. Phytoplancton : composition du peuplement et évolution

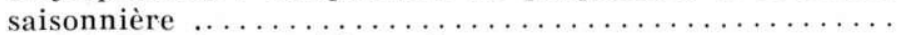

2.1. Peuplement hivernal . . . . . . . . . . . .

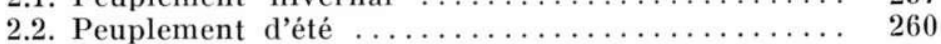

2.2.1. La biomasse et sa composition ........ 260

2.2.2. Répartition du phytoplancton en fonction de la profondeur ................. 262

2.2.3. Cycle saisonnier et répartition verticale des espèces dominantes ................ 263

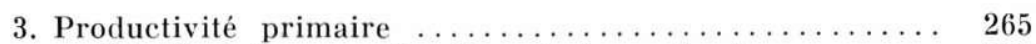

3.1. Variations en fonction de la profondeur ...... 267

3.2. Variations saisonnières $\ldots \ldots \ldots \ldots \ldots \ldots \ldots 267$

3.3. Variations journalières ............... 269

3.4. Assimilation de carbone à l'obscurité ......... 271

1. Ce mémoire constitue une partie d'une thèse présentée devant l'Université Paul-Sabatier de Toulouse en vue de l'obtention du Doctorat ès Sciences Naturelles.

Laboratoire d'Hydrobiologie, Université Paul-Sabatier, 118, route de Narbonne, 31077 Toulouse Cedex. 
III. Gourguet, Gourg Nère Moyen et Gourg Nère Infúrieur II . . . 273

1. Composition et évolution saisonnière du phytoplancton .. 273

2. Productivité primaire $\ldots \ldots \ldots \ldots \ldots \ldots \ldots \ldots \ldots \ldots .279$

3. Comparaisons avec le lac de Port-Bielh .......... 281

IV. Relations entre le phytoplancton, sa productivité et les com-

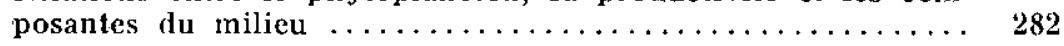

1. Hydrographie $\ldots \ldots \ldots \ldots \ldots \ldots \ldots \ldots \ldots \ldots \ldots \ldots \ldots, 283$

2. Température $\ldots \ldots \ldots \ldots \ldots \ldots \ldots \ldots \ldots \ldots \ldots \ldots, 283$

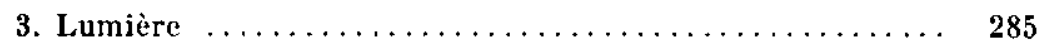

4. Composantes chimiques $\ldots \ldots \ldots \ldots \ldots \ldots \ldots \ldots \ldots \ldots, 294$

5. Composantes biotiques $\ldots \ldots \ldots \ldots \ldots \ldots \ldots \ldots \ldots \ldots .298$

5.1. Biomasse algale $\ldots \ldots \ldots \ldots \ldots \ldots \ldots \ldots \ldots \ldots .298$

5.2. Diversité spéciflque $\ldots \ldots \ldots \ldots \ldots \ldots \ldots \ldots \ldots \ldots, 300$

5.3. Zooplancton $\ldots \ldots \ldots \ldots \ldots \ldots \ldots \ldots \ldots \ldots \ldots \ldots \ldots$

V. Productivité journalière du lac de Port-Biclh $\ldots \ldots \ldots \ldots \ldots, 302$

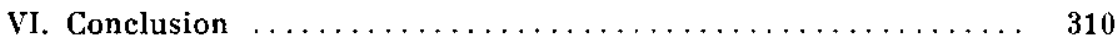

De nombreuses études existent sur l'écologie et la productivité du phytoplancton en milieu marin et en eau douce. Parmi elles, les données concernant les lacs de haute montagne sont récentes et les résultats encore rares.

La terminologie utilisée pour caractériser ces lacs (ultra-oligotrophes, panoligotraphes, allotrophes, kryoeutrophes) reposait sur le postulat de leur extrême pauvreté en phytoplancton. RHODE (1962), le premier, découvrit l'existence d'abondantes populations algales dans ces lacs. Il s'agissait presque exclusivement de formes nannoplanctoniques, vivant toute l'annéc dans la zone pélagique, leur biomasse et leur productivité pouvant atteindre, en profondeur, des valeurs identiques à celles relevées dans l'épilimnion des lacs les plus productifs. Ces résultats ont été confirmés au cours des recherches menées, ces dix dernières années, dans les Alpes autrichiennes (Pechlaner 1964 el 1967, Pechlaner et al. 1972, Tilzer 1972 a), en Laponie suédoise (Rodhe et al. 1966, Nauwerck 1966, 1967 et 1968) et dans les Pyrénées (CapbiaAnco el Iaville 1972, Capblance et al. 1972).

Cette étude du phytoplancton des lacs du vallon de Port-Bielh a commencé en 1967 dans le cadre du Programme Biologique Inter- 
national. Elle s'est développée parallèlement à celle des populations benthiques (Lavilue 1972 a ct b) et zooplanctoniques (REy et CAPBIANCQ en préparation ).

L'objectif final est de préciser les relations au sein de ces écosystèmes, les conditions extrêmes du milieu laissant espérer une structure et un fonctionement relativement simples.

\section{I. - MATẼRIEL ET MẼTHODES}

De 1966 à 1971 ont été réalisées, essentiellement pendant la période de dégel, 48 séries de mesures dans le lac de Port-Bielh et 31 séries de mesures dans les lacs du Gourguet, Gourg Nère Moyen et Gourg Nère Inféricur II. Quelques relevés hivernaux effectués en 1969,1970 et 1971 ont permis de compléter le cycle annuel dans le lac de Port-Biclh.

\section{TECHNIQUES DE TERRAIN}

Les prélèvements d'eau ont élé réalisés avce une bouteille opaque de type Van Dorn d'une capacité de deux litres. Huit profondeurs $(0,1,3,5,8,12,16,18 \mathrm{~m})$ ont été prospectées lors de chaque série d'échantillonnage dans le lac de Port-Bielh. Dans les lacs peu profonds, l'eau a ćté prélevée à $0 \mathrm{~m}, 1,5 \mathrm{~m}$ et $3 \mathrm{~m}$.

Les prélèvements destinés à l'identification et au comptage des algues ont été fixés immédiatement avec quelques gouttes d'une solution de Lugol ( $\mathrm{I}+\mathrm{IK}$ à saturation $+\mathbf{1 0} \%$ acélate de $\mathrm{Na}$ ). Pour les dosages chimiques, l'cau a été conservée jusqu'au retour au laboratoire dans des flacons de verre neutre de Jena maintenus au frais et à l'obscurité. La température, la teneur en oxygène dissous et le pH ont élé mesurés à chaque profondeur au moment des prélèvements.

La méthode du ${ }^{14} \mathrm{C}$ de Steemanv-Nielsen (1952), plus sensible que la méthode de l'oxygène, a été retenue pour mesurer « in situ » l'activité photosynthćtique du phytoplanclon. Pour chaque mesure, nous avons utilisé trois flacons (2 flacons transparents +1 flacon opaque) en verre neutre de Jena d'une capacité de $125 \pm 1 \mathrm{ml}$. L'addition de la solution do ${ }^{14} \mathrm{CO}_{3} \mathrm{NaH}$ d'une aclivilé de $1 \mu \mathrm{C} / \mathrm{ml}$ et conservée en ampoules scellées de $25 \mathrm{ml}$ a été faite à l'aide d'une seringue à butée calibréc à $1 \pm 0,006 \mathrm{ml}$. Après enrichissement, les flacons ont été exposés aux profondeurs de prélèvement et maintenus en position horizontale grâce à un dispositif d'accrochage spécial. Afin de réduire l'erreur provoquée par un confinement prolongé du phytoplancton (Volisenweider et Nauwerck 1961) et pour compenser l'effet de la périodicité journalière de 
la photosynthèse (Doty el Ogitri 1957, Yentsch et Ryther 1957) nous avons choisi des périodes d'exposition de courte durée (4 à $6 \mathrm{~h})$ et symétriques par rapport au midi solaire $(10 \mathrm{~h}-16 \mathrm{~h}$ out $11 \mathrm{~h}-15 \mathrm{~h})$. En 1971, nous avons réalisé, à trois reprises, des séries de mesures de 3 à 5 h sur l'ensemble de la journéc solaire afin de déterminer le rythme journalier de la photosynthèse dans le lac de Port-Bielh.

La filtration de la totalité de l'échantillon a été faite, dès la fin de la période d'exposition, sur des membranes filtranles d'une porosité de $0,2 \mu$ (Menbranfilter, Goltingen). La pression de filtration a été maintenue entre 10 et $15 \mathrm{~cm}$ de $\mathbf{H g}$ afin d'éviler la rupture des formes les plus fragiles. Par ailleurs, nous avons déterminé, à différentes périodes de l'année, les pertes provoquées par la filtration (Arthur el Rigler 1967, Schindere et Holdmgren 1971, Schindefer 1971), en filtrant des fractions de volumes différents d'échantillons d'eau exposés avec du ${ }^{14} \mathrm{COO}_{3} \mathrm{NaH}$. Les fillres porteurs de phyloplancton ont été desséchés immédiatement sur gel de silice avant comptage au laboratoire.

Les données concernant le temps d'insolation el l'intensité de la radiation totale ont été obtenues grâce à un solarigraphe enregisIreur (Kipp and Zonen, Delft, Hollande) placé près du lac de Port-Bielh. La quantité de lumière transmise a été évaluéc par des mesures effec!uées à l'aide d'une cellule photoélectrique (Megatron) protégée par un boitier élanche, combinéc avec les filtres $\mathrm{BG}_{12}, \mathbf{V G} \mathrm{G}_{\mathrm{y}}, \mathbf{R G}_{\mathrm{t} ; \mathrm{3},}, \mathrm{BG}_{12}+\mathrm{UG}_{1}$ (Scholt, Mainz, Allemagne) el reliée à un microampèremètre. Par ailleurs, nous avons noté, lors de chaque série de mesure, la limite de visibilité d'un disque de Secchi blanc de $30 \mathrm{~cm}$ de diamètre.

Le zooplancton a ćté prélevé aux profondeurs de $0,5,10,15$ et $18 \mathrm{~m}$ dans le lac de Port-Bielh avec une bouleille de type VanDorn d'une capacité de 5 litres. Les échantillons ont été concentrés sur un filet à mailles fines ( $40 \mu$ de vide de maille).

\section{TECHNIQUES DE LABORATOIRE}

- Les dosages chimiques ont élé réalisés dès le retour au laboratoire selon les méthodes décrites dans la première partie de ce travail (CAPBdanco et Laville 1969). La teneur en CO. total a été calculéc, à partir des valeurs de température, alcalinité to!ale et $\mathrm{pH}$, à l'aide des tables de Salnders, Trama el Bachmany (1962) et de Saruhashi (1955). En 1968 el 1970 nous avons tenté de préciser l'évolution annuelle du phosphore et de l'azote dissous, généralement considérés comme facleurs limitants de la production primaire. 
- Les complages d'algues onl été effectués avec un microscope inversé (Zeiss) après 24 h de sédimentation des échantillons dans des chambres combinées de $50 \mathrm{ml}$ ou $100 \mathrm{ml}$ (UTERmöHL 1958). Deux bandes diamétrales de $25 \times 0,25 \mathrm{~mm}$ ont été examinées au grossissement $40 \times$ pour les formes les plus grosses et les moins abondantes. Les espèces de petite taille et les formes les plus denses ont élé comptées à l'immersion sur 2 à 5 bandes de $10 \times 0,1 \mathrm{~mm}$. Le volume moyen de chaque espèce a été calculé en ramenant sa forme ì celle d'une figure géométrique dont les dimensions sont celles de l'espèce considérée. En admettant que la densilé des algues est très voisine de 1 , on estime que $10^{\prime \prime} \mu^{\prime \prime} /$ litre $=1 \mu \mathrm{g}$ de poids algal frais $/ \mathrm{litre}=1 \mathrm{mg} / \mathrm{m}^{3}$.
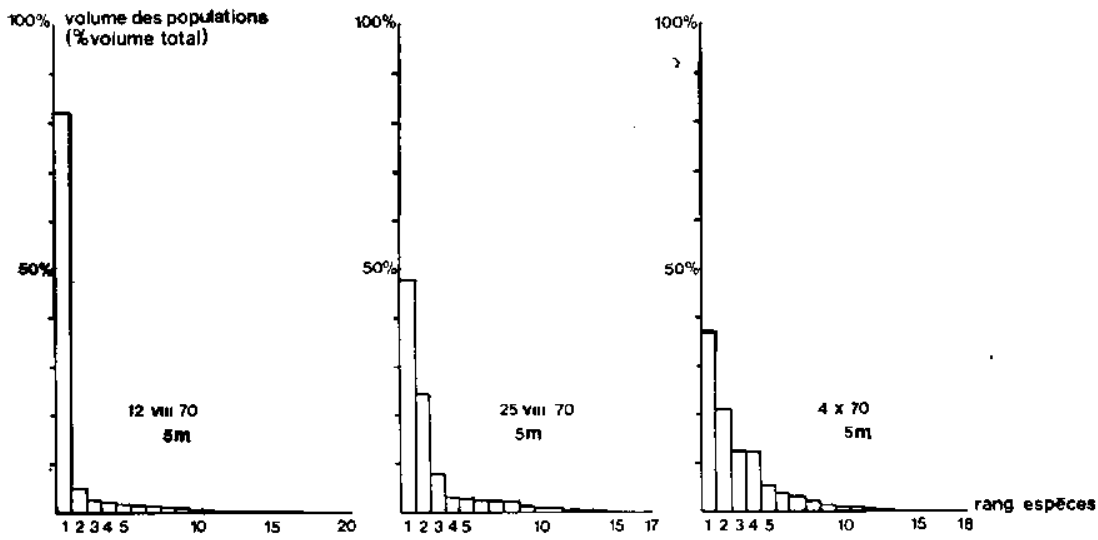

FIG. 1. - Exemples de distribution des hiomasses des diverses populations dans le phytoplancton du lac de Port-Bielh.

La précision dans l'expression du résullat final dépend essentie!lement de la précision des comptages et de la distribution des algues dans le lac. L'erreur sur les complages est inversement proportionnelle au nombre $\mathrm{N}$ d'unités comptées et peut être estimée par la formule (Lund et al. 1958, Javornicky 1958, Nauwerck 1963) :

$$
E \max .= \pm 2 \frac{100}{\sqrt{\mathrm{N}}} \% \text {. }
$$

Fn fait, pour des numérations de l'ordre de 20 à 40 organismes, l'erreur slatis!ique dépasse rarement $15 \%$ (NAuwback 1963). La structure du peuplement phytoplanctonique du lac de Port-Bielh est caractérisée par la dominance de 1 à 2 espèces en juillet et août, 3 à 4 espèces en septembre et octobre qui forment à elles seules plus do $95 \%$ de la biomasse (fog. 1). Pour ces espèces, nous avons complé entre 100 et 400 cellules par échantilion; les comp- 


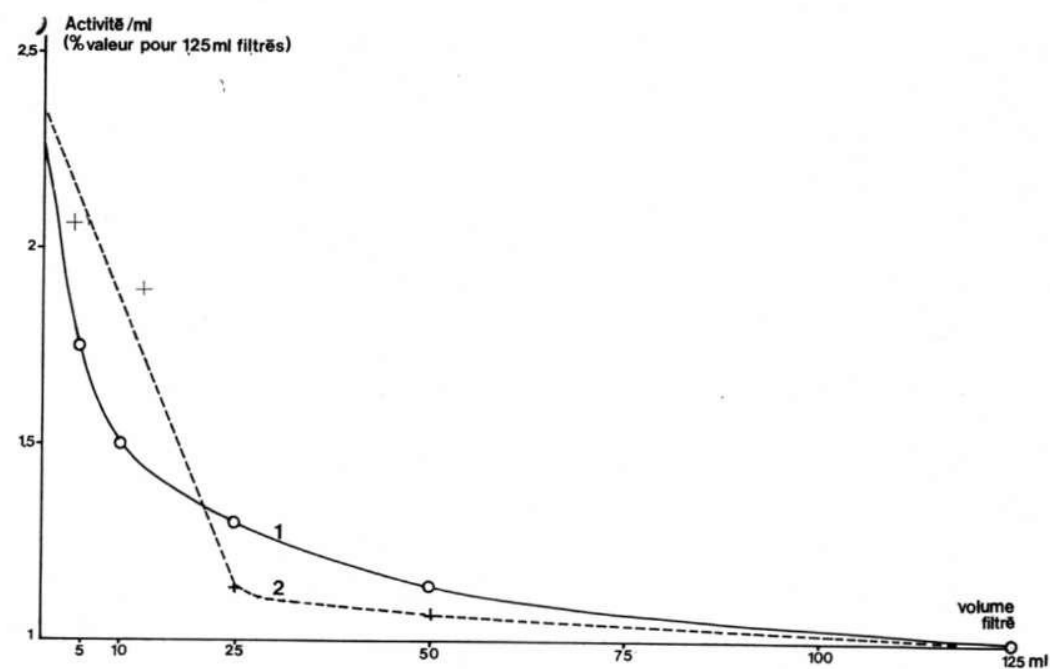

FIG. 2. - Exemple de courbes de correction pour les pertes de radio-activité à la filtration. Courbe 1 : pression $10-15 \mathrm{~cm}$ de $\mathrm{Hg}$; courbe 2 : pression 30 $40 \mathrm{~cm}$ de $\mathrm{Hg}$.

tages ont été limités entre 10 et 50 cellules pour les autres espèces. Dans ces conditions, le résultat global est donné avec une erreur maximale inférieure à $20 \%$.

La distribution des algues dans le lac a été testée sur deux séries d'échantillons prélevés à une profondeur de $5 \mathrm{~m}$ dans des stations réparties sur l'axe longitudinal du lac de Port-Bielh. Les résultats (tableau $\mathrm{I}$ ) révèlent que, pour toutes les espèces considérées, sauf Cryptomonas le 19-IX-68, les valeurs du $x 2$ sont en accord avec l'hypothèse d'une distribution au hasard. Pour des numérations de cellules comprises entre 10 et 100, le coefficient de variation au seuil de probabilité $\mathrm{P}_{0,05}$ est toujours inférieur à $20 \%$; il avoisine très souvent $10 \%$. On peut raisonnablement admettre que l'erreur sur le résultat des comptages ne dépasse pas $\pm 10 \%$.

La technique la plus courante d'étalonnage des solutions de ${ }^{14} \mathrm{CO}_{3} \mathrm{NaH}$ utilisées pour mesurer l'activité photosynthétique du phytoplancton est basée sur une précipitation chimique sous forme de $\mathrm{Ba}^{14} \mathrm{CO}_{3}$. Selon certains auteurs (STEEmanN-Nielsen 1965, GoldMAN 1968) cette méthode peut conduire à des erreurs importantes. Récemment, Woov (1970 et 1971) a montré la validité de la technique d'étalonnage par extrapolation des courbes d'autoabsorption du $\mathrm{Ba}^{14} \mathrm{CO}_{3}$ lorsque sont respectées certaines conditions de détection. Pour cet auteur, la correction proposée par STEEMANN-NIELSEN (1965) et utilisée par l'Agence Internationale pour l'étalonnage du ${ }^{14} \mathrm{C}$ à Charlottenlund Slot (Danemark) est à revoir. 
(7) PHytoplancton de LACS D'Altitude DES PyRÉNÉES

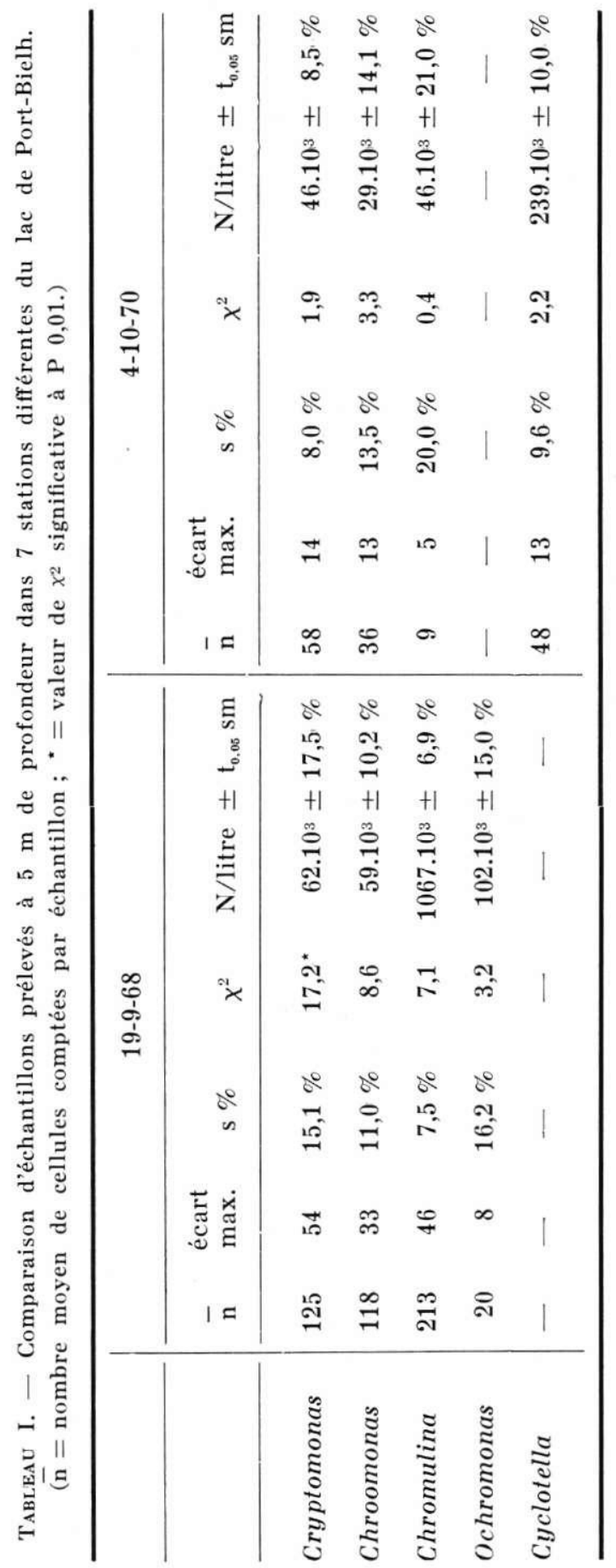


L'élalonnage de la solution de ${ }^{14} \mathrm{CO}_{3} \mathrm{NaH}$ utilisée pour nos mesures a élé fail sur une installation de comptage composée d'un compteur FD1 G.M. à fenêtre ultra-mince et à circulation gazeuse reliće à un compteur d'impulsions type ECT (Saphymo). La technique a consisté à précipiter un volume connu de la solution avec une quantilé donnée de $\mathrm{BaCO}_{3}$ (Yankwiter 1947 in Brovardel et RINK 1963). Comparée avec une méthode de détection en phase gazeuse qui fournit l'activité absoluce, cette méthode, compte tenu de l'efficacité de l'installation de complage, donne des valcurs environ 4 à $5 \%$ inféricures aux valeurs !héoriques (Vollenweregr 1969).

Les pertes de radioactivité au moment de la filtration, miscs en ćvidence par Artiur et Rigler (1967), sont vraisemblablement une des phlus importantes sources d'erreur dans la méthode du ${ }^{14} \mathrm{C}$. Les résultats obtenus par filtration et comptage raclioactif de la totalité de l'ćchantillon $(125 \mathrm{ml})$ ont du être corrigés par un facteur compris entre 1,75 el 3,2, selon le lac étudié el l'époque de la mesure. Én règle générale, ce facteur est d'autant plus élevé que le phytoplancton est dominé par des formes nues de petite dimension. Un exemple de calcul du coefficient de correction est illustré dans la fig. 2 qui représente l'activité par millilitre d'eau filtrée (exprimée en \% de la valeur obtenue pour un échantillon de $125 \mathrm{ml}$ ) en fonction du volume filtré. Les résultats obtenus en augmentant la pression de filtration (courbe en pointillés) semblent confirmer la valeur du coefficient de correction donné par l'extr:ı polation de la courbe. L'importance relative des produits organiques extra-cellulaires, qui peut dépasser $35 \%$ dans les eaux oligotrophes (FogG et al. 1965, Fogg 1971, Watt 1965) es! sans doute très réduite lorsqu'on applique celle correction, Les mesures effectuées par Schindoler (1971), Schindter el Hol.mgren (1971) indiquent que la production de matières extra-cellulaires ne dépasse jamais 1 à $2 \%$ de la totalité de carbone fixé lorsqu'on tient compte des pertes provoquées par la filtration.

Deux flacons transparents ont été utilisés en parallèle dans chacune de nos expériences. La différence entre l'aclivité des deux ćchantillons, expriméc en \% par rapport à leur moyenne, a été ainsi calculée pour 240 couples de mesures. En dehors d'un petit nombre (18\%) d'expériences présentant des différences entre échantillons parallèles comprises entre $25 \%$ ef $55 \%$, les écar's oscillent autour d'une valcur moyenne de $12 \%$ et se distribuent selon une loi de probabilité normale. Il n'existe aucune relation entre la période ou la profondeur de prélèvement et la valeur de ces écarts. Ceux-ci reflètent donc de manière globale la variabilité des mesures, imputable aux différences de répartition du phytoplancton, des conditions d'exposition et de filtration pouvant exister entre les deux flacons. 
On peut démontrer dans ces conditions (Brocander. el Rinck 1963), que la loi de probabilité de la variable principale, à savoir l'homogénéité des mesures, est caractériséc par l'écart-type $\sigma^{\prime}=\frac{\mathrm{M} \vee}{2}-$; la moyenue des écurts calculés $(\mathrm{M})$ est égale à $12 \%$, donc $\sigma^{\prime}=10, \tilde{\delta} \%$. Ce qui signifie que lorsqu'on fait une mesure au hasard, il y a $95 \%$ de chances qu'elle fournisse un résultat ayant moins de $20 \%$ d'écart avec la moyenne du milieu.

La fixation de carbone à l'obscurité est généralement considérée comme résultant des processus d'assimilation biochimique du $\mathrm{CO}_{2}$ par les algues et par les bactéries. Cependant Erster (1965) signale que la radioactivilé du phyloplancton incubé en flacons opaques avec du ${ }^{14} \mathrm{CO}_{3} \mathrm{NaH}$ est indépendante du volume filtré. En se basant sur ce résultat, il considère que les valeurs de radioactivité sont essentiellement dues à une adsorption du radioisotope sur les membranes filtrantes. Afin de lenter de vérifier ce point, nous avons réalisé une sério de $1 \tilde{j}$ expériences. Dans chaque expéricnce, $125 \mathrm{ml}$ d'ean du lac de Port-Biclh légèrement formoléc ont ćté filtrés sur membrane. L'eau recueillic a élé enrichic avec $1 \mathrm{ml}$ cle "CO ${ }^{2} \mathrm{NaH}$ et refiltrée inmédiatement sur la même membrane. Aprìs séchage sur gel de silice à l'obscuri!é, la radioactivilé a ćlé mosurée sur une duréc de 30 minules et la valeur du bruit de fond du compleur déduite du résultat.

L'activité des fillres ainsi traités est do $13 \mathrm{imp./mn}$ en moyenne et, pour les 15 mesures effectuées, varie entre 8 ol $19 \mathrm{imp} . / \mathrm{mn}$. Calte valeur représente $30 \%$ à $85 \%$ de la radioactivité des flacons opaques après 4 à 6 heures d'incubation avec du ${ }^{14} \mathrm{CO}_{3} \mathrm{NaH}$. On peut done admeltre qu'une part de l'activité du phyloplancton dess expériences faites à l'obscurité correspond uniquement à une adsorption du radioisotope sur la membrane filtrante el sur les élémen's planctoniques. Pour l'interprélalion de nos mesures, nous avons soustrait $13 \mathrm{imp} . / \mathrm{mn}$ à toutes les valeurs de radioactivité des «flacons obscurs» en considérant que seule l'activité > $13 \mathrm{imp} / \mathrm{mn}$ correspondait à une manifestation de l'activilé métabolique des algues et des bacléries plancloniques.

\section{PRESENTATION DES RÉSULTATS}

Les résultats des mesures de terrain el les analyses effecluées au laboratoire ont permis de suivre l'évolution de 14 paramètres à 8 profondeurs différentes du lac de Port-Bielh an cours de 41 séries de rolevés. Ces dernières ont été réalisées à la fréquence de deux à trois par mois pendant l'été des années 1967, 1968 et 
1970, de manière plus discontinue pendant l'hiver (1969, 1970, 1971 ) el l'été 1971.

Les résultats des mesures effectuées pendant la période de dégel ont été figurés sur des diagrammes qui illustrent l'évolution des variables en fonction de la profondeur (ordonnée) et du temps (abscisse). La superposition des diagrammes pour chaque année de mesure permet de visualiser les corrélations existant entre les divers paramètres. Les résultats des mesures d'hiver, moins nombreux, ont été analysés séparément.

La valeur moyenne des variables a été calculée pour chaque série de mesure. Les profondeurs de prélèvements étant plus rapprochées au voisinage de la surface, les résultats ont été intégrés de la façon suivante :

(valeur à $0 \mathrm{~m} \times 0,5)+(\grave{a} 1 \mathrm{~m} \times 1,5)+(\grave{a} 3 \mathrm{~m} \times 2)+(\grave{a} 5 \mathrm{~m}$ $\times 2,5)+(\grave{a} 8 \mathrm{~m} \times 3,5)+($ à $12 \mathrm{~m} \times 4)+($ à $16 \mathrm{~m} \times 3)+($ à $18 \mathrm{~m}$ $\times 1$ ).

En divisant cette somme par 18, on obtient la valeur moyenne pour une colonne d'eau de $0 \mathrm{~m}$ à $18 \mathrm{~m}$. Sur le plan quantitatif, cette méthode conduit à surestimer les valeurs de la zone profonde au détriment de celles de surface puisque la cuvette lacustre du Port-Bielh a approximativement la forme d'un cône (Capblanco et Lavili.e, 1969). Elle permet cependant une représentation plus claire de l'évolution saisonnière des diverses composantes.

Dans les lacs de faible profondeur (Gourguet, Gourg Nère Moyen et Gourg Nère Inférieur (II) des mesures bimensuelles ont été effectuées au cours de l'été 1968 . Quclques expériences de productivité ont également été réalisées en 1967 , essentiellement dans le Gourg Nère Inférieur II. Ces lacs, constamment homothermes, présentent de très faibles variations en fonction de la profondeur. Les résultats ont été obtenus en effectuant la moyenne des valeurs mesurées à trois pronfondeurs $(0 \mathrm{~m} ; 1,5 \mathrm{~m} ; 3,50 \mathrm{~m})$.

\section{II. - LAC DE PORT-BIELH}

\section{LE MILIEU.}

\subsection{Température et propriétés chimiques.}

La morphométrie et l'évolution annuelle des propriétés physicochimiques de 9 lacs des vallons de Port-Biclh et d'Estibère ont été décrites dans la première partie de ce travail (Capblance et Laville, 1969). Dans le lac de Port-Bielh, le cycle annuel des températures et des composantes chimiques peut se schématiser de la façon suivante : 


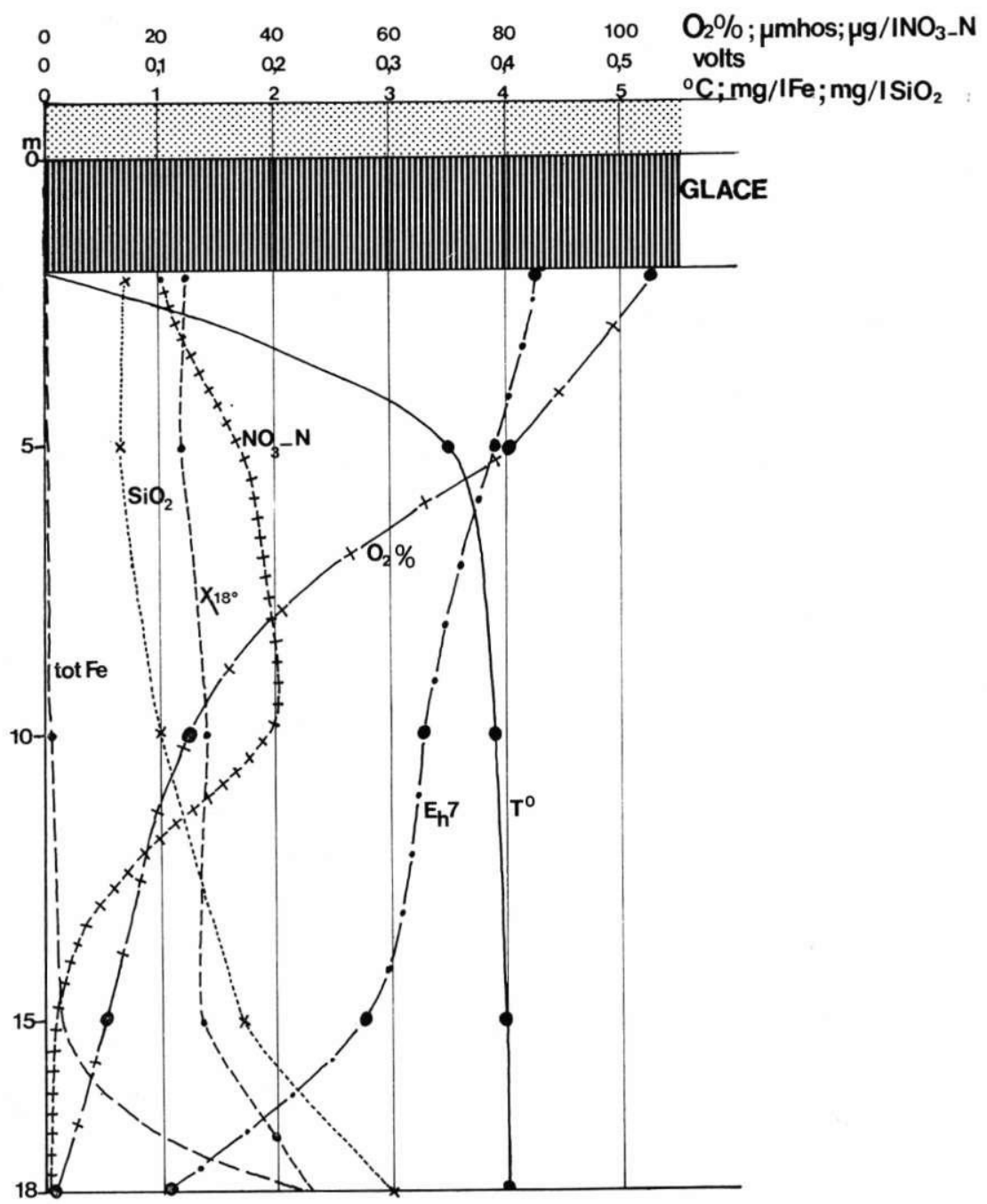

FIg. 3. - Evolution de quelques paramètres physico-chimiques en fonction de la profondeur au lac de Port-Bielh en hiver.

a) Durant la période hivernale, qui se prolonge sept à huit mois par an (fin novembre-début juillet), le lac est recouvert d'une couche de glace et de neige pouvant atteindre une épaisseur maximale de 2,5 m à $3 \mathrm{~m}$ en avril. Au-delà de $5 \mathrm{~m}$ de profondeur, la température se maintient entre $3,5^{\circ}$ et $4{ }^{\circ} \mathrm{C}$ tandis que la teneur en $\mathrm{O}_{2}$ dissous décroît progressivement. Près du fond, elle atteint généralement, dès le mois de février, des valeurs inférieures à $1 \mathrm{mg} / \mathrm{l}$. Dans ces conditions pratiquement anaérobies, les phénomènes de 
réduction au niveau de la vase entraînent des modifications chimiques importantes dans l'eau des couches profondes (tableau II et fig. 3). La diminution des potentiels d'oxydo-réduction, corrálative à la diminution de la teneur en oxygène, s'accentue au voisinage de la vase. Pour des potentiels inférieurs à $\mathrm{E}_{\mathrm{h}} 7=0,2$ volts, la disparition de la microzone oxydée permet le passage dans l'eau des ions libérés par réduction dans la vase (Mortimer, 1941, 1942). Ces phénomènes provoquent une augmentation notable des teneurs en bicarbonates, silicates, phosphates et fer total et une diminution des nitrates. Lorsque le déficit en $\mathrm{O}_{2}$ s'accentue, vers la fin de l'hiver, apparaît du $\mathrm{H}^{2} \mathrm{~S}$ libéré par réduction des ions $\mathrm{SO}_{4}^{=}$.
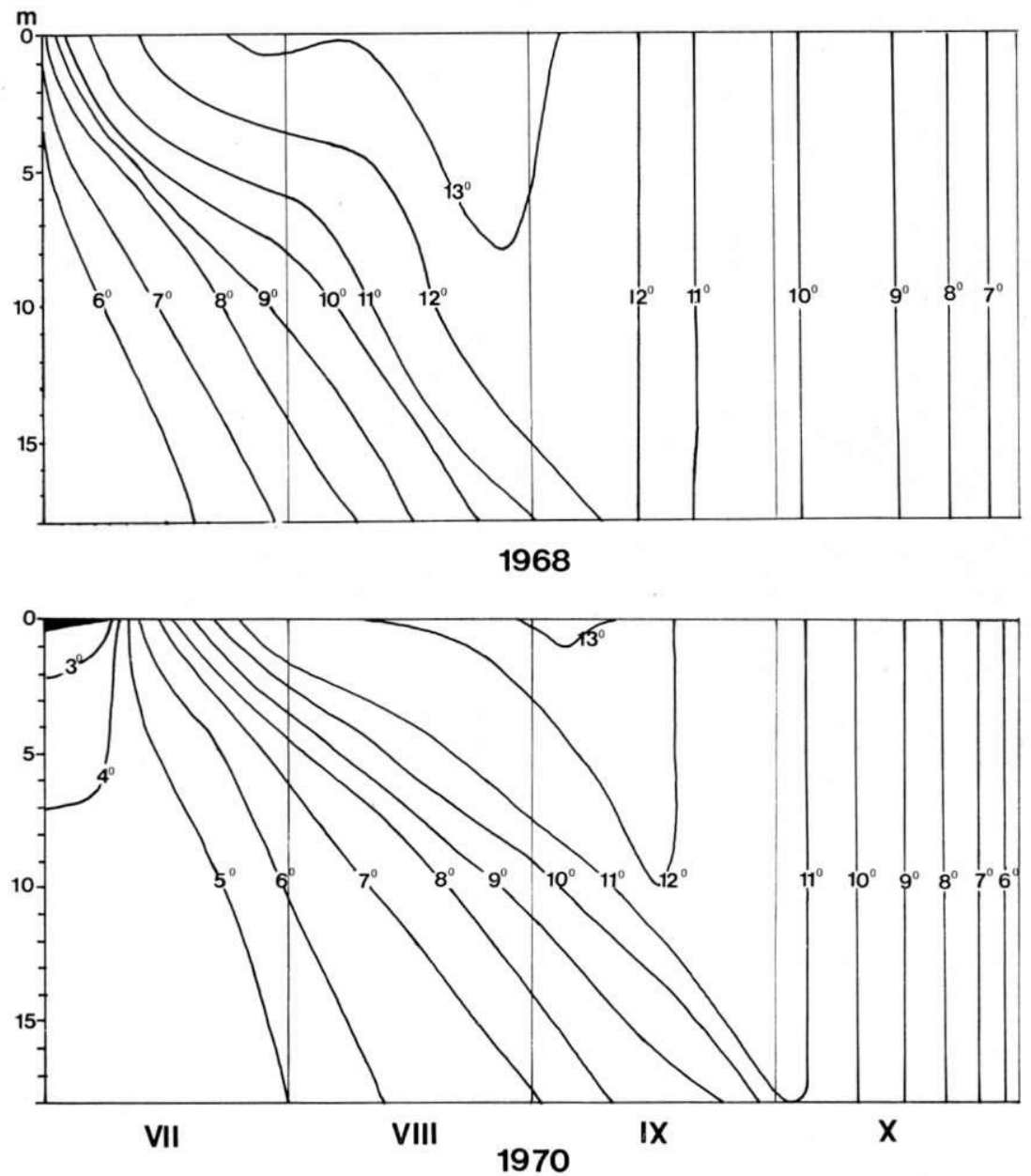

FIG. 4. - Courbes isothermes du lac de Port-Bielh en été. 
Tabsest II. -- Caractéristiques thimiques de l'eau de surface $(5 \mathrm{~m})$ et de profondeur $(18 \mathrm{~m})$ en hiver et en été au lac de Port-Bielh.

\begin{tabular}{|c|c|c|c|c|}
\hline & \multicolumn{2}{|c|}{22 avril 1970} & \multicolumn{2}{|c|}{12 août 1970} \\
\hline & $5 \mathrm{~m}$ & $18 \mathrm{~m}$ & $5 \mathrm{~m}$ & $18 \mathrm{~m}$ \\
\hline Conductivité ( $\chi 18^{\circ} \mathrm{C} \mu$ mlos) & 23,8 & 45,8 & 20,9 & 21,1 \\
\hline $\mathrm{pH}$ & 7,15 & 6,85 & 8,60 & 8,25 \\
\hline $\mathrm{O}_{2}$ (mg/litre) & 7,55 & 0,30 & 9,80 & 9,70 \\
\hline$O_{2}$ (\% saturation) & $78,5 \%$ & $3,1 \%$ & $120 \%$ & $108 \%$ \\
\hline Alcalinite totale (med/litre) & 0,210 & 0,430 & 0,196 & 0,210 \\
\hline $\mathrm{CO}_{2}$ total (ms/litre) & 11,5 & 28,4 & $8,(60)$ & $9, \mathbf{2 5}$ \\
\hline $\mathrm{Cl}$ (med/litre) & $<3.10^{-1}$ & $<3.10^{\circ}$ & $<3.10^{+}$ & $<3.10-$ \\
\hline $\mathrm{SO}_{4}=($ meco/litre $)$ & 0,022 & 0.100 & 0,021 & 0,031 \\
\hline$\Sigma$ Anions (meq/litre) & 0,232 & 0,440 & 0.217 & 0,241 \\
\hline $\mathrm{Ca}^{++}(\mathrm{meq} / \mathrm{litre})$ & 0,172 & 0,325 & 0,182 & 0,200 \\
\hline $\mathrm{Mg}^{++}$(meg/litre) & 0,013 & 0,015 & 0,0006 & 0,005 \\
\hline $\mathrm{K}^{-}(\mathrm{meq} /$ litre $)$ & 0,018 & 0,024 & 0,004 & 0,004 \\
\hline $\mathrm{Na}^{+}$(meg/litre) & 0,020 & 0,032 & 0,015 & 0,022 \\
\hline$\Sigma$ Cations (med/litre) & 0,223 & 0,396 & 0,207 & 0,231 \\
\hline $\mathrm{PO}_{4}-\mathrm{P}\left(\mu \mathrm{g} / \mathrm{litr} \mathrm{e}^{\mathrm{O}}\right)$ & 4 & 13 & 2,4 & 3,5 \\
\hline Tot-P $\left(\mu g / \operatorname{litr} e^{*}\right.$ & 9 & 32 & $\overrightarrow{6}$ & 8 \\
\hline$N\left(0_{3}-N(\mu s / \operatorname{litro})\right.$ & 35 & $<10$ & 92 & 40 \\
\hline Tot-N ( $\mu$ s/litre) & 150 & 584 & 275 & 250 \\
\hline $\mathrm{NH}_{\mathrm{q}}(\mu \mathrm{g} /$ litre $)$ & & 250 & & \\
\hline Tot. Fe (mg/litre) & $(1,01$ & 2,42 & 0,03 & 0,06 \\
\hline $\mathrm{SiO}(\mathrm{mg} /$ litre $)$ & 0,70 & 3,00 & 1,42 & 0,70 \\
\hline $\mathrm{H}_{2} \mathrm{~S}$ (mg/litre) & & 0,30 & & \\
\hline
\end{tabular}

b) La disparition de la glace à la fin du mois de juin (1968) ou à la mi-julled (1970) modilie profondément les conditions de milieu. L’évolution des principaux paramètres physiques et chimiques au cours de la période de dégel des années 1968 et 1970 a été résuméc sous forme de diagrammes (fig. 4 à 9). Ia superposition de ces deux séries de diagrammes et leur comparaison avec les courbes données dans la première partie de ce lravail révèlent une très grande stabilité dans les cycles annuels des différentes composantes.

-.- Température (fig. 4) : l'apport estival do chaleur représente moins de $50 \%$ du budgel calorifique annuel. Par suite, les températures d'été sont relativement faibles et atteignent rarement $14^{\circ} \mathrm{C}$ en surface pendant une brève période all mois d'août. L'évolution des températures estivales permet de distinguer,

- une très brève période d'isothermie au moment du dégel;

* une période de stratification thermique peu prononcée en juillet et août; 

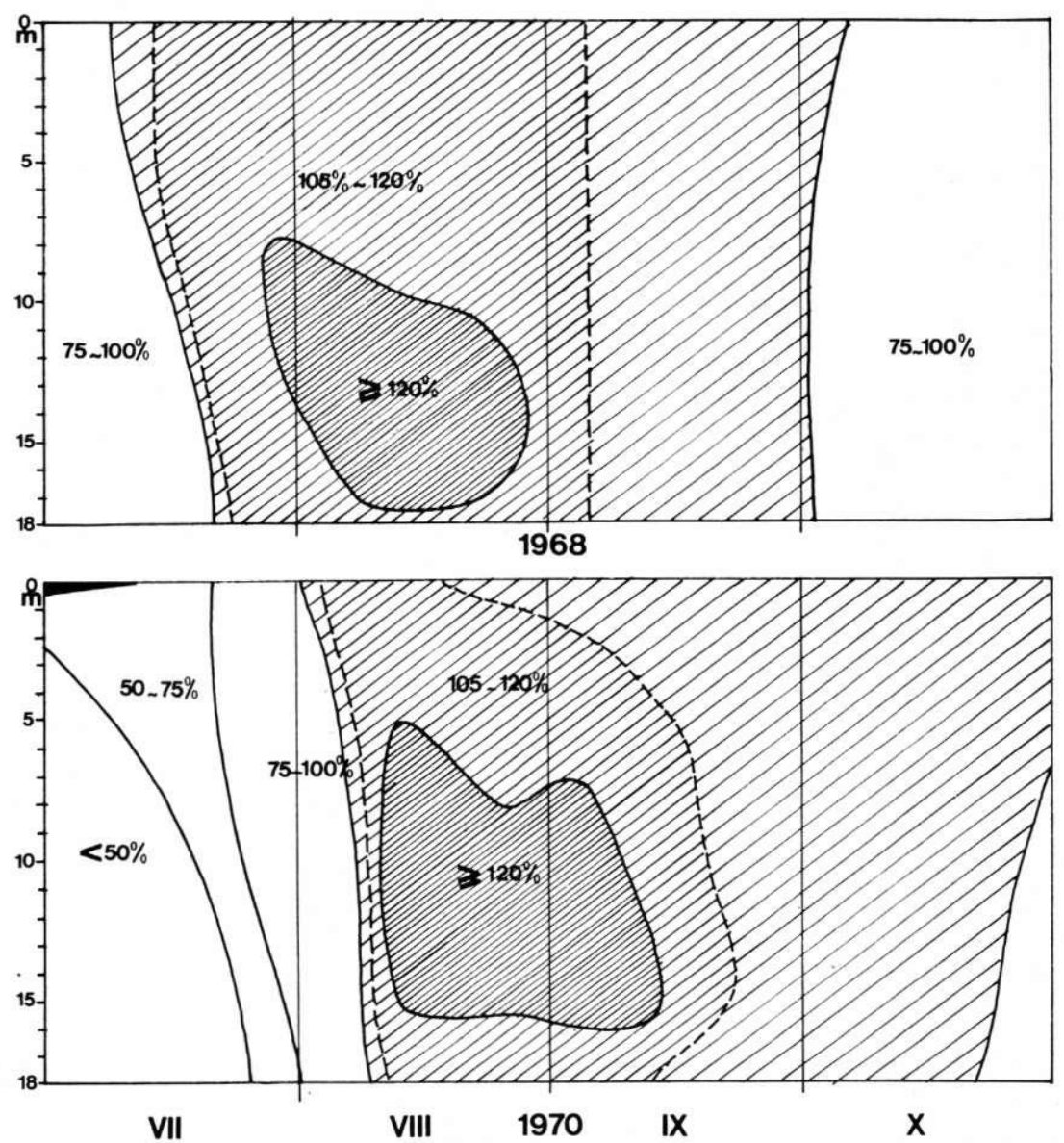

Fig. 5. - Evolution de la teneur en oxygène dissous (\% des valeurs à saturation) aux diverses profondeurs du lac de Port-Bielh, en été.

* une longue période d'isothermie automnale qui débute entre la fin du mois d'août (1968) et la fin du mois de septembre (1970) et se prolonge pendant deux mois ou plus jusqu'au gel du lac (deuxième quinzaine de novembre).

- Propriétés chimiques (fig. 5 à 9) : essentiellement alimenté par les eaux de fonte des neiges, le lac de Port-Bielh se caractérise par des eaux peu minéralisées où les carbonates représentent une proportion élevée des anions (tableau II). Lors de l'isothermie de printemps l'oxygénation de l'eau entraîne l'oxydation des composés ferreux qui précipitent sous forme d'hydroxydes ferriques. 


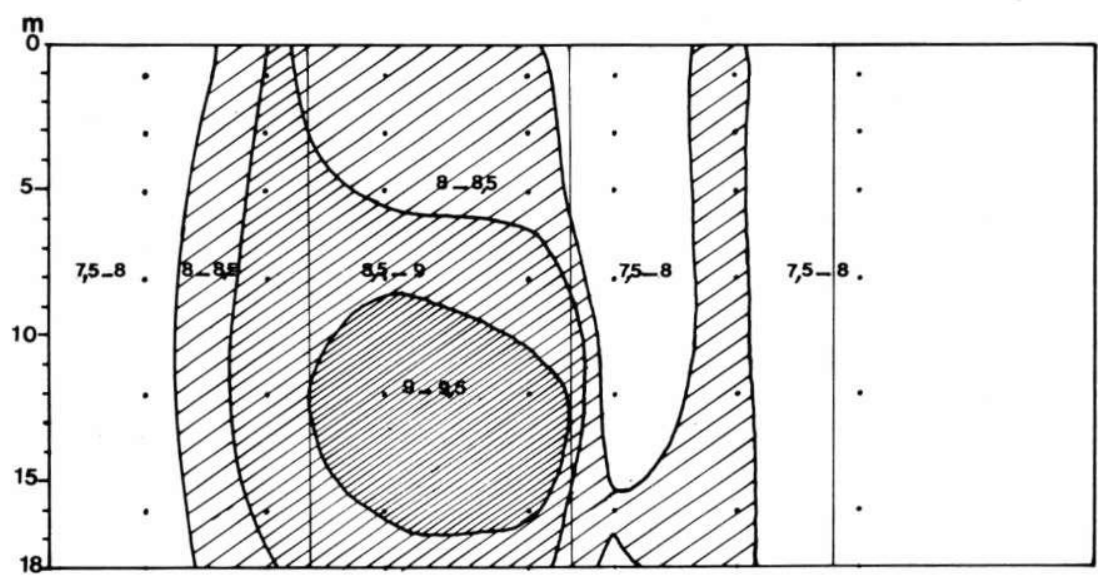

1968

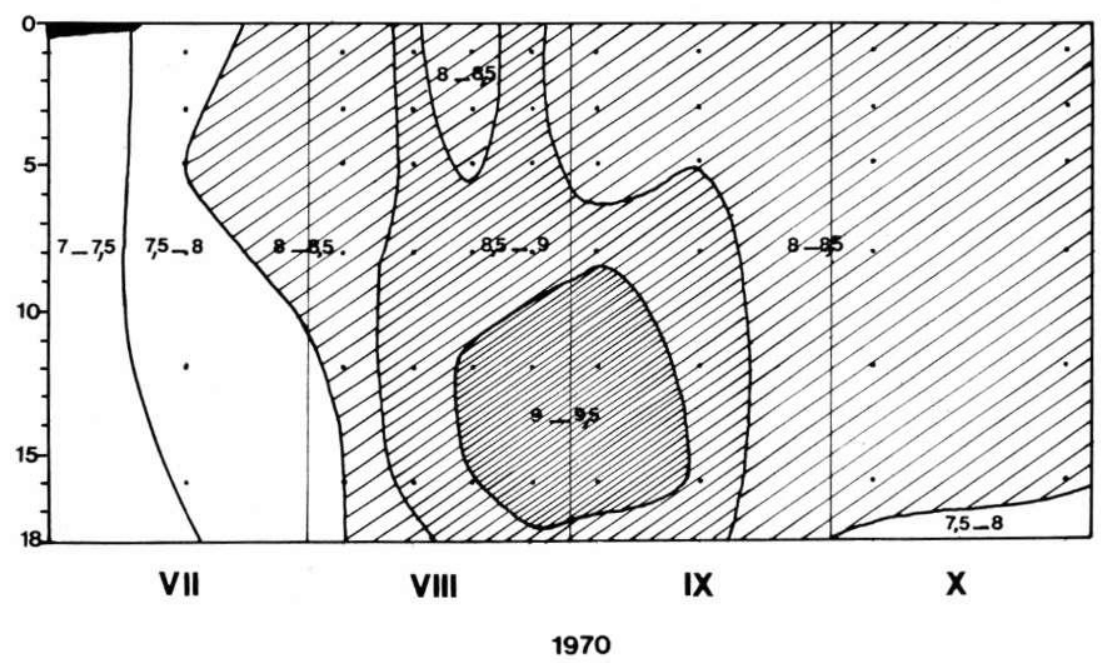

FIG. 6. - Evolution du $\mathrm{pH}$ aux diverses profondeurs du lac de Port-Bielh, en été. Les points indiquent les diverses mesures.

Ce processus provoque une diminution brutale des teneurs en fer, phosphates, silicates et carbonates dans la zone profonde, soit par précipitation sous forme de composés ferriques, soit par adsorption sur les complexes ferriques de la vase (Mortimer, 1941 et 1942). La quantité de nitrates, très faible pendant l'hiver, atteint sa valeur maximale à cette époque de l'année. 

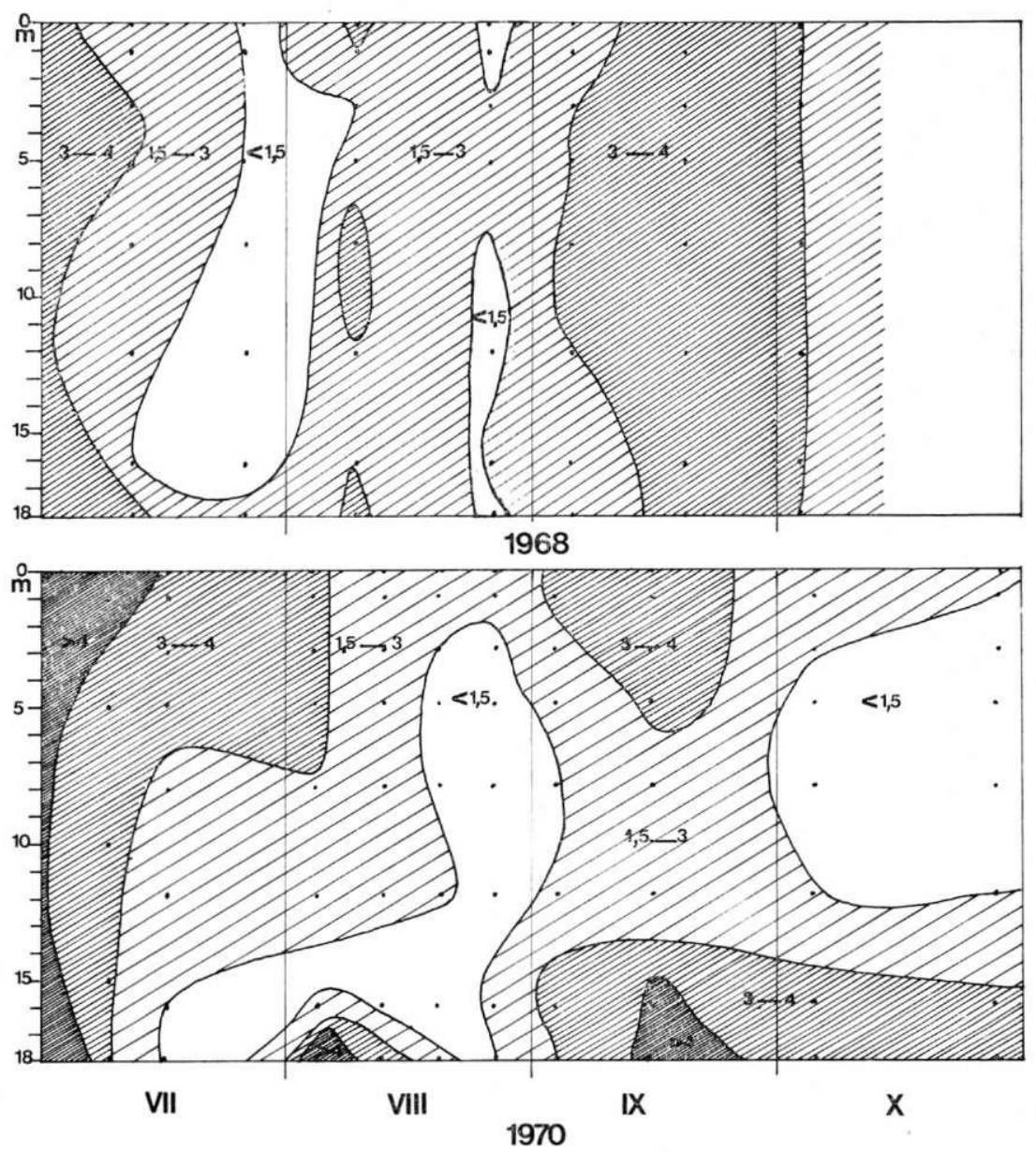

Fig. 7. - Evolution des teneurs en $\mathrm{PO}_{4}-\mathrm{P}(\mu \mathrm{g} / \mathrm{l})$ aux diverses profondeurs du lac de Port-Bielh, en été.

Pendant la stratification thermique d'été, la reprise de la photosynthèse se traduit par une augmentation importante de la teneur en $\mathrm{O}_{2}$ dissous (fig. 5 ) et du $\mathrm{pH}(f i g .6)$. Ce dernier atteint au mois d'août des valeurs étonnamment élevées, supérieures à $\mathrm{pH} 9$ dans la zone profonde. Corrélativement, on observe une diminution des concentrations de $\mathrm{PO}_{4}-\mathrm{P}\left(\right.$ fig. 7), $\mathrm{NO}_{3}-\mathrm{N}\left(\right.$ fig. 8) et $\mathrm{SiO}_{2}($ fig. 9$)$.

L'isothermie d'automne entraine l'uniformisation des composantes chimiques dans toute la masse d'eau. Elle se traduit en particulier par une diminution du $\mathrm{pH}$ et un équilibre entre $\mathrm{l}^{\prime} \mathrm{O}_{2}$ dissous et $\mathrm{l}^{\prime} \mathrm{O}_{2}$ atmosphérique. 

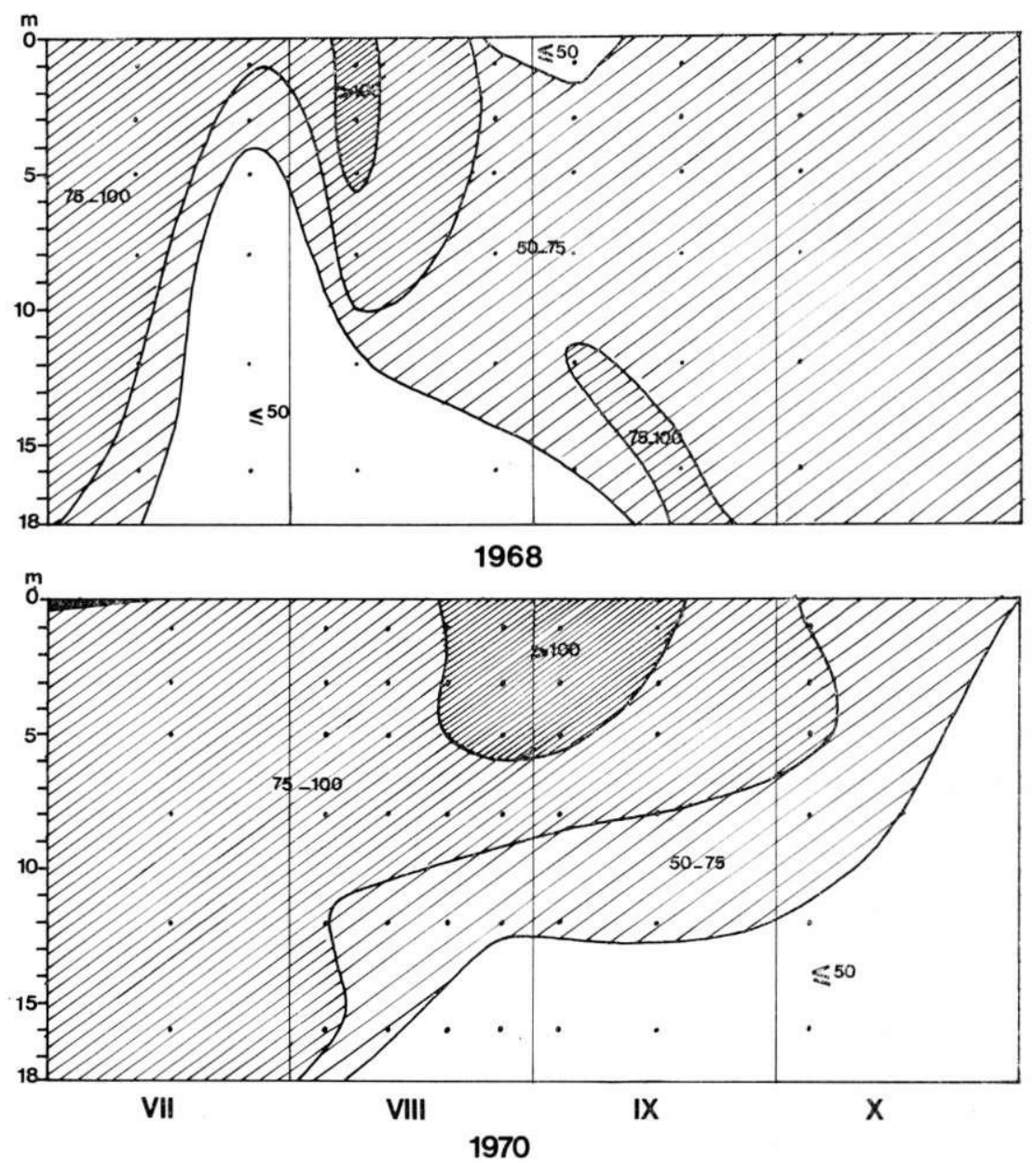

Fig. 8. - Évolution des teneurs en $\mathrm{NO}_{3}-\mathrm{N}(\mu \mathrm{g} / \mathrm{l})$ aux diverses profondeurs cu lac de Port-Bielh, en été.

\subsection{Lumière.}

La quantité et la qualité d'énergie lumineuse disponible aux diverses profondeurs du lac dépend d'un ensemble de facteurs complexes tels la topographie, le climat, la saison et les propriétés optiques de l'eau.

$1^{\circ}$ La topographie et l'orientation du bassin versant agissent sur la quantité totale de radiations solaires pouvant atteindre la surface du lac à une période donnée. L'écran formé par les crêtes peut limiter considérablement la durée d'insolation d'une 

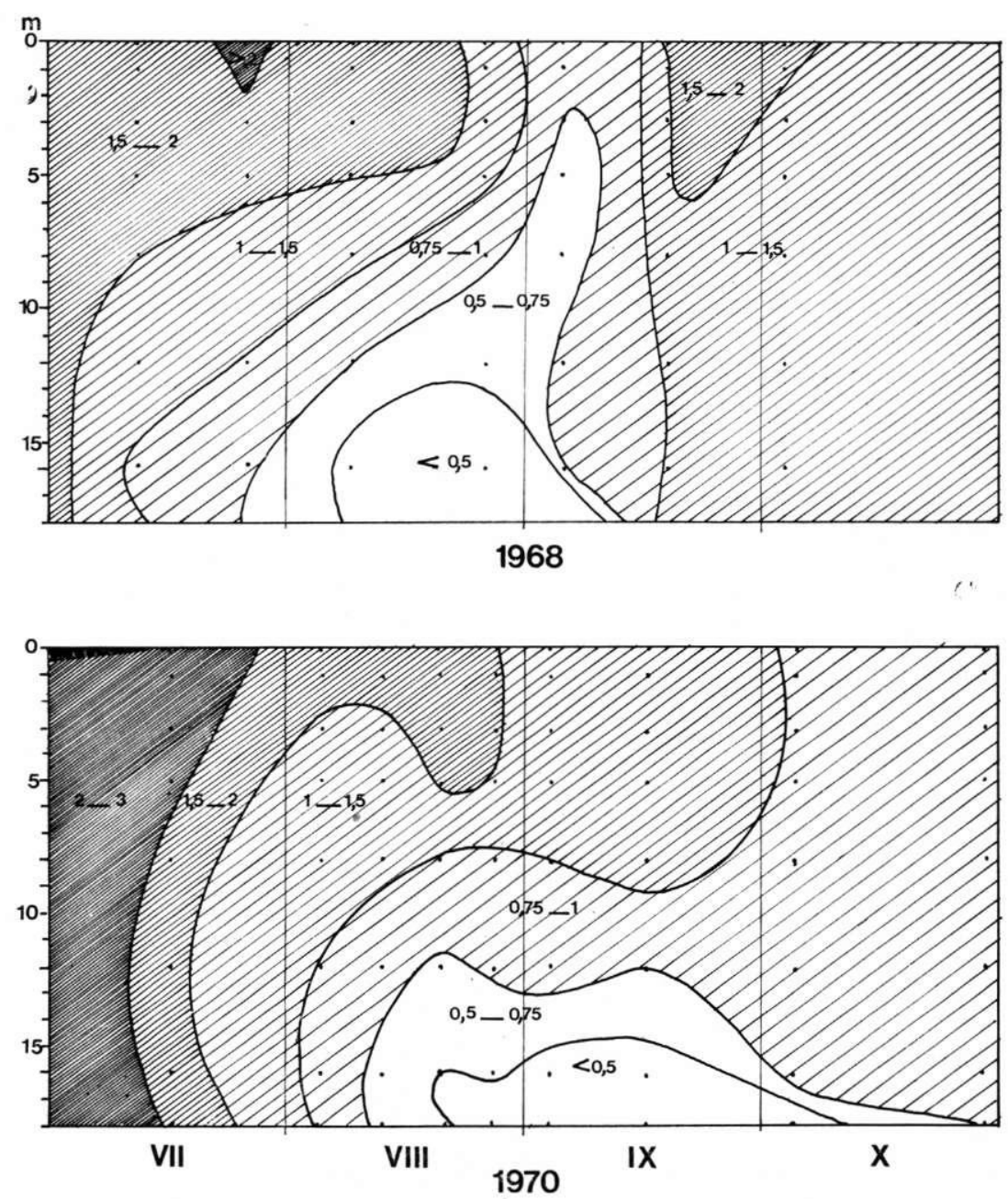

Fig. 9. - Evolution des teneurs en $\mathrm{SiO}_{2}(\mathrm{mg} / \mathrm{l})$ aux diverses profondeurs du lac de Port-Bielh, en été.

station. L'héliogramme de la fig. 10, tracé à partir de la carte IGN au $1 / 25000^{\circ}$, indique le temps d'insolation théorique du lac aux diverses périodes de l'année. Il révèle la faible influence du relief sur les conditions d'éclairement du lac de Port-Bielh, conséquence de la situation de ce lac au fond d'un vallon largement ouvert au sud.

$2^{\circ}$ L'altitude diminue de façon notable l'humidité atmosphérique et favorise ainsi la pénétration des rayons lumineux et ultra-violets. Dans le massif de Néouvielle, ce phénomène est accen- 
tué par l'orientation de la haute vallée d'Aure qui, soumise à l'action des vents du sud, se caractérise par son climat relativement sec. Le plateau d'Aumar $(2200 \mathrm{~m})$ bénéficie, en été, d'une sécheresse diurne et d'une insolation identiques à celles que l'on trouve généralement 1000 à $2000 \mathrm{~m}$ plus haut. (Chouard, 1949). Ces caractéristiques climatiques sont encore plus nettement perceptibles dans le vallon de Port-Bielh, ouvert au sud et protégé par une ligne de crête à l'est, au nord et à l'ouest.

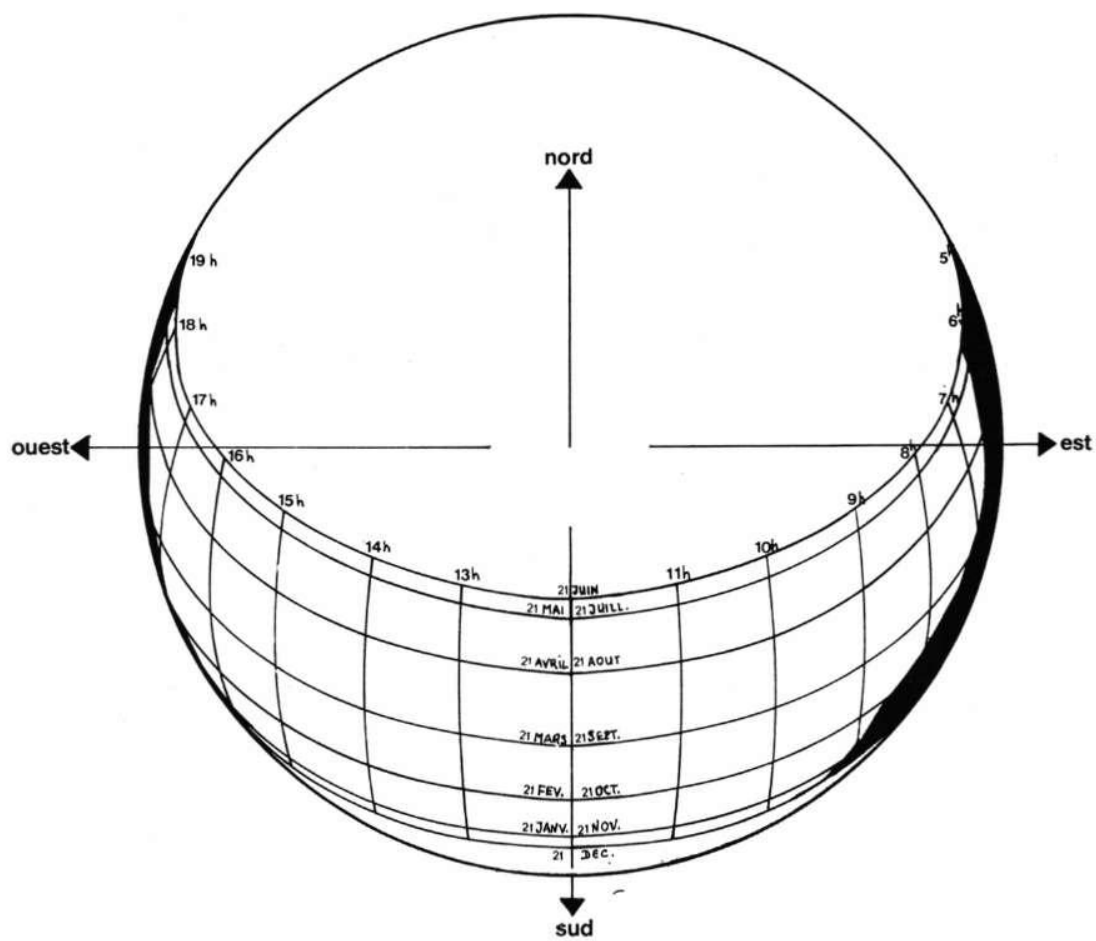

FIg. 10. - Héliogramme relatif au lac de Port-Bielh.

Les enregistrements obtenus au cours de l'été 1967, 1968 et 1970 à l'aide d'un solarigraphe placé près du lac mesurent l'intensité de la radiation totale (radiation directe + radiation diffuse) et l'importance de la nébulosité. Les résultats, exprimés en $\mathrm{Cal} / \mathrm{cm}^{2} /$ jour, sont représentés sur des graphiques (fig. 11) sur lesquels est également indiquée l'intensité de la radiation pour une nébulosité nulle (valeurs enregistrées pendant des jours clairs). L'intensité des rayonnements solaires peut atteindre des valeurs élevées $\left(1,68 \mathrm{cal} / \mathrm{cm}^{2} / \mathrm{mn}\right.$ à $13 \mathrm{~h}$ en juillet $)$. L'atténuation 
des rayonnements par les nuages est relativement faible; elle est très souvent limitée aux dernières heures de la journée par suite de la formation fréquente de brouillards.

La quantité de lumière utilisable pour la photosynthèse à élé évaluée à partir des courbes du solarigraphe en considérant que la fraction d'énengie comprise entre 400 et $700 \mathrm{~m} \mu$ équivaut à $46 \%$ de la radiation totale ( $\mathbf{T}_{\text {ALLing, }} 1957$ a) el que la surface du lac réfléchit $10 \%$ de la radiation totale (Sauberer, 1962).

3" La couverture de glace et de neige réduit dans de fortes proportions la pénétration de l'énergie lumineuse. Ses propriétés optiques varient considérablement entre les périodes de gel et de dégel du lac el d'une année à l'autrc; elles sont essentiellement fonction de l'épaisseur, de la structure et de la densité des couches successives de glace et de neige qui la composent. Le coefficient d'extinction de la glace claire ne diffère pratiquement pas de celui de l'eau distillée (Pechlaner, 1971). Colui de la neige varie entre 0,1 et $0,6 / \mathrm{cm}$ : il est d'autant plus élevé que la densité de la neige est faible (Амвасы et Нангснт, 1962). A travers $1 \mathrm{~m}$ de couches alternées de glace bulleuse et de neige mouillée, qui, dans les conditions naturelles, sont immergées, il pénctre $30 \%$ de l'énergie lumineuse de surface (Pechlaner 1966).

Dans le lac de Port-Bielh, deux séries de mesures ont été réalisées au cour's de l'hiver 1971. Le 2-3-1971, sous $1,65 \mathrm{~m}$ de glace et de neige $(0,60 \mathrm{~m}$ de neige poudreuse, $0,55 \mathrm{~m}$ de neige mouillée, $0,35 \mathrm{~m}$ de glace bulbeuse, $0,15 \mathrm{~m}$ de glace vitreuse), la quantité de lumière a été estimée à $0,85 \%$ de l'intensilé de surface. Le 31-3-1971, sous 2,70 $\mathrm{m}$ de couverture hivernale $(1 \mathrm{~m}$ de neige, $1,10 \mathrm{~m}$ de neige mouillée, $40 \mathrm{~cm}$ de glace bulleuse, $20 \mathrm{~cm}$ de glace dure), elle était de l'ordre de $0,01 \%$. On peut done admettre que pendanl six à sept mois d'hiver, selon l'importance et la précocité des précipitalions de neige, l'intensité lumineuse est réduite de plus de $99 \%$.

$4^{\circ}$ La transparence de l'eau du lac de Port-Bielh est élevée. La profondeur limite de visibilité du disque de Secchi varie entre $9,50 \mathrm{~m}$ el $17,50 \mathrm{~m}$ en été; elle est de $13,65 \mathrm{~m}$ en moyenne sur quatre années de mesures. Il existe une corrélation hautement significative $(r=-0,72)$ entre la transparence et le volume moyen de phytoplancton par $\mathrm{m}^{3}$ d'eau. La dispersion des points dans la zone correspondant aux faibles biomasses (fig. 12) est attribuable au léger trouble de l'eau consécutif à la fonte des neiges.

Pendant l'été 1970 et 1971 , la transmission lumineuse a été mesurée à l'aide d'une cellule photoélectrique immergéc. Les caractéristiques du montage utilisé (cellule + filtres) sont données dans le tableau III. 
(21)

PHYTOPLANCTON DE LACS D'ALTITUDE DES PYRÉNÉES

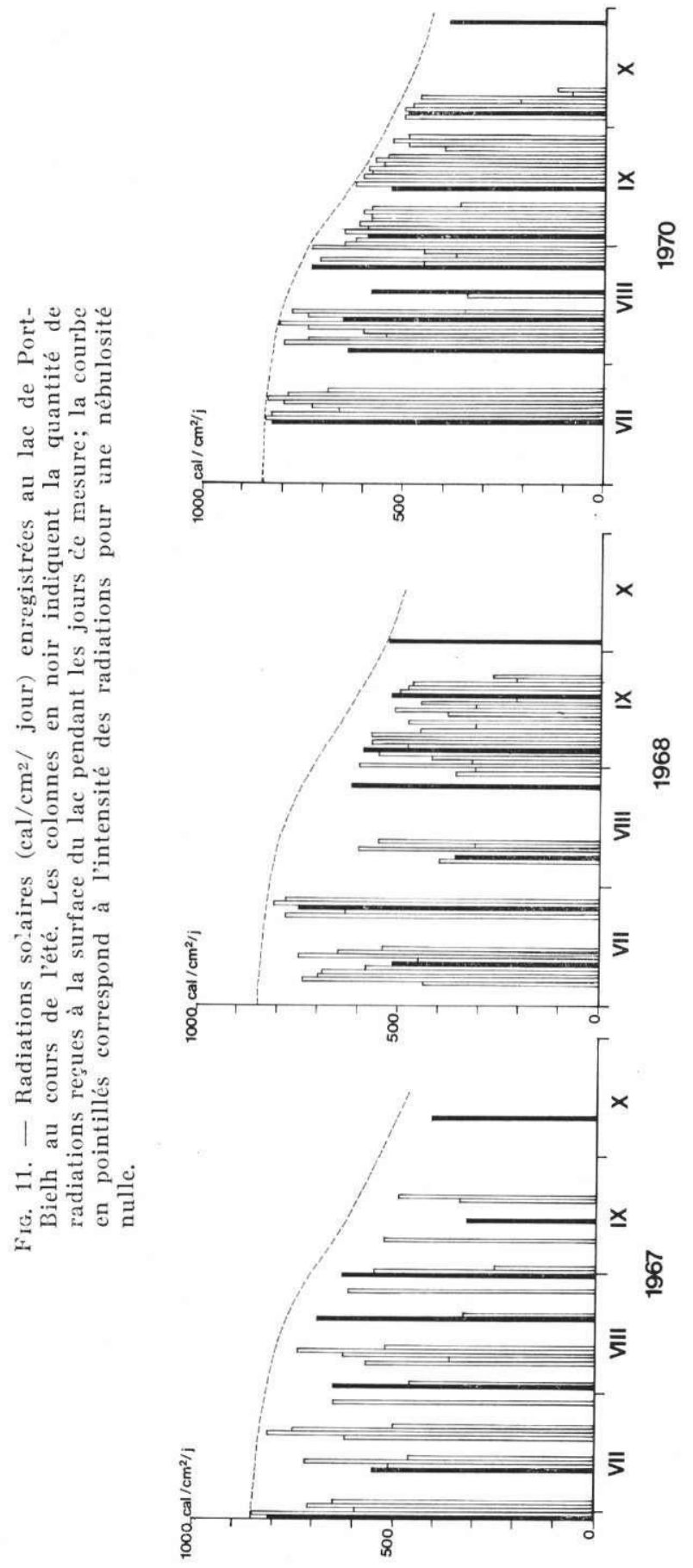


Tableau III. - Sensibilité de la cellule photoélectrique (Megatron, Londres) combinée avec des filtres colorés (Schott et Gen., Mainz, Allemagne).

\begin{tabular}{lcccc}
\hline \multicolumn{1}{c}{ Filtres } & $\mathrm{UG}_{1}+\mathrm{BG}_{12}$ & $\mathrm{BG}_{12}$ & $\mathrm{VG}_{9}$ & $\mathrm{RG}_{630}$ \\
\hline Zone de sensiblité & $320-410$ & $323-515$ & $440-655$ & $600-730$ \\
Zone de sensibilité $\geqslant 50 \%$ & $340-395$ & $402-475$ & $490-580$ & $617-645$ \\
Maximum de sensibilité & 370 & 437 & 530 & 637 \\
\hline
\end{tabular}

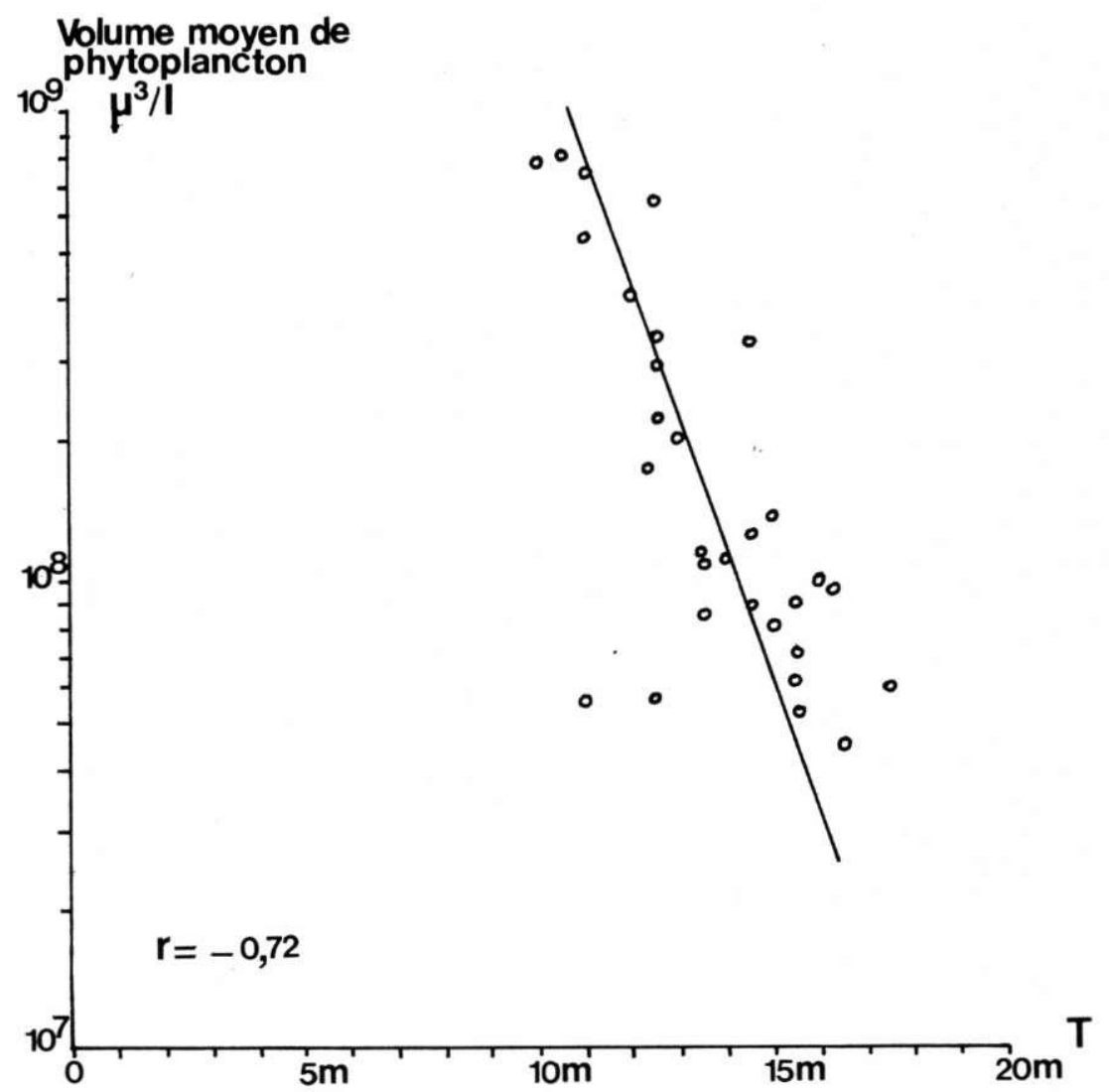

Fig. 12. - Relation entre la biomasse algale moyenne entre $0 \mathrm{~m}$ et $18 \mathrm{~m}$ et la profondeur de visibilité du disque de Secchi (T) au lac de Port-Bielh.

Les propriétés optiques du lac de Port-Bielh, déduites de ces mesures, sont résumées dans la fig. 13 (moyenne de 3 mesures effectuées au mois d'août pour des transparences comprises entre 
9,50 et 11,50 $\mathrm{m}$ et moyenne de 4 mesures effectuées en septembre et octobre pour des transparences variant de 14,50 à $16,50 \mathrm{~m}$ ). Comme dans tous les lacs alpins étudiés jusqu'ici, les rayonnements verts présentent le coefficient d'extinction le plus faible $\left(\alpha_{530}=0,12\right.$ à 0,10 soit 88,5 à $90 \%$ de transmission $)$. Les rayonnements bleus sont également peu atténués $(86,4$ à $86,7 \%$ de transmission). Notons qu'au mois d'août, les courbes de transmission présentent un point d'inflexion vers 8 à $10 \mathrm{~m}$ de profondeur en relation avec l'augmentation de la biomasse du phytoplancton de la zone profonde.
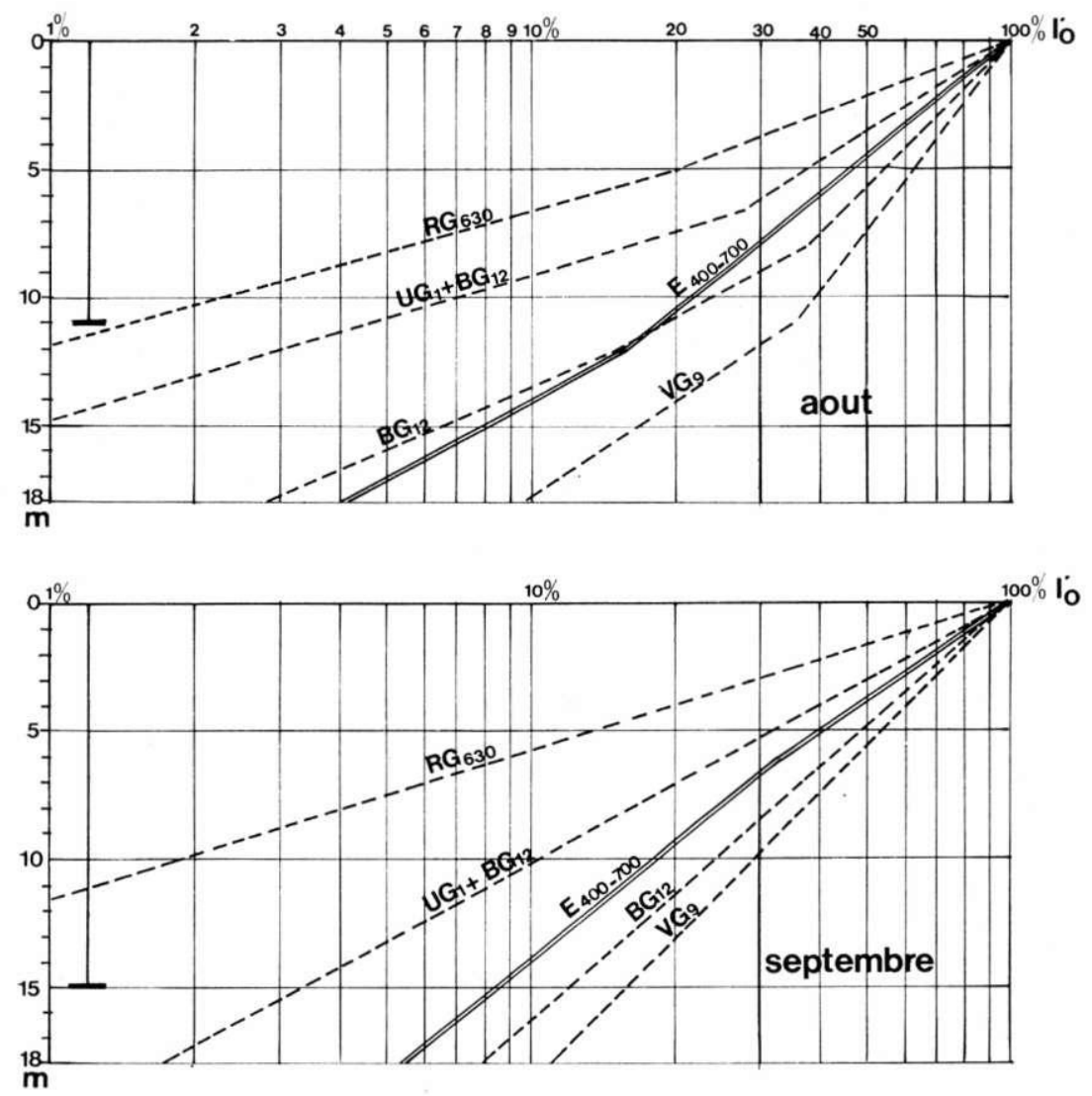

Fig. 13. - Transmission de la lumière au lac de Port-Bielh en août (transparence moyenne $11 \mathrm{~m}$ ) et en septembre (transparence moyenne $15 \mathrm{~m}$ ). Le gradient d'énergie totale dans le domaine du visible $\left(\mathrm{E}_{400}-700\right)$ a été calculé à partir des valeurs mesurées pour le bleu $\left(\mathrm{BG}_{12}\right)$, le vert $\left(\mathrm{VG}_{9}\right)$ et le rouge $\left(\mathrm{RG}_{\mathrm{ese}}\right)$. 
Dans le domaine du visible $(400-700 \mathrm{~m} \mu)$, la transmission caractéristique varie entre $83,85 \%$ et $85,25 \%$. Au cours de l'été, il n'existe done pratiquement pas de variation du coefficient de transmission lumineuse identique à celle constatée pour la transparence. Cette observation est en accord avec les résultats de BeEton (1957) qui note que l'intensité lumineuse à la limite de visibilité du disque de Secchi passe de $15 \%$ à $9 \%$ lorsque la transparence augmente de 10 à $16 \mathrm{~m}$. Les caractéristiques optiques du lac de Port-Bielh sont donc pratiquement constantes au cours de la période de dégel, la tranmission lumineuse étant de $84,5 \%$ en moyenne. Cette valeur est très proche de celle que nous avions estimée à partir de la valeur de la transparence moyenne (CAPBLANCQ et LAVILLE, 1969).

\subsection{Zooplancton.}

Pendant le mois de juillet, le peuplement est essentiellement composé par Mixodiaptomus laciniatus. Les słades naupliens de cette espèce ( $86 \%$ de la population le 21-7-1971) présentent des migrations verticales de faible amplitude et abondent toujours dans la zone supérieure du lac $(0-5 \mathrm{~m})$ où la température est la plus élevée. Pratiquement, seuls les stades naupliens et copépodites jeunes de Cyclops strenuus mènent une vie pélagique; on ne les trouve en forte densité qu'au voisinage du substrat. Daphnia longispina se développe à partir du mois d'août et atteint sa densité maximale annuelle en septembre. Le cycle biologique de cette espèce se caractérise par deux périodes maximales de reproduction parthénogénétique, en août, et en septembre (REY, 1969).

La densité totale des organismes du zooplancton augmente considérablement au cours de l'été ('ableau IV). Pratiquement toutes les espèces atteignent un maximum annuel au mois de septembre. La biomasse, estimée d'après les relations taille-poids chez les crustacés (Osmera, 1966, Edmonson et Winberg, 1971) est à cette époque 10 à 15 fois plus forte qu'au mois de juillet; elle est composée à plus de $70 \%$ par Daphnia longispina et les stades copépodites de Mixodiaptomus laciniatus.

\section{PHYTOPLANCTON : COMPOSITION DU PEUPLEMENT ET EVOLUTION SAISONNIERE.}

L'examen, au microscope inversé, de 320 échantillons fixés et l'observation de matériel frais après concentration par centrifugation ont permis de dénombrer environ 50 espèces dans le phytoplancton du lac de Port-Bielh. Leur liste est donnée dans le 


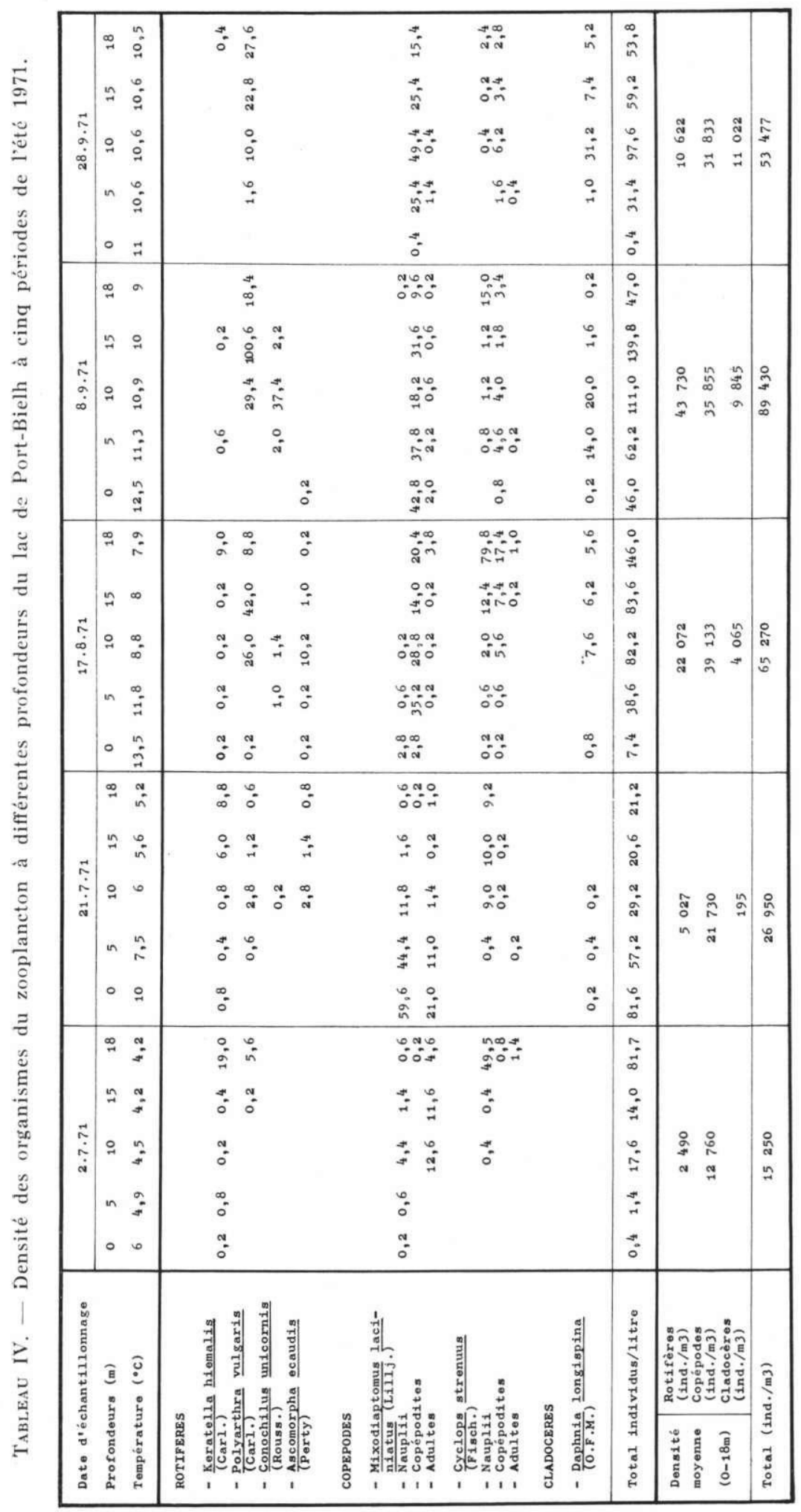


tableau $\mathrm{V}$ avec, pour les formes abondantes, le volume moyen d'un organisme. Trois remarques générales peuvent être faites à la lecture de ce tableau.

Tableau V. -.- Liste des espèces du phytoplancton du lac de Purt-Bielh et volume moyen des formes abondantes.

Volume moyen

Cyanophycées

- Microcystis aeruginosa Kuetzing

- Aphanocapa elachista var. conferta W. et G.S. West

$1000 \mu^{3}$

$200 \mu^{3}$

- Chroococcus sp.

-.. Anabaena cylindrica I.emmermann

$100 \mu^{3}$

- Oscillatoria limnetica Lemmermann

Chlorophycées

-... $\mu$ algues (Chlorella sp.; Coccomyxa sp.)

- Chlamydomonas sp. A

- Chlamydomonas sp. B

- Sphaerocystis schroeteri Chodat

- Oocystis pusilla Hansgirg

- Oocystis submarina Iagerheim

- Oocystis solitaria Wittrock

- Pediastrum boryanum var, rugulosum G.S. West

- Tetraëdron simmeri Schmille.

- Tetraëdron caudalum var. incisum Lagerheim

-. Tetraëdron minimum f, apiculatum Reinsch

-- Scenedesmus sp.

--- Crucigenia rectangularis (Nāg) Gay

- Crucigenia fenestrata Schmidle

- Ankistrodesmus falcatus (Goria) Ralfs

- Cosmariam humile (Gay) Nordstedt

- Cosmarium blyttii Wille

Euglenophycées

- Astasia sp.

Chrysophycées

- Chromulina of. minima Doflein

- Chromalina ef. glacialis Skuja

- Chromalina sp. + Ochromonas sp.

- Ochromonas ef. elegans Dollcin

- Ochromonas sp. + Chromulina sp.

- Pseudokephyrion sp.

- Erkenia subaequiciliata Skuja

-. Dinobryon cylindricum var. alpinum Imhof

- Uroglena europaea (Pascher) Conrad

- Monas sp.

Xanthophycées

-..- Pseudostaurastrum (= Isthmochloron) trispinatum W. et G.S. West 
Volume moyen

Diatomées

- Cyclotella comta (Ehrl).) Kuctzing

- Cyclotella stelligera (Cleve et Grunow) van Heurck

- Synedra nana Meister

-- Eunotia arcus Ehrenberg

- Achnanthes minutissima var. cryptocephala Grunow

-. Diatoma hiemale (Lynghie) Heiberg

Cryptophycées

- Navicula sp.

- Chroomonas minuta Skuja (- Rhodomonas minula Skuja)

- Chroomonas sp.

- Cruplomonas marssonii Skuja

- Cryptomonas onata Ehrenberg

- Katablepharis ovalis Skuja

$850 \mu^{3}$

$90 \mu^{3}$

$250 \mu^{3}$

Péridiniens

- Gymmodinium sp.

$1^{\circ}$ Le nombre des espèces phytoplanctoniques du lac est relalivement faible. En comparaison, Ie peuplement algal benthique présente une diversité beaucoup plus importante puisque 77 espèces sont recensées dans le seul groupe des Diatomées (Besch et al., 1972). Sur une quaranlaine d'espèces véritablement planctoniques, 15 seulement jouent un rôle appréciable sur le plan quantitatif.

$2^{\circ}$ Seules quelques formes coloniales, en général peu abondantes (Crucigenia reclangularis, Sphacrocystis schroeteri, Pediastrum boryanum, Dinobryon cylindricum), ont une taille supérieure à $30 \mu$. Dans leur grande majorité (+ de $90 \%$ ) les espèces ont une dimension comprise entre 2 et $20 \mu$. Ces formes nannoplanctoniques constituent 99 à $100 \%$ de la biomasse algale.

3" Les organismes flagelles representent environ la moitié des espèces. Numériquement, les Chlamydomonas, les Chrysomonadines et les Cryptomonadines forment 90 à $100 \%$ du peuplement.

Le phyloplancton du lac de Port-Biclh présente donc les caractéristiques générales de peuplement des lacs oligolrophes alpins et arctiques : une faible diversité spécifique, et une dominance ou une exclusivité des formes nannoplanctoniques mobiles.

\subsection{Peuplement hivernal.}

La biomasse et la composition spéciftque du phytoplancton hivernal varient selon la date et la profondeur d'échantillonnage. Les prélèvements réalisés entre la fin du mois de novembre et le mois 
de juillet révèlent l'existence d'une relation très nette entre l'évolution du peuplement et celle des paramètres chimiques. Les diagrammes (fig. 14) illustrent, pour différentes dates, les variations qualitatives et quantitatives du phytoplancton aux diverses profondeurs. Elles permettent de distinguer, à partir du mois de janvier, deux zones différentes dans le lac.
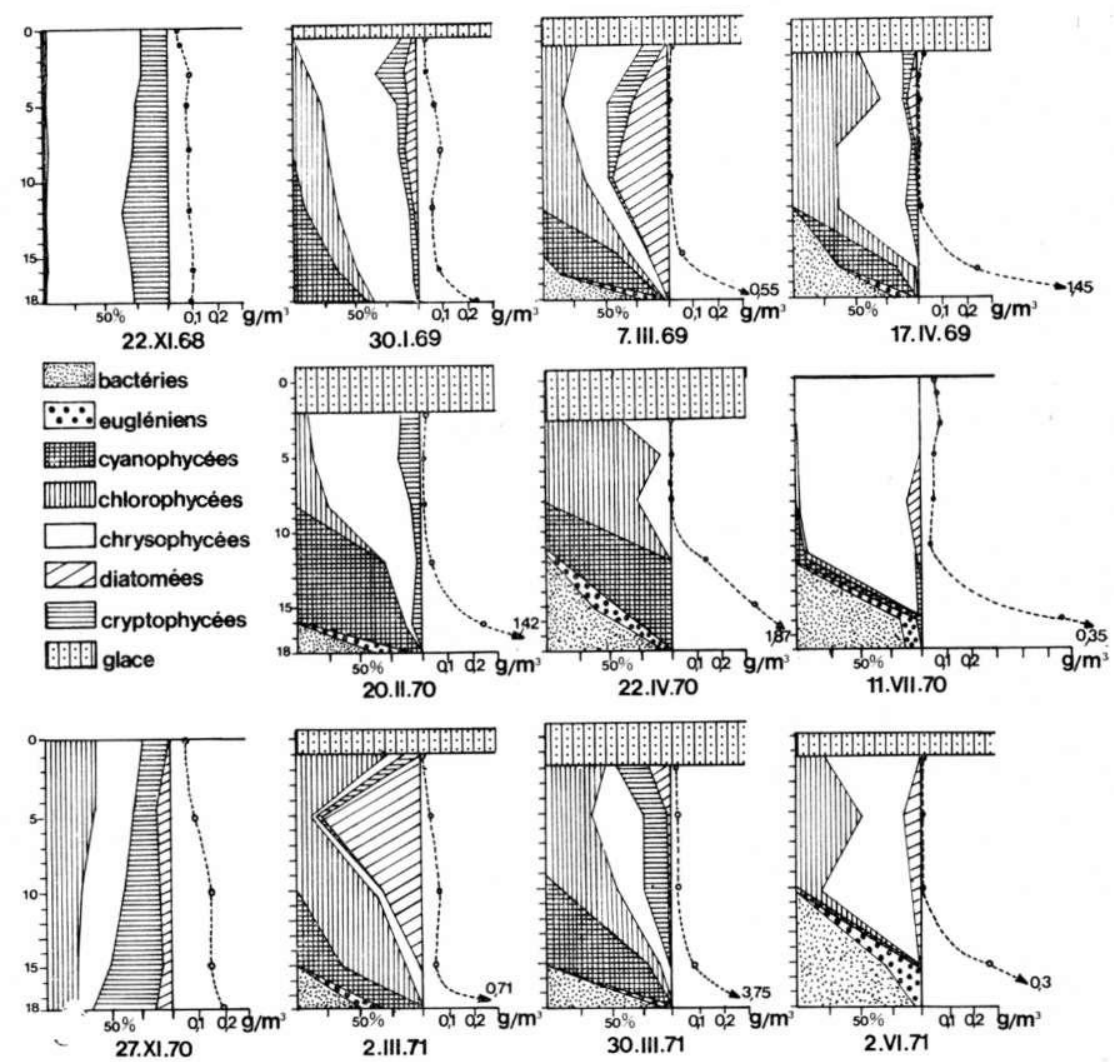

Fig. 14. - Biomasse ( $g$ de Poids frais $/ \mathrm{m}^{3}$ ) et composition ( $\%$ du volume total) du phytoplancton aux différentes profondeurs du lac de Port-Bielh, en hiver.

a) Entre la surface et une profondeur de 10 à $12 \mathrm{~m}$, la biomasse de phytoplancton est très réduite et généralement inférieure $10^{7} \mu^{3} /$ litre $(10 \mu \mathrm{g} / \mathrm{l}$ de poids algal frais). Les Chlorophycées (Chlorella sp., Oocystis pusilla, Chlamydomonas sp. A), les Chrysomonadines (Chromulina sp., Monas sp.) et les Cryptomonadines 
(Chroomonas minuta, Katablepharis ovalis) y dominent; la présence des Diatomécs (Cyclotella comta et C. stelligera) est plus irrégulière. Toutes ces espèces sont, pour la plupart, présentes dans les relevés du mois de novembre. Le peuplement hivernal apparaît donc comme dépourvu d'espèces caractéristiques; il est composé de formes automnales dont les populations persistent au début de l'hiver et déclinent progressivement au fur el à mesure que l'épaisseur de la glace et de la neige augmente. Ainsi, Oocystis pusilla a été trouvé le 30-1-1969 et le 2-3-1971 avec des densités de l'ordre de $3.10^{4}$ cellules/litre entre 5 et $12 \mathrm{~m}$ de profondeur; seuls quelques cxemplaires de celle espèce subsistent en avril et juin. Une évolution comparable a été notéc pour Chroomonas minula et Chromulina sp. Ces flagellés sont, avec Chlamydomonas sp. A, plus abondants dans les cinq premiers mètres sous la surface de la glace. Chlamydomonas subsiste pendant tout l'hiver; il est présent dans $85 \%$ des relevés effectués entre $0 \mathrm{~m}$ el $12 \mathrm{~m}$; le 17-4-1969 nous l'avons trouvé avec une densité de $10^{5}$ cellules/litre à $0,2 \mathrm{~m}$ sous la surface de la glace.

Cyclolella stelligera, absent des prélèvements de 1969 et 1970 , semble s'être maintenu durant tout l'hiver en 1971 (105 cellules/ litre entre 5 et $10 \mathrm{~m}$ le $2-3-1971,5000$ à 10000 cell./l le 2-6-1971). En janvier et mars 1969 , seul $C$. comta $(2000$ a 5000 cell./1) a été trouvé.

Il faut noler enfin que la proportion des flagellés incolores Kíatablepahris obalis, Monas sp.) augmente en même temps que la quantité do phyloplancton décroît. Ies derniers représentent 5 à $80 \%$ de la biomasse de Chrysomonadines à pariir du mois de mars.

b) Le peuplement phytoplanclonique de la zone profonde (12 m$18 \mathrm{~m})$ se caractérise par l'apparition de groupes très rares ou ahsents pendant la période estivale. Entre 12 et $15 \mathrm{~m}$ de profondeur, des Cyanophycécs (Microcystis aeruginosa, A phanocapsa elachista, Chrooccocus dispersus) se développent et représentent 60 à $100 \%$ de la biomasse algale, einq à dix fois plus élevée qu'en surface. Près du fond, un peuplement composé essentiellement de bactéries oligoaérobies (Spirillum sp., Chromatium sp., Achroma lium sp., Siderocapsa sp.) associées à Astasia sp. remplace les Cyanophycées. La densité de ces organismes augmente progressivement au cours de l'hiver et corrélativement à la diminution du taux $\mathrm{d}^{\prime} \mathrm{O}_{2}$ dissous $\left(7-10^{7}\right.$ bactéries/litre le $30-3-1971$ à $18 \mathrm{~m}$; 8-105 cellules d'Aslasia/litre le 22-4-1970 à $18 \mathrm{~m}$ ). Dans ce dernier mètre d'eau se forment ainsi des biomasses considérables : 1,9 mg/l le $22-4-1970 ; 3,75 \mathrm{mg} / \mathrm{I}$ le $30-3-1971)$. 


\subsection{Peuplement d'été.}

\subsubsection{LA BIOMASSE ET SA COMPOSITION.}

L'augmentation de l'éclairement et les modifications chimiques de l'eau consécutifs à la disparition de la glace et à l'isothermie de printemps se traduisent par un changement total du peuplement et une croissance rapide des algues planctoniques. Les variations quantitatives et qualitatives du phytoplancton au cours de la période de dégel sont représentées dans la fig. 15. Une évolution identique a pu être observée au cours des trois années de prélèvement :

- La biomasse algale présente une phase de croissance rapide et atteint une valeur maximale $\left(0,6\right.$ à $0,8 \mathrm{~g} / \mathrm{m}^{3}$ d'eau) entre le 15 juillet (1968) et le 15 août (1970) soit régulièrement trois semaines à un mois après la fusion totale de la glace. Durant cette période, elle est composée presque exclusivement de Chrysomonadines (70 à $90 \%$ du volume total de phytoplancton).

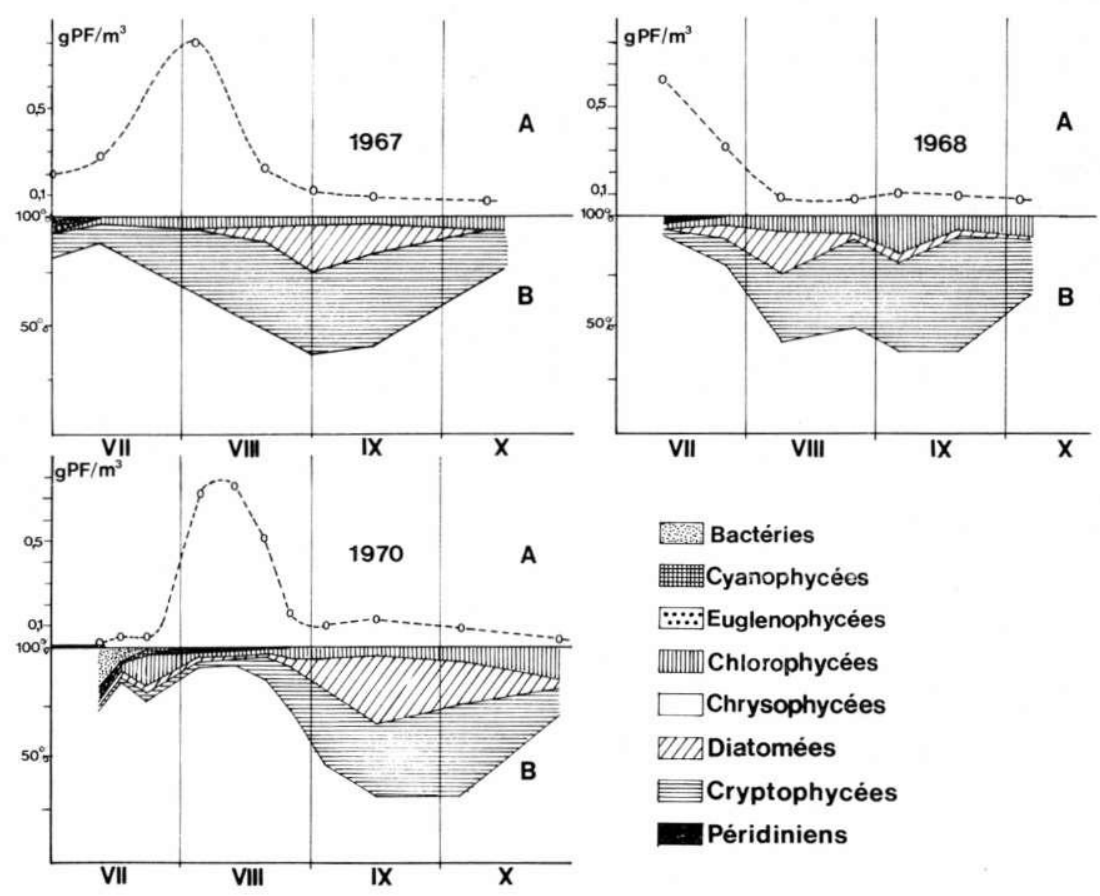

Fig. 15. - Evolution de la biomasse de phytoplancton du lac de Port-Bielh en été.

A : g de poids frais $/ \mathrm{m}^{3}$, moyenne entre $0 \mathrm{~m}$ et $18 \mathrm{~m}$; B : importance relative (\% biomasse totale) des divers groupes. 

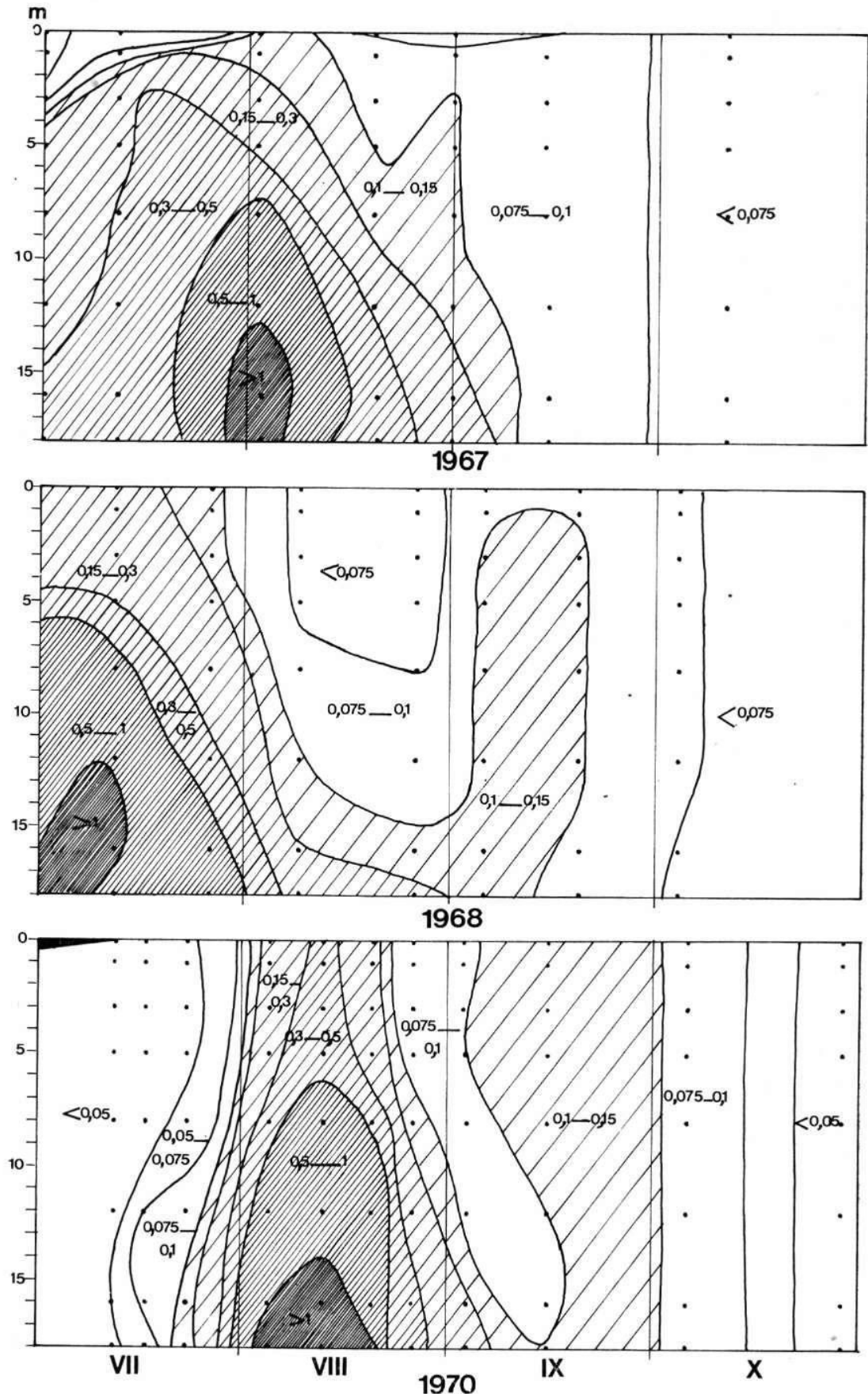

Fig. 16. - Évolution de la biomasse de phytoplancton (g de poids frais $/ \mathrm{m}^{3}$ ) aux diverses profondeurs du lac de Port-Bielh, en été. 
- Le peuplement phytoplanctonique décline au mois d'août. La biomasse, relativement faible $\left(0,1 \mathrm{~g} / \mathrm{m}^{3}\right.$ en moyenne) se maintient à une valeur à peu près constante jusqu'au gel. L'abondance relative des Chrysomonadines décroît au profit des Diatomées et des Cryptomonadines qui représentent ensemble 50 à $70 \%$ de la biomasse de septembre.

- Parmi les groupes systématiques représentés, Chrysomonadines, Cryptomonadines et Diatomées dominent sur le plan quantitatif. Les Chlorophycées dépassent rarement $10 \%$ du volume total de phytoplancton. Leur abondance relative augmente légèrement à l'automne; c'est un des groupes dominants dans le peuplement de surface en hiver. Les Cyanophycées et les Péridiniens ne se développent qu'au début de l'été. Ces deux groupes jouent un rôle quantitatif négligeable et ne forment jamais plus de $2 \%$ dans la biomasse.

\subsubsection{RÉPARTITION DU PHYTOPLANCTON EN FONCTION DE LA PROFON- DEUR.}

Les diagrammes (fig. 16) illustrent la répartition verticale du phytoplancton au cours de l'été. Il existe, en fait, un parallélisme assez étroit entre la distribution des algues et les conditions thermiques du lac.

Pendant la stratification thermique des mois de juillet et août, les algues se développent essentiellement dans la zone profonde du lac, au-delà de 10 à $12 \mathrm{~m}$. Au moment de la croissance optimale du phytoplancton, plus de $50 \%$ de la biomasse sont concentrés dans les cinq derniers mètres d'eau. Ce type de distribution, caractéristique des lacs transparents d'altitude (NAUwErcK, 1966, Rodhe et al., 1966, Pechlaner, 1967), s'atténue lorsque la stabilité thermique du lac diminue (fig. 17). A la fin du mois d'août, les
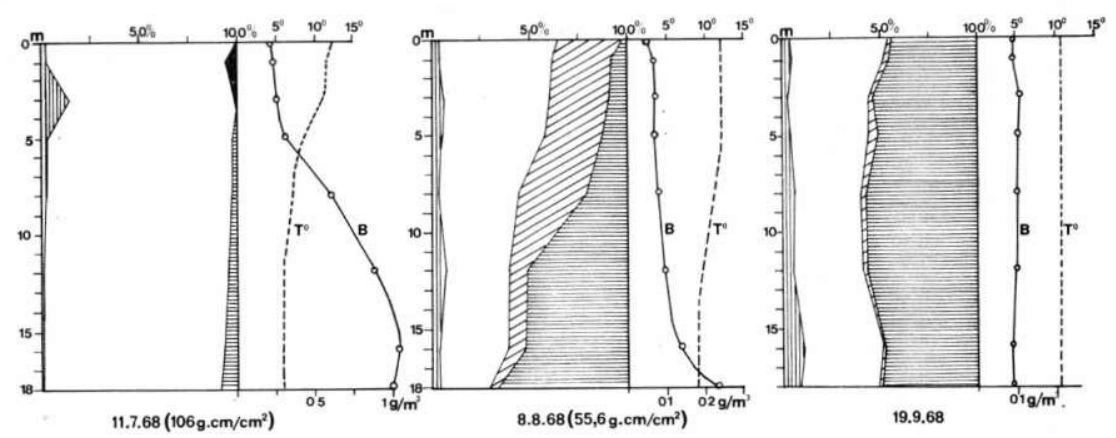

Fig. 17. - Types de répartition quantitative et qualitative du phytoplancton du lac de Port-Bielh, en été. Les valeurs de la température et de la stabilité thermique sont indiquées sur les figures. Symboles : voir fig. 15. 
différences de biomasse entre la surface et la profondeur s'amoindrissent. Qualitativement, il existe cependant une différence très nette entre le phytoplanclon de surface, composé de Chrysomonadines et de Diatomées et celui de la zone profonde où dominent les Cryplomonadines (fig. 17). L'isothermie d'automne entraîne une uniformisation de la biomasse et de sa composition dans toute la masse d'eau : ces conditions dureront jusqu'au gel pendant une période de deux mois ou plus.

\subsubsection{Cycle Saisonnier et RÉPARTItion verticale des Espèces DOMINANTES.}

Les résultats des comptages d'organismes ont été figurés sous forme de diagrammes (fig. 18 à 21). Ils illustrent l'évolution numérique des populations des 14 espèces dominantes du phytoplancton du lac de Port-Bielh en fonction de la profondeur (ordonnée) et du temps (abscisse).

\section{* Bactérioplancton.}

Le peuplement hivernal de la zone profonde disparaît très rapidement au début de l'été. Le 22-7-1970, soit huit jours après la fusion complète de la glace, il ne subsistait aucun exemplaire des formes qui abondaient encore le 11-9-1970 (10 bactéries/litre à $18 \mathrm{~m}$ ). Une évolution identique avait été observéc entre le 29-61967 (lac à moilié dégelé) et le 11-7-1967.

Pendant l'été, les bactéries planctoniques sont peu abondantes à tous les niveaux. Les comptages par dilution en milieu liquide effectués par G. Micher (comm. verb.) ont révélé des densités très faibles, de l'ordre de 1000 germes/litre. Les valcurs de l'assimilation de ${ }^{14} \mathrm{C}$ à l'obscurité qui mesurent essenticllement l'activité hétérotrophe des bactéries (Sorokin et KaDota, 1972), sont en général relativement faibles.

\section{* Cyanophycées.}

Cette classe n'est jamais présente en abondance dans les prélèvements de l'été, Chroococcus dispersus en est l'élément dominant mais il n'atteint jamais de fortes densités. Nous ne l'avons trouvé en quantités notables $\left(10^{4}\right.$ à $2.10^{4}$ colonies/litre $)$ que dans les échantillons de 15 et $18 \mathrm{~m}$ de profondeur au début de l'été 1967 et 1970 . Celte espèce disparaît progressivement lorsque la teneur en $\mathrm{O}_{2}$ dissous augmente.

\section{* Chlorophycées (fig. 18).}

Elles ne forment jamais une biomasse importante dans le phytoplancton du lac de Port-Biclh. Numériquement deux espèces du genre Chlamydomonas et deux espèces du genre Oocystis $(O$. pusilla et $O$. submarina) dominent le groupe des algues vertes. Sphaerocystis schroeleri n'est jamais très abondant (1 000 à 5000 
colonies/litre) mais, de par sa taille plus élevéc, il peut former plus de $50 \%$ du volume total de Chlorophycées.

Chlamydomonas spp. apparaissent dans le plancton de façon précoce et se succèdent dans le temps et dans l'espace : Chlamydomonas sp. $A(7 \times 5 \mu)$ est une forme de surface $(0-5 \mathrm{~m})$ qui apparaît dès le dégel du lac; elle domine dans le peuplement d'hiver. Chlanydomonas sp. $B(3 \mu)$ lui succède et se développe de préférence entre 5 et $12 \mathrm{~m}$ de profondeur.

Sphaerocystis schroeteri et Oocystis sp. sont des formes automnales. Elles apparaissent simultanément dans le phytoplancton au mois d'août et présentent leur maximum en septembre ou oclobre selon les années. Oocystis pusilla ne disparaît qu'en avril.

\section{- Euglénophycées.}

Le seul représentant de ce groupe (Astasia sp.) suit un cycle parallèle à celui des bactéries et disparaît à l'isothermie de printemps.

* Chrysomonadines (fig. 19).

Elles constituent le groupe dominant du phytoplancton tant par le nombre d'espèces que par leur biomasse. Chromalina spp., Ochromonas spp. et Erkenia subaequiciliata atteignent des densités généralement supérieures à $10^{6}$ cellules/litre pendant tout l'été.

Les difficultés d'observation de ces flagellés nannoplanctoniques (2 à $8 \mu$ ), liées à l'extrême fragilité du matériel frais el à leur déformation par les fixateurs, ne nous ont pas permis de distinguer les espèces des genres Chromulina et Ochromonas. Il s'avérait d'ailleurs pratiquement impossible de reconnaître les espèces lors des comptages de matériel fixé au lugol. Nous avons ten!é de séparer les différentes formes en nous basant sur le nombre de flagelles et sur la taille des organismes. Ces critères n'ont cependant pas permis la différenciation rigoureuse des formes de taille identique lorsque les fouets n'étaient pas toujours bien visibles. Nous les arons regroupées sous la même rubrique (Chromulina + Ochromonas).

Les unitès systématiques ainsi définies se distribuent dans le temps et dans l'espace selon le même schéma général, chaque année. Fntre le dégel el le gel, elles se succèdent rapidement de la façon suivante :

- Chromulina sp. + Ochromonas sp. $(4-5 \mu)$ au dégel Ochromonas sp. + Chromulina sp. $(7-10 \mu)$ et Dinobryon cylindricum - Erkenia subaequiciliata - Pseudokephyrion sp, et Chromulina (cf. minima) - Chromulina (cf. glacialis) et Ochromonas (cf. elegans) en automne.

Dans leur majorité, ces espèces semblent trouver les conditions de développement optimales en zone profonde entre 10 et $18 \mathrm{~m}$. Chro- 
mulina (cf. minima) et Pseudokephyrion sp. sont plus abondants près de la surface $(0-8 \mathrm{~m})$.

* Dialomées (fig. 20).

Les Diatomées sont essentiellement représenlées dans le plancton du Port-Bielh par deux Cyclotella (C. stelligera et C. comta). Synedra nana ne forme jamais de populations abondantes (5 000 cellules/litre au maximum). Quelques formes benthiques (Achnanthes minutissima var. cryptocephala, Navicula sp., Cymbella sp., Eunotia arcus) apparaissent de façon irrégulière dans les prélèvements de 12 à $18 \mathrm{~m}$.

Cyclotella stelligera et $C$. comta se développent simultanément dans le plancton de surface $(0-12 \mathrm{~m})$. L'opitimum se situe au début du mois d'août en 1968, du mois de septembre en 1967 et coïncide chaque annéc avec la chute du peuplement phyloplanctonique et avec les températures maximales de l'eau.

" Cryptomonadines (fig. 21).

Cet ordre forme, avec les Chrysomonadines, I'élément dominant du phytoplancton. Deux espèces de Cryptomonas peuplent la zone pélagique. C. marssonii a été trouvé dans tous les prélèvements à partir du mois de juillet, avec une densité optimale au mois de septembre. C. ovata se développe seulement dans la zone profonde où il forme des populations relativement abondantes entre 12 et $18 \mathrm{~m}$ all mois d'août.

Chroomonas minuta est une forme constante du phytoplancton. Nous l'avons trouvé en quantité souvent imporlante $\left(10^{5}\right.$ à $10^{6} \mathrm{cel}-$ lules/litre) à partir de $12 \mathrm{~m}$ de profondeur enlre juillet et octobre avec un maximum en juillet (1968) ou en août (1967 et 1970$)$. Un autre Chroomonas apparaît de façon très éphémère dans la zone profonde au moment du dégel. Nous ne l'avons récolté en grande quantité $\left(10^{6}\right.$ cellulcs/litre $)$ que le 29-6-1967 à $16 \mathrm{~m}$ alors que le lac était encore partiellement gelé.

Katablepharis ovalis est présent dans tous les prélèvements d'été avec une densité optimale $\left(2.10^{5}\right.$ à $3.10^{j}$ cellules/litre) entre $12 \mathrm{~m}$ et $18 \mathrm{~m}$ au mois d'août.

\section{* Péridiniens.}

Ils sont pratiquement absents du phytoplancton du lac de PortBielh. Quclques exemplaires du genre Gymnodinium (2 000 ind./1 au maximum) ont été dénombrés dans des prélèvements du début du mois de juillet.

\section{PRODUCTIVITÉ PRIMAIRE}

Le taux d'accroissement de la biomasse phytoplanctonique et l'évolution du $\mathrm{pH}$ et de l'O $\mathrm{O}_{2}$ dissous reflètent l'existence d'une activité photosynthétique dans toute la masse d'eau au cours de 


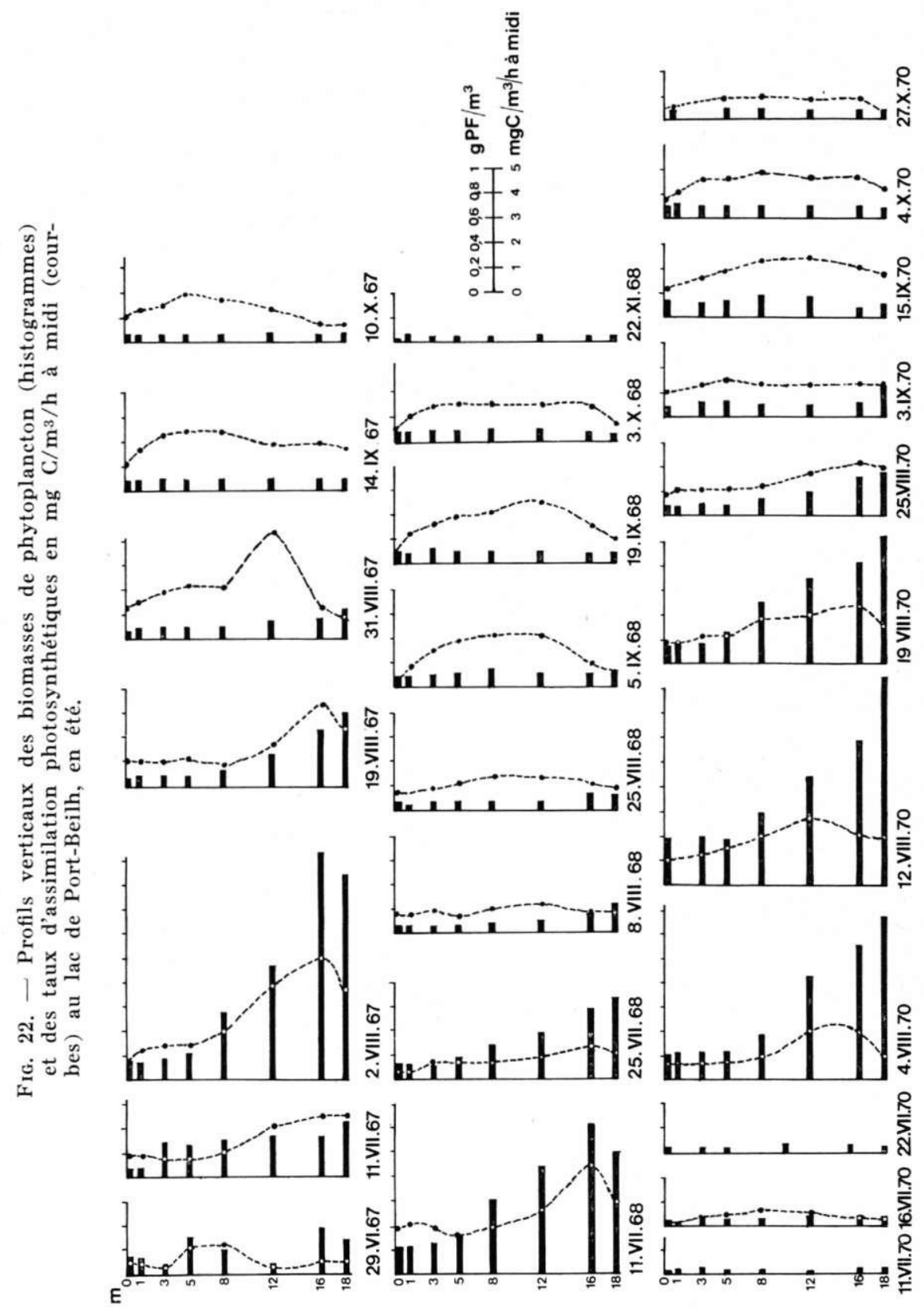


l'été. Ces paramètres globaux n'ont cependant qu'une valeur indicatrice dans la mesure où ils peuvent être influencés par d'aulres composantes du milieu (nutrition du zooplancton, circulation des eaux à l'isolhermie). Des mesures directes du taux de photosynthèse des algues phytoplanctoniques ont été effectuées avec la technique du ${ }^{14} \mathrm{C}$. Les résultats de 23 séries de mesures réalisées au cours de l'été en 1967,1968 et 1970 ont été représentés sous forme de courbes dans la fig. 22. Elles indiquent, pour chaque date de mesure, l'importance du taux de photosynthèse (exprimé en mg de carbone assimilé $/ \mathrm{m}^{3}$ d'eau/heure au milieu de la journée solaire) aux diverses profondeurs. La valeur de la biomasse algale a également été figurée.

\subsection{Variations en fonction de la profondeur.}

Il existe un parallélisme assez net entre la distribulion des algues phytoplanctoniques en profondeur et les courbes de productivité. Ces dernières traduisent des taux de photosynthèse relativement faibles près de la surface, plus élevés en profondeur (12 à $16 \mathrm{~m}$ ), dans la zone à fortes biomasses de phytoplancton. Durant la période de stratification thermique, plus de $50 \%$ du carbone assimilé entre 0 et $18 \mathrm{~m}$ provient de la photosynthèse du phytoplanclon des cinq derniers mètres.

I,es courbes obtenues au moment de l'isothermie automnale correspondent à une répartition qualitative et quantitative du phytoplancton relativement homogène. Elles se caractérisent par l'existence d'un maximum peu distinct situé entre 5 el $12 \mathrm{~m}$ selon les dates de mesure et sont comparables aux courbes de type II (lacs oligotrophes) décrites par Findenegg (1964).

L'assimilation de carbone par photosynthèse est très réduite en hiver et n'est décelable que dans les deux premiers mètres immédiatement sous la surface de la glace. Elle est d'autant plus faible que l'épaisseur de la couverture hivernale est forte $(0,162 \mathrm{mg}$ $\mathrm{C} / \mathrm{m}^{3} / \mathrm{h}$ à midi sous la glace le $30-1-1969 ; 0,018 \mathrm{mg} \mathrm{C} / \mathrm{m}^{3} / \mathrm{h}$ à midi sous la glace le 17-4-1969). Au-delà d'une profondeur de $5 \mathrm{~m}$, l'assimilation de ${ }^{14} \mathrm{C}$ dans les flacons opaques est toujours identique à celle des flacons Iransparents.

\subsection{Variations saisonnières.}

L'intégration des courbes de productivité permel d'évaluer le taux de photosynthèse moyen $\left(\mathrm{mg} \mathrm{C} / \mathrm{m}^{3} / \mathrm{h}\right.$ à midi) entre 0 et $18 \mathrm{~m}$ de profondeur pour chaque série d'expériences. Les résultats ont été représentés dans la fig. 23. Un diagramme retraçant l'évolution de la productivité estivale dans le temps et dans l'espace permet une comparaison directe avec les autres variables. 
Fig. 23. - Assimilation photosynthétique $\left(\mathrm{mg} \mathrm{C} / \mathrm{m}^{3} / \mathrm{h}\right.$ à midi) aux diverses profondeurs du lac de Port-Bielh, en été, et évolution du taux d'assimilation moyen entre $0 \mathrm{~m}$ et $18 \mathrm{~m}$ (courbes en pointillés).

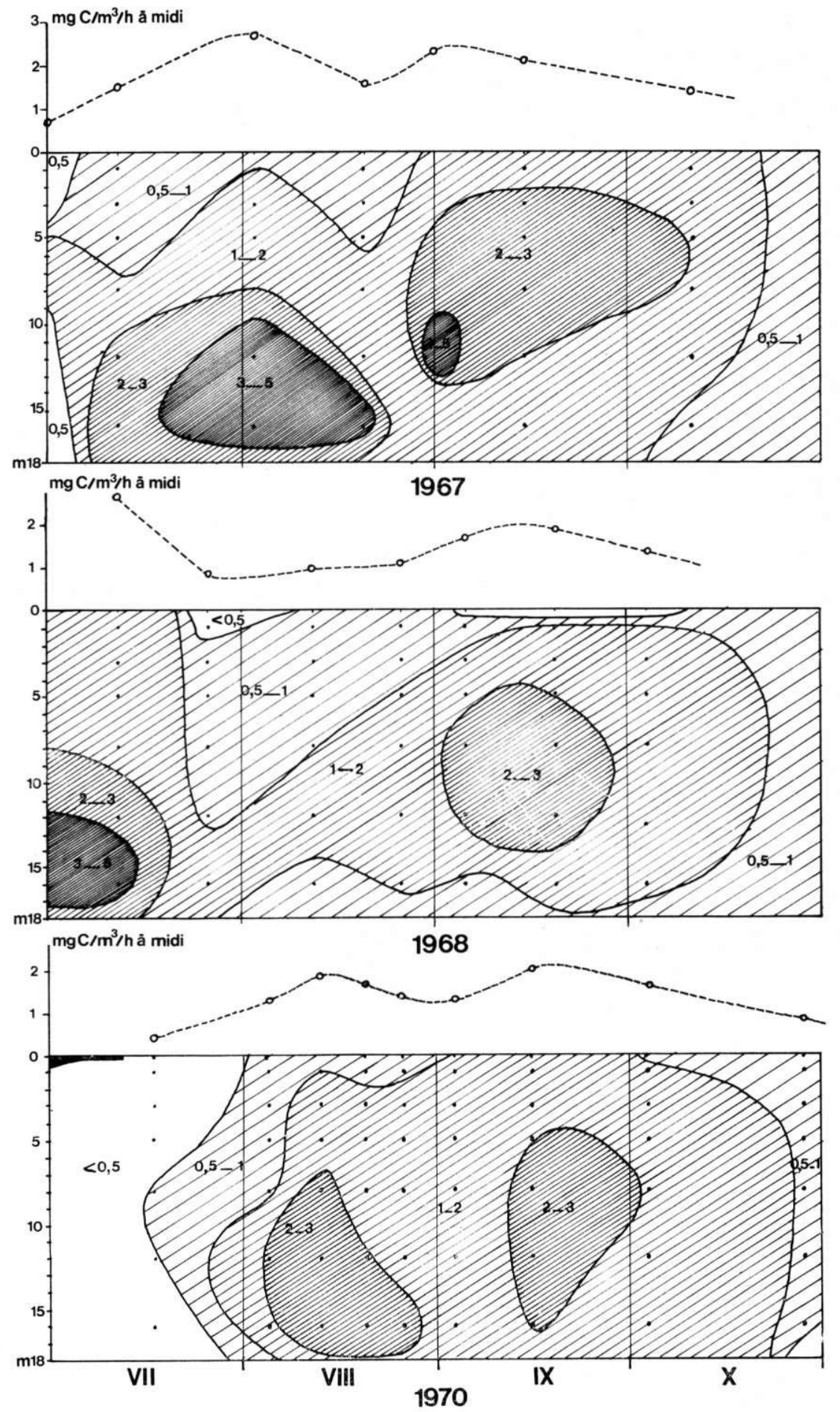


Entre le mois de janvier et le mois de juin, la photosynthèse est pratiquement négligeable et limitée à la couche superficiclle du lac. On peut estimer que la productivité moyenne est généralement inférieure à $1 \mu \mathrm{g} \mathrm{C} / \mathrm{m}^{3} / \mathrm{h}$ à midi dès que la coluche de glace et de neige dépasse une épaisseur d'un mètre.

L'augmentation de l'éclairement à la fin de la période de gel entraîne une reprise rapide de la pholosynthèse. Deux maxima distincts ont été observés chaque année pendant la période de dégel. Le premier correspond aux fortes biomasses algales qui se développent dans le lac au cours du premier mois qui suit le dégel. Le second se situe au mois de septembre et coïncide avec le début de l'isothermie d'automne. La fin de la période de stratification d'été est caractérisée par la diminution du taux de photosynthèse et de la biomasse phytoplanctonique. Cette évolution traduit vraisemblahlement l'épuisement du milieu en un ou plusieurs éléments nutritifs. Contrairement à ce qui se passe au début de l'ćté, le pic de photosynthèse automnal ne s'accompagne jamais d'un accroissement notable de la biomasse algale.

\subsection{Variations journalières.}

Lcur misc en évidence résulte d'expériences successives, de courte durée ( 3 à $5 \mathrm{~h}$ ) réalisées entre le lever et le coucher du soleil. La fig. 24 illustre l'évolution de l'ensoleillement el de la quantité moyenne de carbone assimilé pendant chaque expérience $\left(\mathrm{mg} \mathrm{C} / \mathrm{m}^{3} / \mathrm{h}\right)$ aux diverses profondcurs. Ies trois séries de courbes correspondent à des condilions différentes :

- stratification thermique avec augmentation de la biomasse algalc en fonction de la profondeur; mesures effectuées un jour sans nuage (4-8-1971) et un jour avec brouillard l'après-midi (12-8-1970);

- isothermie d'automne avec répartition homogène du phytoplancton à toutes les profondeurs (17-9-1971).

Trois caraclères généraux apparaissent à la lecture de ces courbes :

1" Dans tous les cas, le taux de photosynthèse diminue au milieu de la journée et ceci d'autant plus que l'intensité des radiations solaires est forte. Ce phénomène d'inhibition par la lumière est perceptible jusqu'à $10 \mathrm{~m}$ de profondeur au mois d'août; seule la courbe de $1 \mathrm{~m}$ présenle celte dépression le 17-9-1971. A $16 \mathrm{~m}$, les taux de photosynthèse sont pratiquement proportionnels à l'intensité des radiations solaires.

$2^{\circ}$ Toutes les courbes présentent une dissymétrie par rapport au midi solaire. A l'exception des courbes du 12-7-1971 où cette dissymétrie résulte de la formation de nuages en fin de journée, 
FIg. 24. - Variations journalières de l'assimilation photosynthétique à diverses profondeurs du lac de Port-Bielh. Les courbes d'ensoleillement correspondant aux journées de mesure sont reproduites. Les profils verticaux représentent la productivité journalière aux différentes profondeurs.

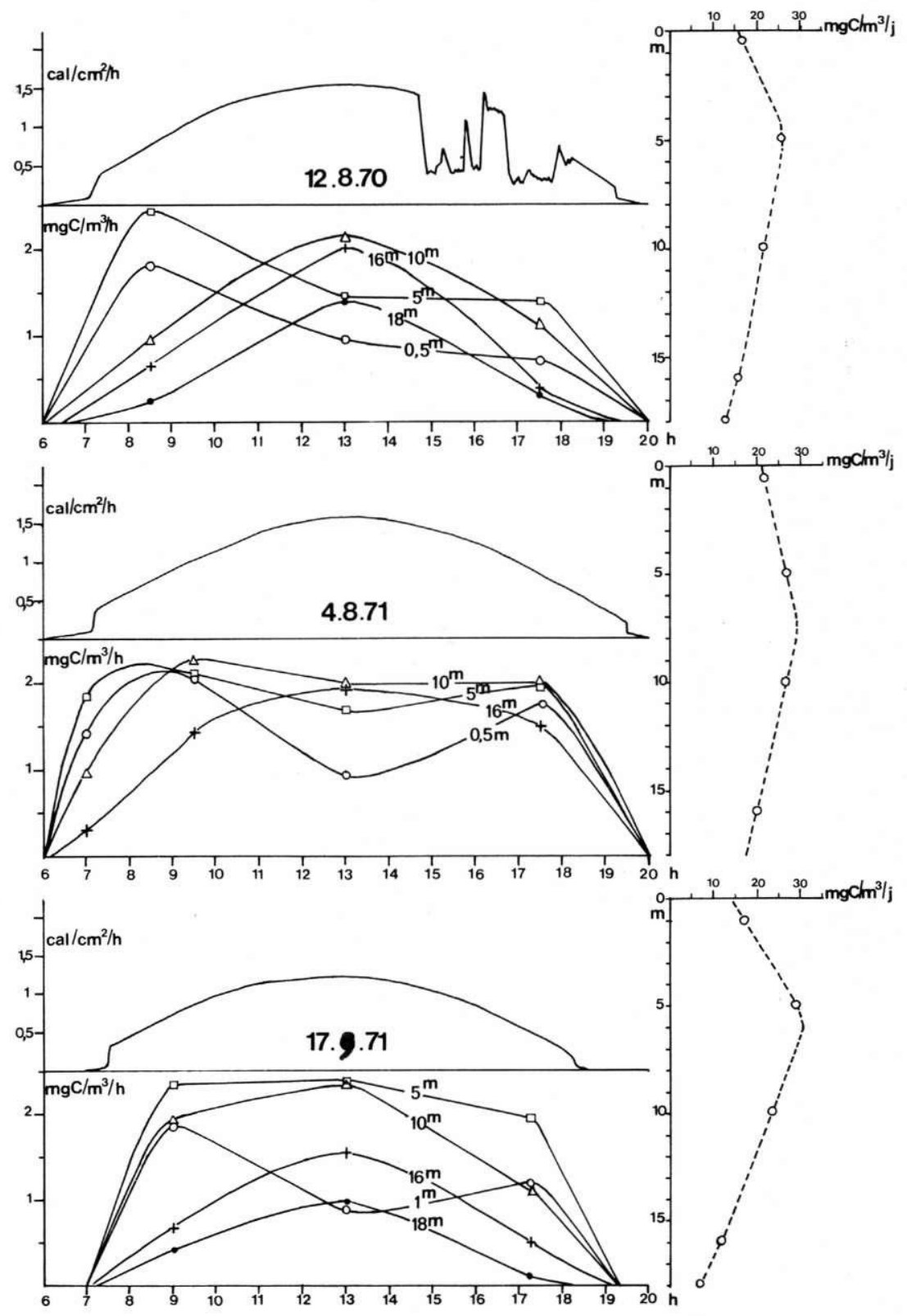


on observe, pour une énergie radiante identique, des taux d'assimilation plus élevés aux premières heures de la journée qu'en fin d'après-midi. Ce résultat est en accord avec les obscrvations de Ohle (1958), Doty et Ogtri (1959), Vollenweider et Najwerck (1961).

$3^{\circ}$ La surface délimitée par les courbes représente la productivité journalière aux profondeurs correspondantes. Les profils verticaux ainsi obtenus (fig. 24) diffèrent sensiblement de ceux qui décrivent les résultats des expériences réalisées entre $11 \mathrm{~h}$ et $15 \mathrm{~h}$. L'optimum apparaît entre 5 et $10 \mathrm{~m}$ de profondeur : c'est la zone où le taux de photosynthèse reste relativement élevé pendant la plus grande parlie de la journée solaire. En période de stratification thermique, les différences entre la distribution verticale de la biomasse et les profils de productivité journalière méritent d'être soulignées.

\subsection{Assimilation de carbone à l'obscurité.}

Pendant la période de dégel, l'assimilation de carbone dans les flacons opaques représente presque toujours un faible pourcentage (1 à $4 \%$ ) de l'assimilation photosynthétique. Ces valeurs sont très semblables à celles qu'indique Stekmaniv-NiELSEv (1960 a) pour la mer.

Ia fixation de carbone à l'obscurité varie en fonction de la profondeur de manière sensiblement identique à la photosynthèse. Pour l'ensemble des mesures (fig. 25), les valeurs moyennes aux différentes profondeurs varient peu jusqu'à $12 \mathrm{~m}(18$ à $26 \mu \mathrm{g}$ $\mathrm{C} / \mathrm{m}^{3} / \mathrm{h}$ soit 1 à $2 \%$ de la photosynthèse). Par contre, un maximum très net $\left(62 \mu \mathrm{g} \mathrm{C} / \mathrm{m}^{3} / \mathrm{h}\right.$ soit $3,5 \%$ de la photosynthèse $)$ apparaît entre 16 et $18 \mathrm{~m}$. Dans cette zone, l'assimilation obscure a atteint $0,12 \mathrm{mg} \mathrm{C} / \mathrm{m}^{3} / \mathrm{h}(19-9-1967$ à $16 \mathrm{~m})$ à $0,19 \mathrm{mg} \mathrm{C} / \mathrm{m}^{3} / \mathrm{h}$ (5-9-1968 à $18 \mathrm{~m}$ ) soit respectivement $3,5 \%$ et $23 \%$ de l'assimilation à la lumière.

L'assimilation du carbone à l'obscurité évolue au cours de l'été (fig. 26) : un maximum apparaîl dans la deuxic̀me quinzaine du mois d'août (1967 et 1970) ou aul début du mois de septembre (1968). Ces valcurs, deux à trois fois supérieures à la moyenne d'été, correspondent à la période où la température du lac est lá plus élevée. En 1967 et 1970 , elles coincident avec la diminution la la biomasse et du taux de photosynthèse du phytoplancton. En 1968, I'optimum a été noté au début de l'automne, deux mois après le pic de biomasse. Le faible éclairement en hiver et, par conséquence, la baisse du laux de photosynthèse augmente l'importance relative de l'assimilation de carbone à l'obscurité. Au-delà d'une profondeur de $5 \mathrm{~m}$, l'activité des flacons opaques est égale ou par- 


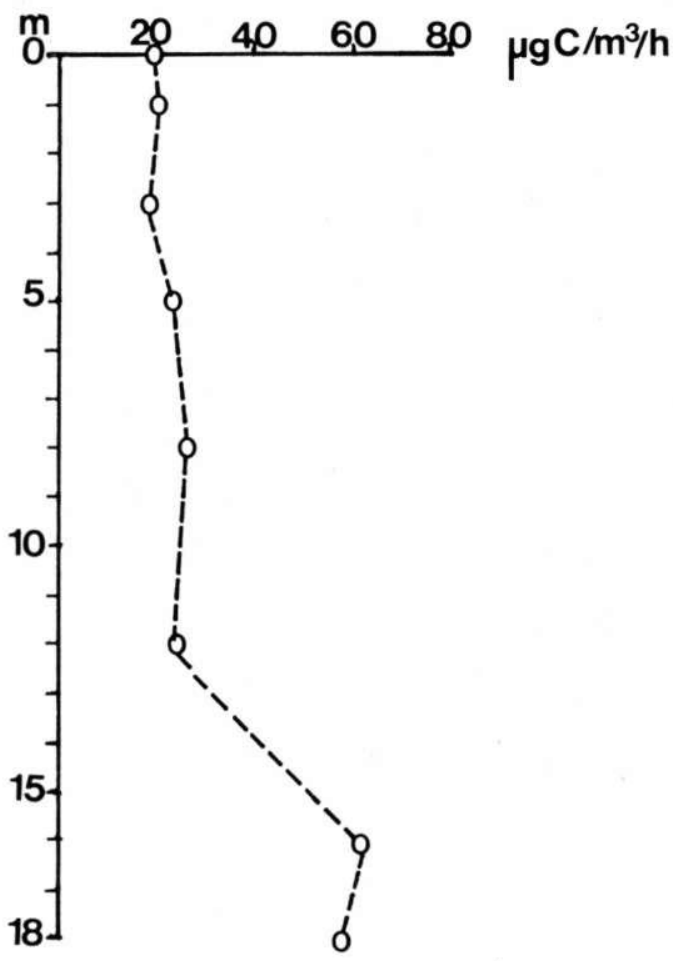

FIg. 25. - Assimilation de carbone à l'obscurité aux différentes profondeurs du lac de Port-Bielh, en été (moyenne des valeurs mesurées de 1967 à 1971).

fois légèrement supérieure à celle des flacons transparents. Les valeurs restent cependant toujours faibles et inférieures à $10 \mu \mathrm{g}$ $\mathrm{C} / \mathrm{m}^{3} / \mathrm{h}$ sauf au contact du fond où, corrélativement à la présence des bactéries anaérobies, elles dépassent en général $0,2 \mathrm{mg} \mathrm{C} / \mathrm{m}^{3} / \mathrm{h}$. Le 20-2-1970 nous avons mesuré une assimilation de 0,79 mg $\mathrm{C} / \mathrm{m}^{3} / \mathrm{h}$ à $18 \mathrm{~m}$; le $30-4-1969$ elle atteignait $2,30 \mathrm{mg} \mathrm{C} / \mathrm{m}^{3} / \mathrm{h}$ à la même profondeur.

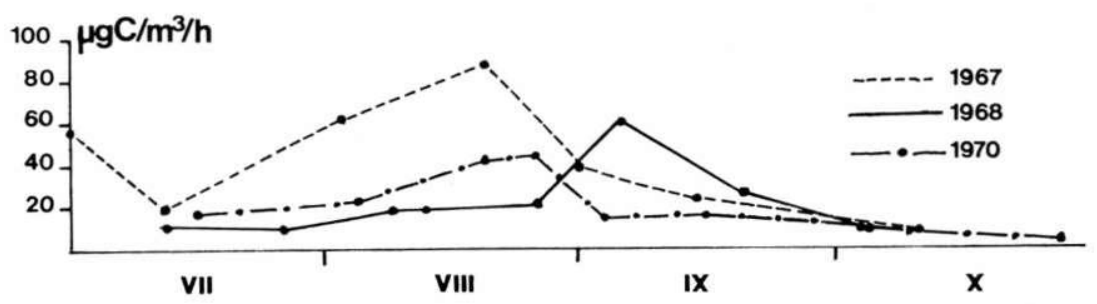

Fig. 26. - Variations de l'assimilation de carbone à l'obscurité au cours de l'été (moyenne entre $0 \mathrm{~m}$ et $18 \mathrm{~m}$ ) dans le lac de Port-Bielh. 
Les travaux de Romanenko (1964) et de Sorokis (1965) montrent que, dans les caux normalement oxygénées, il existe une relation entre l'assimilation de carbone à l'obscurité et la production bactérienne. On peut admettre que les bactéries hétérotrophes assimilent en moyenne $6 \%$ du carbone néccssaire à leur biosynthèse à partir du $\mathrm{CO}_{2}$ de l'eau (Sorokin et Kadota 1972). Toutefois, pendant la période de dégel, les algues peuvent également jouer un rôle dans les processus d'hétérotrophie (TILzer 1972 a et b, Hobbie et Wright 1965). Dans le lac de Port-Bielh, les valeurs optimales d'assimilation obscure correspondent assez bien au développement du flagellé incolore Kalablepharis ovalis en 1967 et 1970 . Pour ces deux années, on pourrait admettre que le pic de phytoplancton entraîne une augmentation de substances dissoutes qui seraient utilisées par les organismes hétérotrophes (bactéries et flagellés incolores) et par les algues.

Dans les eaux faiblement oxygénées, tous les groupes intermédiaires entre les hétérotrophes vrais et les chimioautotrophes peuvent coexister. La quantité de $\mathrm{CO}_{2}$ utiliséc varic selon les groupes entre $6 \%$ et $100 \%$ du carbone total mis en jeu dans les processus de biosynthèse. Les valeurs d'assimilation, mesurées en profondeur en hiver, sont de ce fait difficiles à interpréter. En outre, il faut noter l'influence possible de phénomènes purement chimiques lors du transvasement dans les flacons d'expériences: l'aération de l'eau, normalement dépourvue en $O_{2}$ dissous peut entraîner la précipitation d'hydroxyde ferrique. Celui-ci peut alors former des complexes adsorbants qui fixent une part $d u{ }^{14} \mathrm{C}$ ajouté.

\section{III. - GOURGUET, GOURG NERE MOYEN ET GOURG NÈRE INFÉRIEUR}

Ces trois lacs peu profonds $(3,5$ à $5 \mathrm{~m})$ el de faible superficie $(0,6$ à 2,5 hectares $)$ diffèrent du lac de Port-Bielh par des températures sensiblement plus élevées en été et par l'absence de stratification thermique. Leurs caractéristiques morphométriques et physico-chimiques ont été définies dans la première partie de ce travail (CAPBLANco et Laville 1969). Rappelons que dans ces lacs, la minéralisation de l'eau augmente du dégel à l'automne, entre une période de renouvellement total par l'eau de fonte des neiges et une période de basses eaux due à la pauvreté de l'alimentation

\section{COMPOSITION ET ÉVOLUTION SAISONNIERE DU PHYTO- PLANCTON}

Le tableau VI et les fig. 27 à 29 résument les résultats des prélèvemenls effectués entre le 30 juin et le 3 octobre 1968. 
Tarlzau VI. - Liste des especes du phytoplancton des petits lacs du vallon de Port-Bielh (les formes abondantes ont été indiquées par deux croix). G : Gourguet; GNI : Gourg Nère Inférieur; GNM : Gourg Nère Moyen.

\begin{tabular}{llll}
\hline & GNI & GNM & G \\
\hline
\end{tabular}

Cyanophycées

- Microcystis aeruginosa Kuetzing

- Aphanocapsa elachista W. et G.S. West

- Aphanothece castagnei (Breb.) Rabenhorst

- Chroococcus minutus (Kuetz) Naegeli

- Chroococcus lurgidus (Kuetz) Naegeli

- Chroococeus tenax (Kirchn.) Hieron

- Coelosphaerium kuelzingianum Naegeli

- Gloeocapsa sp.

- Oscillatoria tenuis Agardh

$\begin{array}{lll}+ & + & + \\ + & + & + \\ + & & \\ + & + & \\ + & + & \\ + & & \\ + & & \\ + & + & \\ & + & +\end{array}$

Chlorophycées

- Chlamydomonas spp.

- $\mu$ algues (Chlorella sp.)

- Sphaerocystis schroeteri Chodat

- Pediastrum boryanum var, rugulosum G.S. West

- Pediastrum boryanum var. longicorne Al Braun

- Oocystis pusilla Ilansgirg

- Oocystis elliptica W. West

-. Oocystis submarina Lagerheim

- Oocystis solitaria Wittrock

- Scenedesmus ovalternus Chodat

- Scenedesmus brasiliensis Bohlin

- Scenedesmus serralus (Corda) Bohlin

- Scenedesmus cf. acutiformis Schröeder

- Diciyosphaerium pulchellum var. minulum Defllandre

- Crucigenia rectangularis var, irregularis (Wille) Brunnthaler

- Coelastrum proboscideum Bohlin

- Ankistrodesmus falcatus (Corda) Ralfs

- Ankistrodesmus convolutus Corda

-- Ankistrodesmus ef. setigerus Schöcder G.S. West

$\rightarrow$ Gonatozygon monotaenium de Barry

- Cosmarium angulosum Brébisson

-- Cosmarium botrytis Meneghini

- Cosmarium tetraophtalmum Brébisson

-- Cosmarium anceps Iund

- Euasirum verrucosum Ehrenberg

- Staurasirum alternans Brébisson

$\rightarrow$ Stcurastrum gracile Ralfs

- Staurastrum teliferum RaIfs

- Oedogonium sp.

- Ulothrix sp.

- Mougeotia sp.

$++t+t$

$+++++$

$++t$

$+\quad+$

$+$

$+$

$++$

$+$

$+$

$++$

$+$

$+$

$++\quad+$

$++\quad+$

$+t$

$++$

$++$

$+\quad++$

$+$

$+$

$+$

+
$+\quad+$

$+$

$\begin{array}{rr}+ & + \\ + & +\end{array}$ 


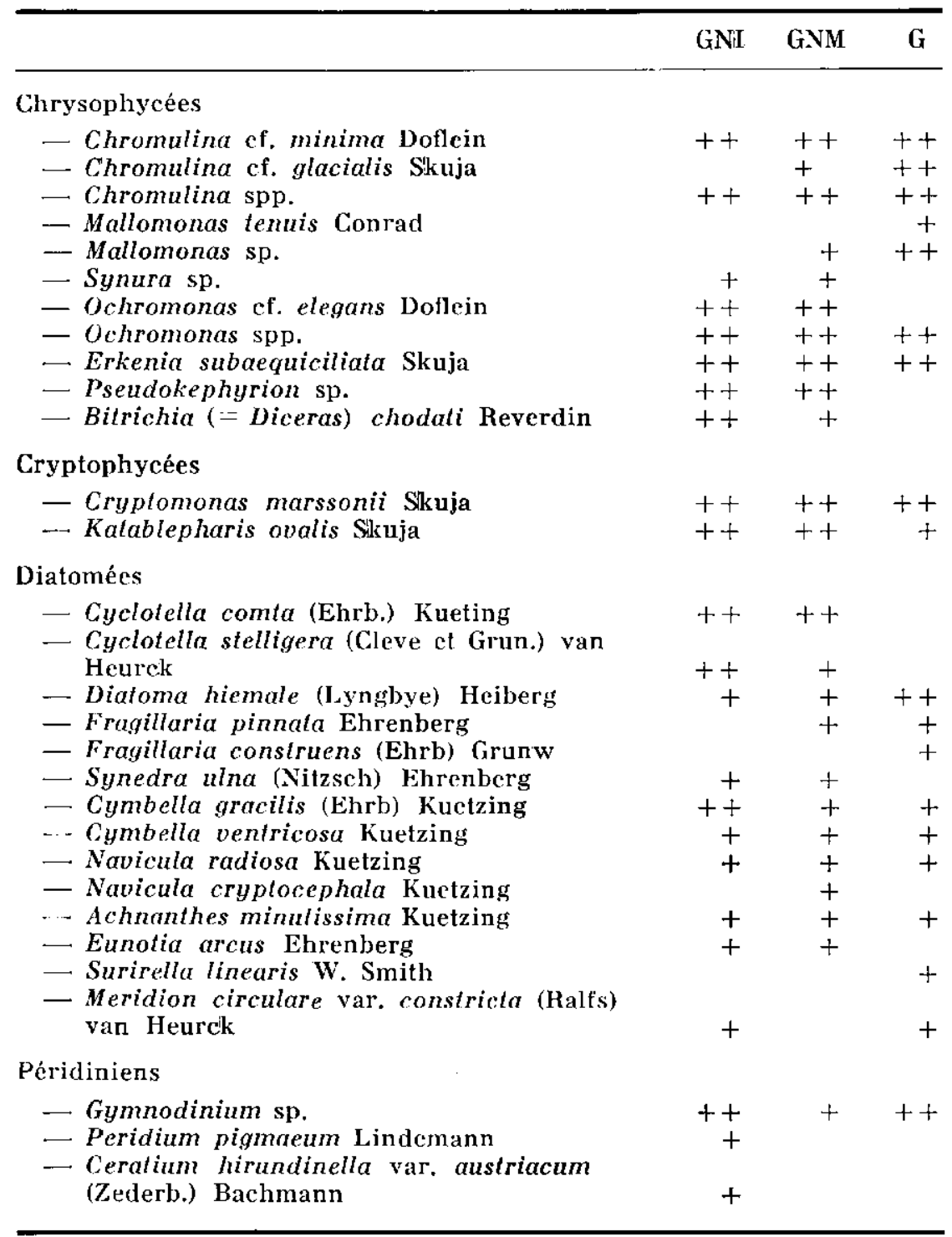

Le peuplement de tous ces lacs est, comme celui du lac de PortBielh, dominé par les formes nannoplanctoniques. Ces dernières forment la totalité de la biomassc dans le lac du Gourguet. Dans les Gourgs Nère, les prélèvements effectués au filet fin ont révélé la présence d'espèces de plus grande taille. Parmi elles, Sphaerocystis schroeteri, Crucigenia rectangularis et Ceratium hirundinella atteignent des densités élevées au Gourg Nère Inférieur II. 
La proportion importante de formes tychoplanctoniques caractérise le phytoplancton de ces lacs. La majorité des espèces de Diatomées et près de la moitié des espèces de Chlorophycées énumérées dans le tableau VI sont des formes benthiques. Elles peuvent représenter parfois une part non négligeable de la biomasse algale, notamment après une période de vent et d'orage.

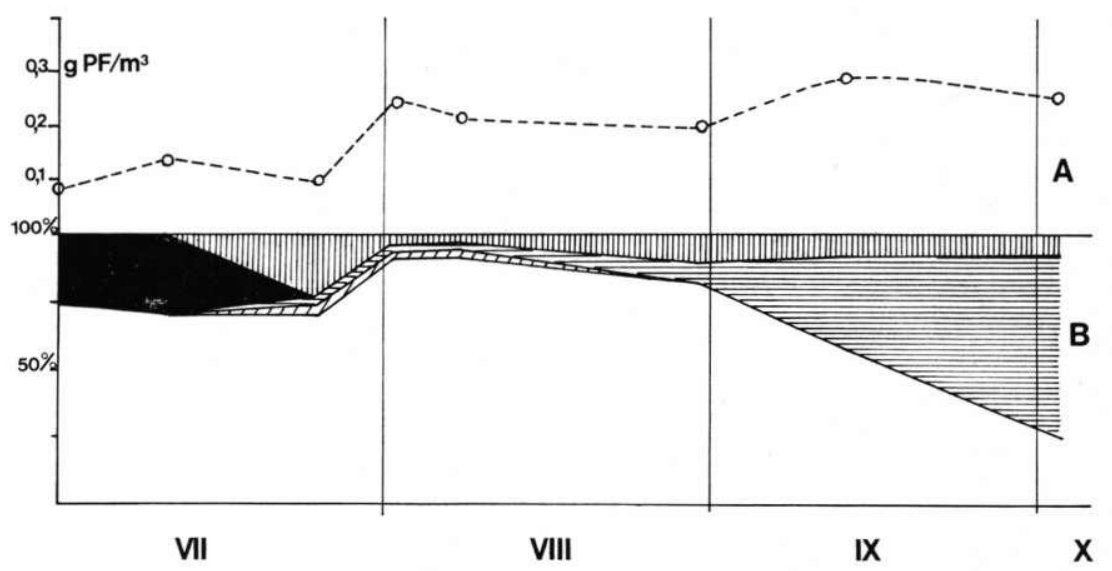

FIG. 27. - Evolution de la biomasse de phytoplancton du Gourguet (été 1968). A : $\mathrm{g}$ de poids frais $/ \mathrm{m}^{3} ; \mathrm{B}$ : importance relative ( $\%$ biomasse totale) des divers groupes. Symboles : voir fig. 15.

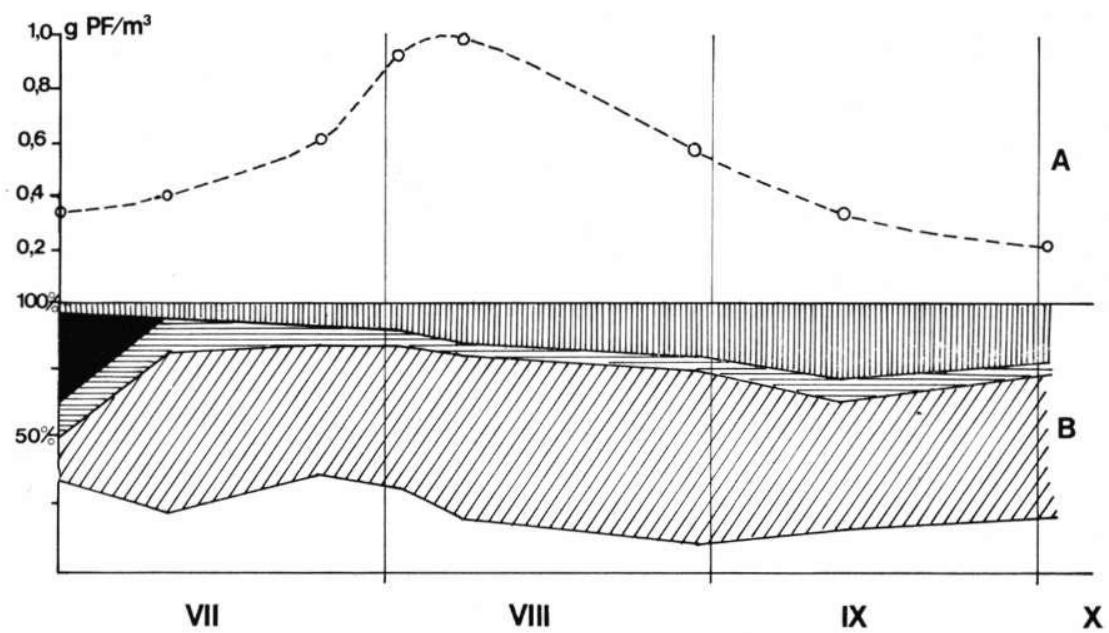

FIG. 28. - Évolution de la biomasse de phytoplancton du Gourg Nère Inférieur (été 1968).

A : g de poids frais $/ \mathrm{m}^{3}$; $\mathrm{B}$ : importance relative (\% biomasse totale) des divers groupes. Symboles : voir fig. 15. 


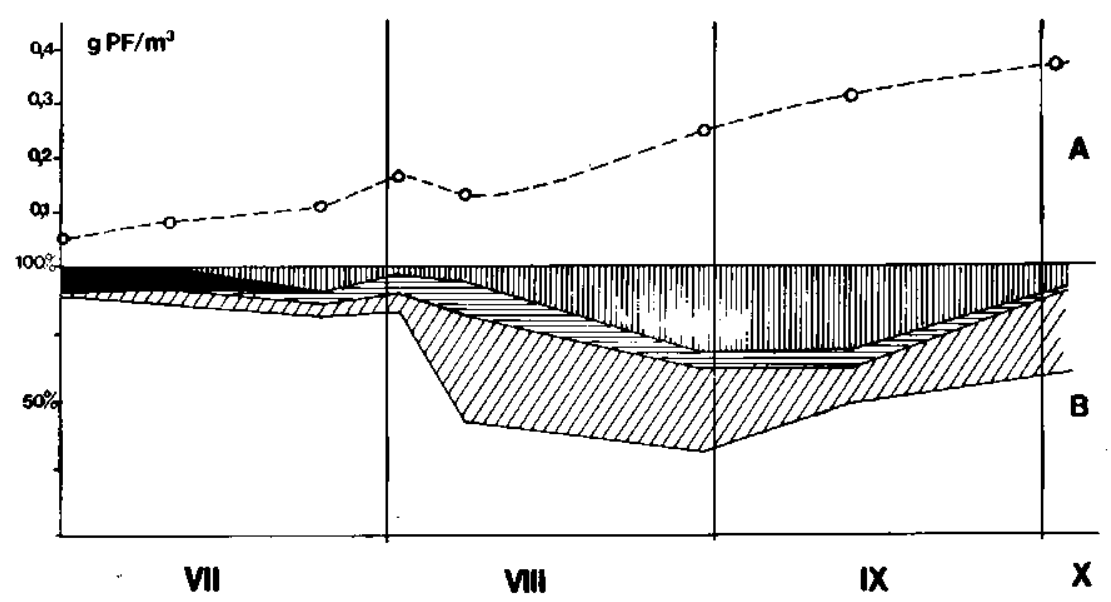

Fig. 29. - Evolution de la biomasse de phytoplancton du Gourg Nère Moyen (été 1968).

A : g de poids frais $/ m^{3}$; B : importance relative (\% biomasse totale) des divers groupes. Symboles : voir fig. 15.

La diversité spécifique augmente progressivement entre le lac du Gourguet et le Gourg Nère Inférieur II. Nous n'avons trouvé qu'une dizaine d'espèces dominantes dans le lac du Gourguet; plus de 20 espèces sont numériquement abondantes dans le Gourg Nère Inférieur II (tableau VI).

Il n'existe pratiquement aucune variation de densité du phytoplancton en fonction de la profondeur. Dans ces lacs peu profonds et constamment homothermes, le brassage de l'eau par le vent entraîne une homogénéisation du peuplement algal. La biomasse algale en surface atteint, en moyenne, $90 \%$ de celle de la zone profonde. Cette différence est essentiellement le fait des formes mobiles (Cryptomonas, Chrysomonadines) qui, par temps calme, tendent à se concentrer dans la zone la plus profonde. Ainsi, le 1-8-1968, la biomasse de ces deux groupes était 2,1 fois plus élevée à $3 \mathrm{~m}$ de profondeur qu'en surface au Gourg Nère Inférieur II alors qu'elle était identique pour les Chlorophycées et les Diatomées.

Une succession comparable à celle rencontréc dans le lac de Port-Bielh (Péridiniens et Chrysomonadines au dégel - Cryptomonadines et Diatomées en été — Chlorophycées en automne) apparaît plus ou moins nettement dans ces lacs. Cependant, la composition et l'évolution saisonnière du peuplement algal varient d'un lac à l'autre.

* Gourguet (fig. 27).

Le phytoplancton de ce lac, le plus froid et le moins minéralisé de la série, est dominé tout l'été par les Chrysomonadines (Chro- 
mulina spp., Ochromonas spp., Erkenia subaequiciliata, Mallomonas sp.) qui forment 70 à $90 \%$ de la biomasse. Les Cryptomonadines (Cryptomonas marssonii) se développent en automne : elles représentaient $70 \%$ du volume algal le 2-10-1968. Les Chlorophycées et les Péridiniens, peu abondants, constituent rarement plus de $10 \%$ de la biomasse. Les Diatomées ne sont représentées que par quelques formes benthiques (Diatoma hiemale notamment); les espèces du genre Cyclotella qui peuplent tous les autres lacs, n'ont jamais été récoltées dans le Gourguct.

La biomasse du phytoplancton varie peu au cours de l'été. Un peu plus faible au mois de juillet $\left(100\right.$ à $\left.135 \mathrm{mg} / \mathrm{m}^{2}\right)$, elle se maintient à des valeurs relativement constantes en août et septembre (200 à $\left.300 \mathrm{mg} / \mathrm{m}^{3}\right)$.

* Gourg Nère Inférieur II (fig. 28).

Le volume de ce lac est quatre fois plus faible que celui du Gourguet. Il ne possède pas d'autre source d'alimentation que l'eau de fonte des neiges. Ces conditions se traduisent par des températures estivales et une minéralisation plus élevées que celles des autres lacs du vallon de Port-Bielh (Capblance et Laville 1969).

Le phytoplaneton ne présente que peu d'analogies avec celıi du lac du Gourguet. L'abondance relative des Chrysomonadines et des Cryptomonadines ast réduite par rapport à celle des Chlorophycées et des Diatomées. Ces dernières dominent, les deux Cyclotella (C. comta et C. stelligera) formant $50 \%$ à $65 \%$ de la biomasse algale alors qu'elles sont absentes au Gourguet.

Les Chlorophycées sont, avec les Chrysomonadines, le groupe le plus diversifié. Parmi les espèces numériquement bien représentées dans le phytoplancton du Gourg Nère Inférieur II (tableau VI) seuls Crucigenia rectangularis et Sphaerocystis schroeteri ont été retrouvées, en faibles quantités, dans les relevés de la fin du mois de septembre au lac du Gourguet. C. rectangularis abonde pendant tout l'été dans le Gourg Nère Inféricur II où il constitue, du fait de la taille relativement grande des colonies, $90 \%$ de la biomasse des Chlorophycées au mois d'août $\left(55.10^{3}\right.$ colonies/litrc le 7-8-1968). En septembre, nous avons noté le développement de formes rares ou absentes dans le Gourguet: Ankistrodesmus falcalus, Oocystis spp., Scenedesmus spp. el Dictyosphaerium pulchellum var. minutum $\left(4.10^{6}\right.$ à $10^{7}$ colonies/litre lo $12-9-1968$ et le 2-10-1968).

Trois Chrysomonadines abondantes dans le Gourg Nère Inférieur II (Pseudokephyrion sp., Ochromonas (cf. elegans) et Bitrichia chodati) n'ont jamais été trouvées dans le lac du Gourguet. Dans leur majorité, les espèces de ce groupe présentent un optimum en juillet et au début du mois d'août. Bitrichia chodati n'apparaît que 
dans les prélèvements de septembre $\left(25.10^{3}\right.$ à $30.10^{3}$ cellules/litre le 12-9 et le 2-10-1968). Nous n'avons jamais trouvé de Mallomonas $s p$. dans le Gourg Nère Inférieur II ; Chromulina (cf. glacialis), abondant tout l'été dans le Gourguet, est également absent.

Lcs Péridiniens, el essentiellement le genre Gymnodinium, apparaissent immédiatement après le dégel comme dans les autres lacs du vallon de Port-Bielh. Toutefois, le Gourg Nère Inférieur II est le seul lac où les prélèvements réalisés au filet fin ont révélé la présence de Ceratium hirandinella var. austriacum.

Relativement élevée, la biomasse de phytoplanclon présente un maximum très net au début du mois d'août $\left(0,91\right.$ et $0,98 \mathrm{~g} / \mathrm{m}^{3}$ le 1-8 et le 7-8-1968). Elle atleint à cette période des valeurs équivalentes à celles rencontrées dans la zone profonde du lac de Port-Bielh, au momen! du maximum estival.

* Gourg Nère Moyen (fig. 29).

Le peuplement de ce lac se caractérise par la succession de deux périodes distinctes. Pendant tout le mois de juillet, le lac est alimenté par le déversoir du Gourg Nère Supérieur; par suite de son faible volume $\left(12540 \mathrm{~m}^{3}\right)$, son eau est renouvelée très rapidement. Pendant toute cette période, la biomasse algale reste faible (100 à $150 \mathrm{mg} / \mathrm{m}^{3}$ ); elle est quasi exclusivement composée de Chrysomonadines (Chromulina spp., Ochromonas spp., Pseudokephyrion sp.). La diminution du débit du déversoir au mois d'aô̂f et son assèchement en septembre se traduisent par le développement des populations de Cyclotella comta, Ochromonas (cf. elegans) et Dictyosphaerium pulchellum var. minutum, formes dominantes dans Ie phytoplancton du Gourg Nère Inférieur II en automne. Le 12-9-1968 et le 2-10-1968, ces trois espèces formaient $75 \%$ de la biomasse algale, alors trois fois plus élevée qu'au mois de juillet (315 et $375 \mathrm{mg} / \mathrm{m}^{3}$ ).

\section{PRODUCTIVITÉ PRIMAIRE}

Les résultats de 31 séries de mesures effectuées dans ces trois lacs apparaissent dans le tableau VII.

Dans le Gourg Nère Inférieur II, les valeurs du taux de photosynthèse restent à peu près constantes pendant tout l'été : de l'ordre de 3 à $4 \mathrm{mg} \mathrm{C} / \mathrm{m}^{3} / \mathrm{h}$ à midi. Un maximum, peu prononcé, apparaît en 1967 et en 1968 aı début du mois d'août. Dans les deux autres lacs, le taux de photosynthèse augmente progressivement au cours de l'élé el atteint, en septembre, les plus forles valeurs jamais mesurées sur l'ensemble des lacs du vallon $\left(6,16\right.$ à $7,65 \mathrm{mg} \mathrm{C} / \mathrm{m}^{3} / \mathrm{h}$ à midi).

D'une manière générale, les taux de photosynthèse sont légèrement plus élevés près du fond. La productivité moyenne, calculèe 


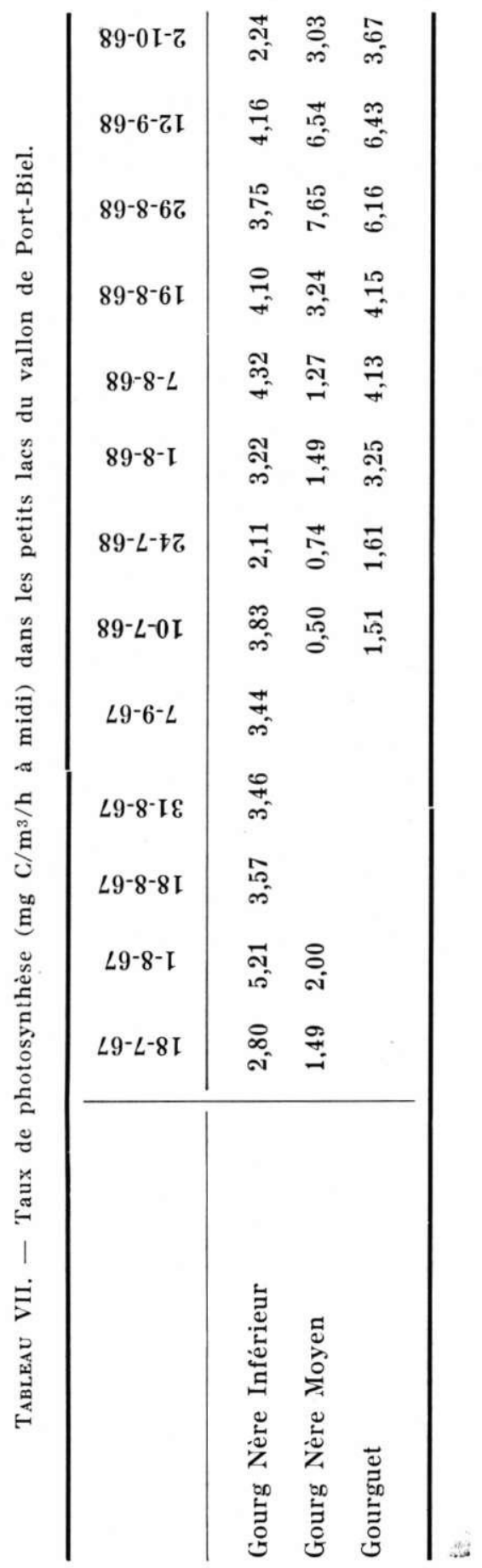


à chaque profondeur et exprimée en \% de la valeur optimale donne les résultats suivants :

- Gourguet :

\section{- Gourg Nère Moyen :}

$$
3,50 \mathrm{~m}=100 \% ; 1,50 \mathrm{~m}=96,4 \% ; 0 \mathrm{~m}=78,5 \% \text {; }
$$

\section{— Gourg Nère Inférieur II :}

$$
2,70 \mathrm{~m}=100 \% ; 1 \quad \mathrm{~m}=95,2 \% ; 0 \mathrm{~m}=80 \% ;
$$

$$
3,50 \mathrm{~m}=100 \% ; 1,50 \mathrm{~m}=85,2 \% ; 0 \mathrm{~m}=72,5 \% .
$$

En fait, les valeurs sont fréquemment identiques à toutes les profondeurs el les taux optima sont parfois mesurés à 1,50 m.

\section{COMPARAISON AVEC IIE LAC DE PORT-BIELH}

La quantité moyenne de phytoplancton est à peu près semblable dans les lacs de Port-Bielh, du Gourguet et dans le Gourg Nère Moyen (tableau VIII). Ice Gourg Nère Inféricur II, le plus chaud et le plus minéralisé de la séric, abrite par contre un peuplement plus riche et plus diversifié. L’abondance relative des Diatomées et des Chlorophycées distingue nettement les deux Gourgs Nère du lac de Port-Bielh dont le peuplement se rapproche davantage de celui du lac du Gourguet. Quelques espèces (Sphaerocystis schroeteri, Chromulina (cf. minima), Erkenia subaequiciliata, Cryptomonas marssonii) présentent un taux de développement identique dans tous les lacs. Inversement, beaucoup d'espèces n'abondent que dans un ou deux lacs (Crucigenia rectangularis (GNI), Dictyosphaerium pulchellum (GNI cl GNM), Bitrichia chodati (GNI), Mallomonas sp. (G), Dinobryon cylindricum (PB), Cryptomonas ovata (PB), Chroomonas minuta (PB)) (et sont rares ou absentes dans les autres.

Les taux de pholosynthèse sont netlement plus élevés dans les petits lacs que dans le lac de Port-Biclh (tableau VIII). Cette diffé-

TAbiseuv VIII. - Comparaison de la biomasse (mg de Poids frais $/ \mathrm{m}^{3}$ ) et du taux de photosynthèse ( $\mathrm{mg} \mathrm{C} / \mathrm{m}^{3 / h}$ à midi) moyens dans la zone pélagique des lacs du vallon de Port-Bielh, en été.

\begin{tabular}{lccccc}
\hline & Port-13ielh & Gourguet & $\begin{array}{c}\text { Gourg } \\
\text { Nère } \\
\text { Moyen }\end{array}$ & $\begin{array}{c}\text { Gourg } \\
\text { Nère } \\
\text { Inféricur }\end{array}$ \\
\hline & $0-18 \mathrm{~m}$ & $0-5 \mathrm{~m}$ & $0-3,50 \mathrm{~m}$ & $0-3 \mathrm{~m}$ & $0-3,50 \mathrm{~m}$ \\
\hline B (mg de Poids frais $\left./ \mathrm{m}^{3}\right)$ & 220 & 120 & 206 & 225 & 575 \\
$P\left(\mathrm{mg} C / \mathrm{m}^{3} / \mathrm{h}\right.$ à midi) & 1,50 & 1,08 & 4,60 & 3,06 & 3,45 \\
\hline
\end{tabular}


rence est encore plus apparente si on compare ces lacs à la zone superficielle du lac de Port-Bielh $(0-5 \mathrm{~m})$. Pour une même quantité d'énergic lumineuse, la productivité est donc beaucoup plus forte dans les lacs peu profonds. Les données du tableau VIII montrent, par ailleurs, que la biomasse algale n'est pas une fonction directe de la productivité.

\section{IV. - Relations entRe Le PHYTOPLANCTON, SA PROductivité ET LES COMPOSANTES DU MIIIEU}

Les facteurs de milieu généralement considérés comme responsables de l'évolution saisonnière et de la distribution verticale du pcuplement phytoplanctonique peuvent être classés en facteurs physiques (hydrographie, température, lumière), chimiques (éléments minéraux et organiques dissous) et biotiques (compétition spécifique, prédation par le zooplancton). Cette classification est en fait très artificielle.

Les travaux de Rutreer (1937), Rodhe (1948) et de FindenegG (1943) ont abouti à un schéma général suivant lequel l'action simultanée de la lumière et de la température permet d'interpréter la succession des espèces dans l'espace et dans Ic temps. Mais, en été, des gradients verticaux de température et d'éclairement coexistent dans un lac; il est rarement possible de dislinguer le facteur principal de la distribution et de la productivité du phytoplancton suivant la profondeur. Cependant, si la lumière et la température influencent de conccrt le taux de division d'Asterionella formosa, l'un ou l'autre de ces facteurs devient prépondérant selon la saison et la profondeur (Lund 1949). De nombreux exemples indiquent par ailleurs que les composantes chimiques peuvent modifier la réponse des algues à ces deux facteurs. L'équilibre est souvent fragile : des cultures d'algues peuvent survivre plusicurs mois dans des milieux appauvris en sels nutritifs si l'éclairement et la température, qui agissent sur le taux de photosynthèse et par conséquent sur le taux d'utilisation des sels nutritifs, demeurent faibles (LuND 1965). Dans ces cultures, toute augmentation de l'éclairement ou de la température épuise le milieu et entraîne la disparition des algnes.

Ainsi, un complexe de facleurs, agissant en étroite interaction, détermine-t-il le cycle saisonnier du phytoplancton. Toutefois, pour plus de clarté, nous envisagerons séparément le rôle des diverses composantes du milieu. Les données du lac de Port-Bielh nous serviront de base. 


\section{HYDROGRAPHIE}

Les lacs de montagne se caractérisent par un important apport d'eau au moment de la fonte des neiges. Le débit du déversoir du lac de Port-Bielh passait ainsi de $0,35 \mathrm{~m}^{3} / \mathrm{s}$ au dégel en 1972 à $0,03 \mathrm{~m}^{2} / \mathrm{s}$ à la fin du mois d'octobre de la même année. On peut estimer qu'en période estivale, entre le dégel et le gel, un volume d'eau égal à celui du lac franchit le déversoir; plus de $50 \%$ de cet écoulement se produit en juillet. D’après Pechlaner (1971), le ruissellement maximal survient lorsque le lac est encore gelé : l'eau de fonte, froide, parcourt alors le lac en surface, sous la glace. En été, une partie de l'eau d'alimentation du Port-Biclh se réchauffe en surface avant de parvenir au lac. Elle ne se mélange probablement pas à l'hypolimnion, plus froid, et le renouvellement affecte essentiellement l'épilimnion. Il s'ensuit une perte de phytoplancton par l'émissaire, ce qui accentue la répartition verticalc des algues.

L'influence des conditions hydriques apparaîl avec plus de nelteté dans les lacs de faible volume. Nous avons dejjà indiqué (CAPBlance el Iaville 1969) que l'évolution des composantes chimiques en été est dépendante du mode d'alimentation de ces lacs. Il en est de même pour la densité du phyloplancton et la productivité primaire. Au Gourguet, biomasse algale et productivité restent faibles après le dégel quand les apports d'eau extérieurs demeurent importants. Au Gourg Nère Inférieur, où les apports cessent dès la fin de la fonte des neiges, la biomasse algale et la productivité primaire augmentent rapidement en juillet. A la même altitude, le Gourg Nère moyen est alimenté jusqu'à la mi-août par le déversoir du Gourg Nère Supérieur; son faible volume permet un renouvellement rapide de l'eau, et le phytoplancton reste peu abondant. Il augmente en septembre lorsque le déversoir du Gourg Nère Supérieur ne coule pratiquement plus. Cette augmentation de biomasse s'accompagne d'une modification qualitative du peuplement phytoplanctonique qui devient identique à celui du Gourg Nère Inférieur II.

\section{TEMPERATURE}

Le rôle de la température joint à celui de la lumière, a été considéré par de nombreux auteurs comme fondamental dans l'écologie des algues planetoniques. Dans les lacs de montagne, les conditions thermiques sont vraisemblablement responsables de la composition du peuplement phytoplanctonique. Les Chrysomonadines sont en général bien représentées dans tous les lacs étudiés; 
selon Bourreley (1954) ce groupe abonde surtout dans les eaux pures et claires des climats tempérés et froids où la température semble, dans de nombreux cas, conditionner la vie de l'espèce. Le nannoplancton forme toujours la quasi-totalité de la biomasse algale; son importance est également considérable dans le plancton hivernal des lacs tempérés (Pavoni 1963, RodHe et al. 1965). Pour Nauwerck (1966), 40 \% des espèces peuplant six lacs d'altitude du Tyrol et de Laponie sont des formes sténothermes d'eau froide, l'abaissement de la température réduisant la diversité spécifique du phytoplancton. Pour les quatre lacs du vallon de Port-Bielh, les listes d'espèces (tableau $V$ et VI) montrent une augmentation de la diversité spécifique en fonction de la tempéralure moyenne des lacs.

Les variations qualitatives et quantitatives du phytoplancton du lac de Port-Bielh se reproduisent chaque année avec une régularité remarquable. Les trois années d'observations, résumées dans les fig. 15 à 23 se caractérisent par un dégel du lac plus ou moins précoce $(3-7-1967,22-6-1968,14-7-1970)$. Un décalage analogue peut être observé dans le cycle du phyloplancton. Les biomasses maximales $(2-8-1967,11-7-1968,12-8-1970)$ apparaissent régulièrement trois semaines à un mois après la date de disparition de la glace. Une remarque identique peut être faite en ce qui concerne le cycle des espèces dominantes. Par suite, l'eau se réchauffant toujours à la même vitessé, ce's cycles coïncident avec celui de la température. Ainsi, pour la majorité des espèces, les densités optimales correspondent toujours aux mêmes températures $\left(10-12^{\circ}\right.$ pour Cyclotella stelligera, $6-7^{\circ}$ pour Dinobryon cylindricum, $10-11^{\circ}$ pour Cryptomonas marssonii, clc.).

La succession saisonnière (Chrysomonadines et Gymnodinium au dégel - Diatomées et Cryptomonadines en été - Chlorophycées plus abondantes en septembre) retrouvée dans les quatre lacs du vallon de Port-Bielh est sensiblement identique à celle que l'on connaît dans des lacs tempérés. Cependant, l'abondance des Chlorophycées est réduite, principalement dans les lacs les plus froids (Gourguet, Port-Bielh). Dans ce dernier, le développement de Oocystis $s p$. paraît d'autant plus intense que le dégel est précoce et, corrélativement, les températures d'été plus élevées (fig. 18). Dans le Gourg Nère Inférieur, où la température dépasse généralement $15^{\circ} \mathrm{C}$ en été, les Chlorophycées sont plus diversifiées et plus abondantes. De même, Cyclotella conta atteint dans ce lac des densités dix à vingt fois supérieures à celles du lac de PortBielh. Les deux espèces de Cyclotella n'abondent dans le lac de Port-Bielh que lorsque la température dépasse $10^{\circ} \mathrm{C}$; elles sont absentes dans le plancton du lac du Gourguet. 
Des rapports étroits apparaissent donc entre le peuplement phytoplanctonique et le régime thermique des lacs du vallon de PortBielh. Cependant, les différences de peuplement soulignées dans le \$ III (3) ne peuvent être attribuées à l'influence de ce seul facteur. D’après Jund (1965) nous ne possédons pas de preuve expérimentale de l'existence d'espèces sténothermes d'eau froide. Il n'existe en outre aucune relation apparente entre le taux de photosynthèse du phytoplancton et la température de l'eau.

Soulignons aussi que les composantes chimiques varient d'un lac à l'autre; pour un même lac, elles évoluent au cours de l'été parallèlement à la température. Dans ces conditions, l'influence directe de la température sur le peuplement phytoplanctonique peut être mise en doute. L'augmentation de la température ne serait qu'indireotement responsable de la disparition des espèces à développement précoce; d'une part, en permettant la croissance rapide des algues, elle provoque l'appauvrissement du milieu en substances nutritives; d'autre part, elle favorise la croissance du zooplancton, entraînant une filtration plus intense au détriment $\mathrm{du}$ phytoplancton.

Dans le lac de Port-Bielh, ce mécanisme est sans doute à l'origine de la chute du peuplement à la fin du mois d'août. Dans les lacs moins profonds, les echanges permanents entre la vase et l'eau entraînent un renouvellement constant des sels nutritifs. Fxception faite pour le Gourg Nère Moyen, la composition spécifique du peuplement y est beaucoup plus stable que dans le lac de Port-Bielh.

\section{LUMIERE}

Ia luminosité des lacs de montagne dépend de l'alternance de deux périodes opposées.

En hiver, la couverture de glace et de neige réduit fortement la pénétration des rayons lumineux. Fn général, la photosynthèse s'annule pratiquement lorsque l'intensité lumineuse devient inférieure à $1 \%$ de l'énergie de surface. Cependant, Rodhe (1962) et Wright (1964) ont décelé une photosynthèse dans des lacs couverts de glace en hiver à des intensités égales à $0,06 \%$ et $0,07 \%$ de l'énergie de surface. Pechlaner (1967) et Hobnie (1964) ont trouvé un phénomène analogue dans des lacs du Tyrol et de l'Alaska. Les mesures effectuées sous la glace dans le lac de PortBielh ont également montré l'exislence d'une assimilation photosynthétique près de la surface, à des intensités lumineuses inférieures à $1 \%$ de celles de surface. Les valeurs sont cependant très faibles et le phénomène devient d'autant moins décelable que l'épaisseur de la couche de neige et de glace s'accroît. En consé- 
quence, la biomasse algale diminue progressivement au cours de l'hiver et, à partir du mois de mars, devient extrêmement réduite.

En juillet, la fonte de la glace entrainc une augmentation considérable de la lumière. Ces nouvelles conditions se traduisent par une croissance rapide des algues planctoniques qui, comme en témoignent les prélèvements effectués au moment de la débâcle, commence avant la complète disparition de la glace. Dans tous les lacs, les biomasses sont plus faibles en surface qu'en profondeur. Ce phénomène apparait avec netteté dans le lac de Port-Bielh où d'importantes populations algales se développent dans la zone profonde. Par suite, l'optimum de croissance de la majorité des espèces correspond à des températures relativement faibles, de l'ordre de $5{ }^{\circ} \mathrm{C}$ à $6{ }^{\circ} \mathrm{C}$. Quelques espèces, plus héliophiles, se développent près de la surface. Parmi elles, les Diatomées du genre Cyclotella (fig. 20) présentent une répartition identique à celle décrite par Nauwerck (1966) dans un lac du Tyrol, le Gossenkolensec. Les expériences réalisées par Jø̨RGENSEN (1964) sur $C$. meneghiniana Kulz. montrent d'autre part que cette algue est capable de résister à des intensités lumineuses très élevées sans réduction notable du taux de photosynthèse. D'autres espèces (Dinobryon cylindricum, Cryptomonas ovata, Chroomonas minuta) se développent presque exclusivement au-delà de dix mètres dc profondeur dans le lac de Port-Bielh. L'affinité des Cryptomonadines pour les zones profondes à faible éclairement a élé signalée par plusieurs auteurs (Nauwerck 1963 et 1966, Pechlaner 1967). Cette répartition permet d'expliquer leur absence dans les lacs peu profonds, exception faile pour C. marssonii.

Plus généralement, la concentration du phytoplancton en profondeur caractérise des lacs transparents de haute montagne (Ronhe 1962, RodHe et al. 1966, Pechlaner 1967 et 1971, NalWERCK 1966 et 1968). Elle apparaît comme la conséquence directe des conditions d'éclairement. Rорне (1962), Rovнe et al. (1966) l'attribuent en partic à l'action des rayonnements ultra-violets. Il est possible que leur action soit plus prononcée dans ces lacs où la transmission, aux longueurs d'onde proche's de $300 \mathrm{~m} \mu$, est assez élevée. Selon HaLldal (1967), seuls les rayonnements compris entre 280 et $313 \mathrm{~m} \mu$ ont un effet inhibileur; au-dessus de $313 \mathrm{~m} \mu$, l'effet des rayons ultra-violets est identique à celui de la lumière dans le domaine du visible.

Dans la majorité des milieux aqualiques, les profils verticaux de pholosynthèse se caractérisent par une inhibition plus ou moins intense jusqu'à une profondeur où l'intensité lumineuse est 1,5 à 3 fois plus faible qu'en surface (STEEmann-Nielsen $1960 \mathrm{~b}$, Rodhe 1965). Dans les lacs de montagne, la transparence élevéc des eaux 


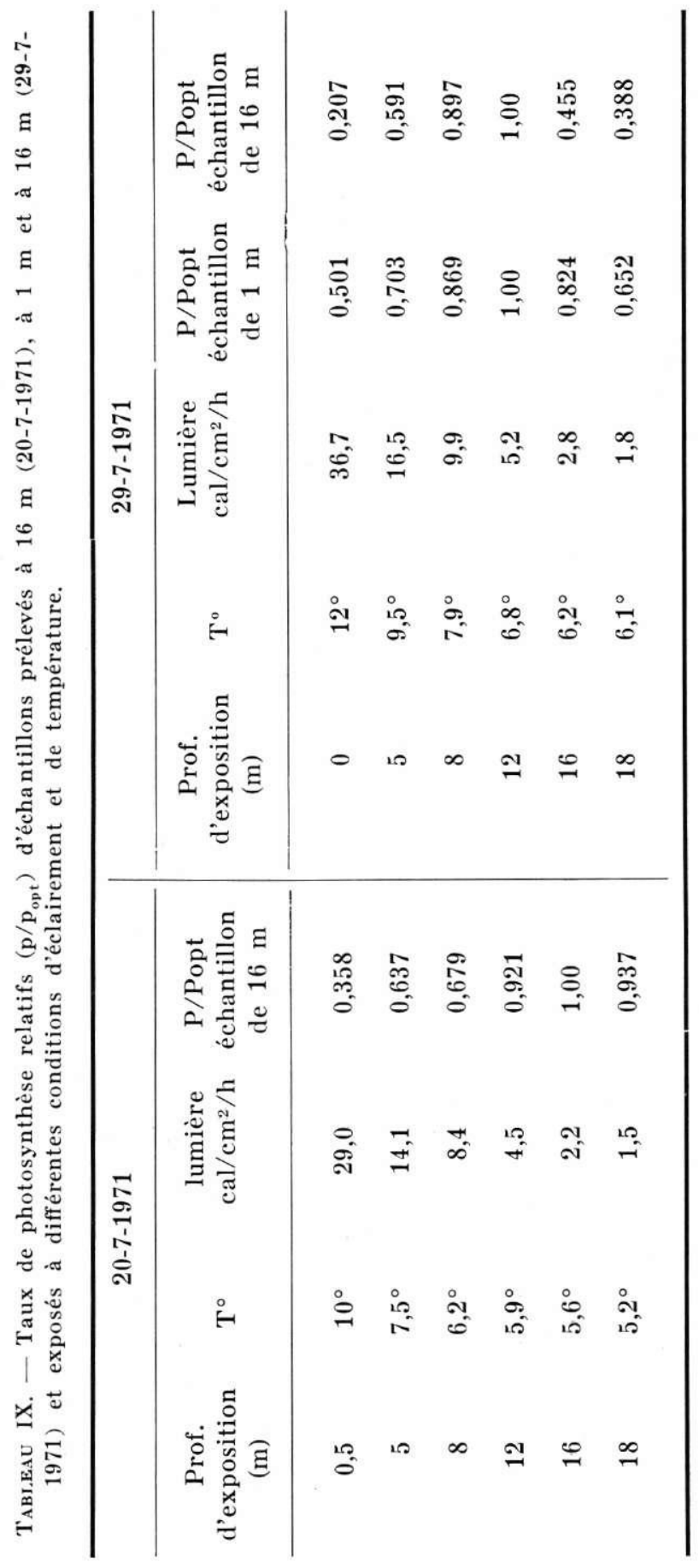


augmente l'importance de la zone d'inhibition. Trois séries de résultats permettront d'illustrer ce phénomène.

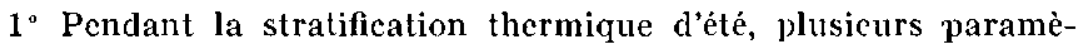
tres varient simulanément en fonction de la profondeur : l'éclairement, la température, les composantes chimiques, la composition spécifique du pcuplement et la biomasse algale. Au cours de trois séries d'expériences, des échantillons d'eau ont été prélevés à une profondeur donnée puis exposés à des conditions de température et d'éclairement différentes. Les résultats (tableaux IX et $\mathrm{X}$ ) conduisent aux remarques suivantes:

- Pour une densité d'algues et des conditions chimiques identiques, les taux de photosynthèse sont toujours plus élevés en profondeur qu'en surface (tableau IX). L'optimum se situe entre 12 et $16 \mathrm{~m}$, pour des intensités d'éclairement comprises entre 2 et $5 \mathrm{cal} . / \mathrm{cm}^{2} / \mathrm{h}$ ( $7 \%$ à $15 \%$ de l'énergie en surface). L'activilé photosynthétique est fortement réduite dans les échantillons exposés en surface, malgré l'élévation de température qu'ils subissent pendant la durée de l'expérience et qui, théoriquement, devrait augmenter le taux d'assimilation (Ruttner 1953, Talling 1957 a).

- Sous des conditions d'élairement identiques, l'inhibition par les fortes intensités lumineuses est plus importante pour les échantillons prélevés à $16 \mathrm{~m}$ que pour les échantillons provenant de la surface (tableaux IX et $X$ ). Les expériences de STEEMANN-NIEISEN (1962) el de JøRgensen (1964) ont montré que le laux de photosynthèse d'algues développées à des éclairemen!s faibles diminue lorsqu'on transfère ces algues à des intensités lumineuses plus élevées. Par ailleurs, le coefficient d'activité du phytoplancton décroît lorsque la biomasse augmente et, pour une biomasse donnée, est plus faible aux fortes intensités lumineuses (§ IV 5.1.). Enfin, l'effet inhibiteur de la lumière pourrait s'accroître lorsque la concentration en sels nutritifs diminue. Durant la stratification thermique d'été, l'eau de profondeur est plus alcaline, moins riche en éléments dissous et plus densément peuplée que l'cau de surface.

- Le phytoplancton de surface $(0-5 \mathrm{~m})$ présente des taux d'assimilation sensiblement identiques lorsqu'il est transféré dans des zones où l'éclairement et la température sont plus faibles (tableaux IX et $\mathrm{X}$ ). Ce phénomène tend à démontrer que le peuplement de surface, quotidiennement soumis à de fortes variations d'éclairement, est plus euryphote et plus curylherme que celui de profondeur. Sur le plan qualitatif, nous rappellerons qu'il est essentiellement composé de formes abondantes à toutes les profondeurs. 


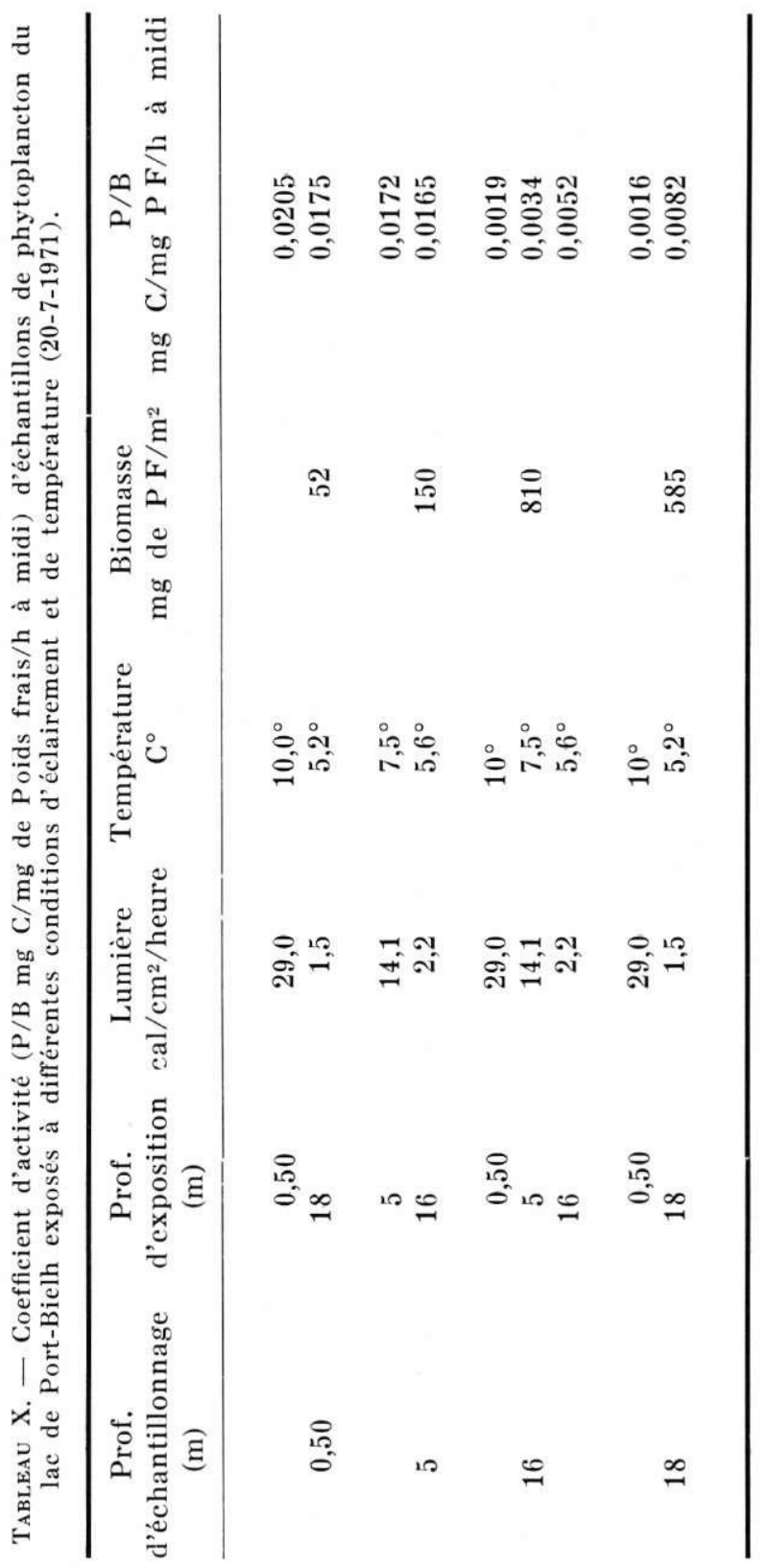




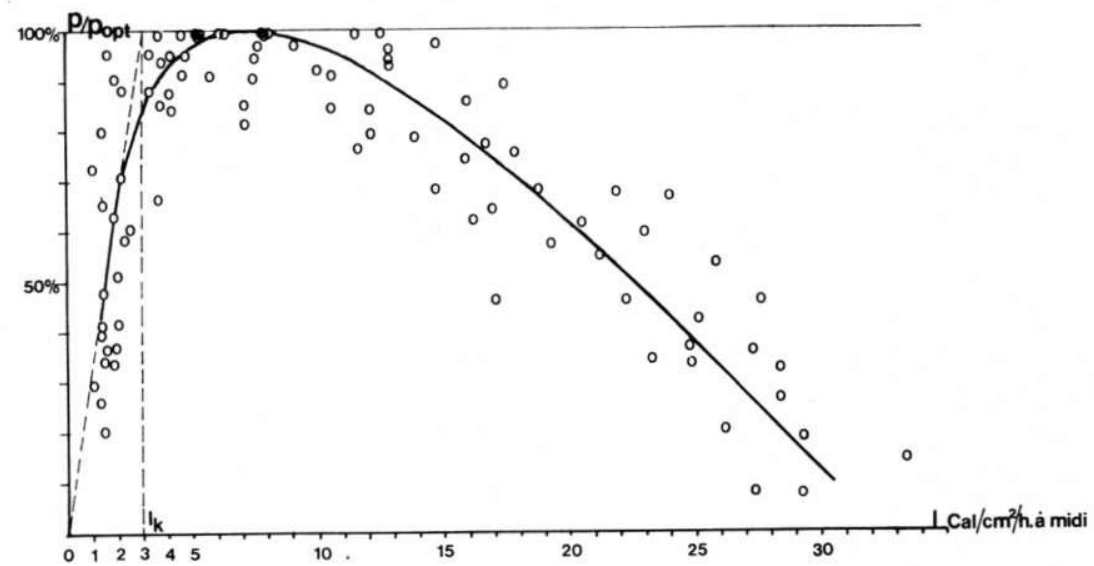

Fig. 30. - Taux de photosynthèse relatifs $\left(\mathrm{p} / \mathrm{p}_{\text {opt }}\right)$ en fonction de l'énergie lumineuse moyenne disponible pendant le temps d'exposition (I $\mathrm{cal} / \mathrm{cm}^{2} / \mathrm{h}$ à midi). La courbe représente la moyenne des valeurs mesurées au cours de onze séries d'expériences réalisées pendant l'isothermie d'automne.

$2^{\circ}$ L'isothermie d'automne qui, dans le lac de Port-Bielh, se maintient pendant deux mois ou plus, entraîne l'uniformisation des paramètres chimiques et biotiques dans toute la masse d'eau. La biomasse algale est alors qualitativement et quantitativement identique à toutes les profondeurs et généralement comprise entre 70 et $110 \mathrm{mg}$ de poids frais $/ \mathrm{m}^{3}$ d'eau. Dans ces conditions, on peut admettre que seul le gradient d'éclairement détermine l'allure des courbes de productivité (courbes de septembre et octobre 1967, 1968 et 1970 ; fig. 22). Onze séries de mesures ont été effectuées durant la période d'isothermie automnale entre 1966 et 1971 . Les résultats calculés par rapport aux taux d'assimilation optimal $\left(\mathrm{p} / \mathrm{p}_{\text {opt }}\right)$ sont représentés en fonction de l'énergie lumineuse (I) exprimée en cal./ $\mathrm{cm}^{2} / \mathrm{h}($ fig. 30$)$ et en pourcentage de l'intensité I'o de surface (fig. 31). Les courbes, obtenues en reliant les valeurs moyennes, montrent l'existence d'une relation très nette entre le taux de photosynthèse et l'énergie disponible aux différentes profondeurs :

- pour de faibles intensités lumineuses et si l'on considère que $\mathrm{p}=0$ lorsque $\mathrm{I}=0$, le taux de photosynthèse augmente proportionnellement à la lumière. L'amorce d'une saturation apparaît vers 1,5 à $2 \mathrm{cal} . / \mathrm{cm}^{2} / \mathrm{h}$. Le taux optimal $\left(\mathrm{p}_{\text {opt }}\right)$ se situe généralement entre 5 et $8 \mathrm{cal} . / \mathrm{cm}^{2} / \mathrm{h}(18 \%$ à $35 \%$ de I'o $)$, valeurs très voisines de celles déduites des figures de Ryther (1956) et GoLDMaN et al. (1963). La valeur de Ik qui caractérise l'effet de saturation par la lumière (TALLiNg 1957 a et $1957 \mathrm{~b}$ ), peut être estimée à $3 \mathrm{cal} . / \mathrm{cm}^{2} / \mathrm{h}(f i g .30)$ ou à $0,10 \mathrm{I}^{\prime}$ o. Elle est très proche de la 


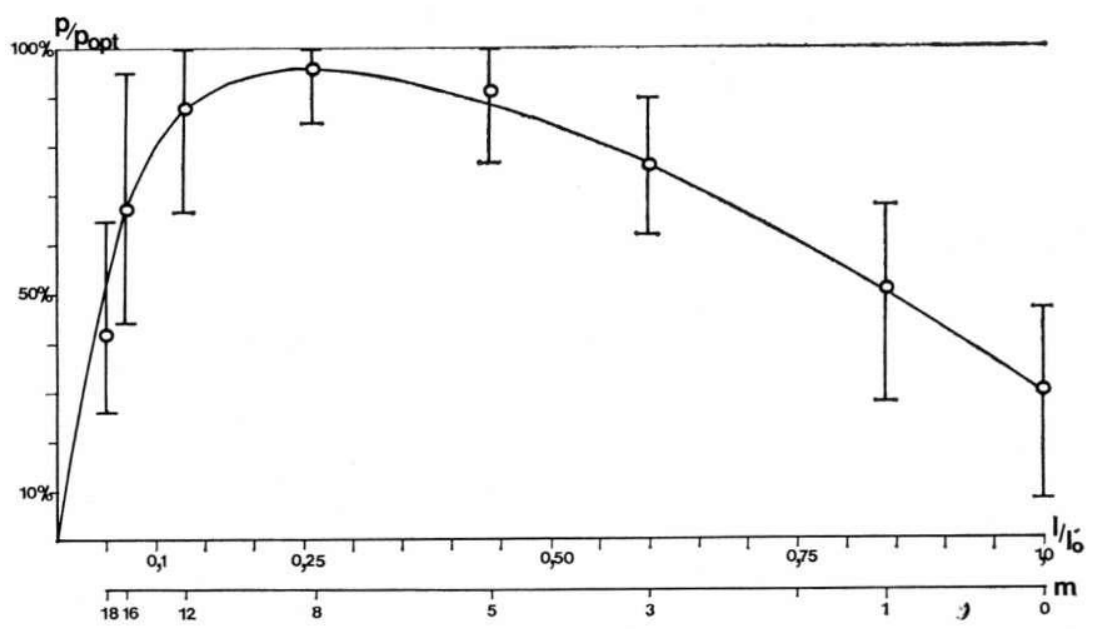

Fig. 31. - Amplitude et moyenne arithmétique des taux de photosynthèse relatifs $\left(\mathbf{p} / \mathbf{p}_{\text {opt }}\right)$ aux différentes profondeurs en fonction de l'énergie lumineuse $\left(\mathrm{I} / \mathrm{I}^{\prime} \mathrm{O}\right)$. La courbe représente la fonction :

$$
\begin{gathered}
\mathrm{p}=\mathrm{p}_{\mathrm{opt}} \frac{\mathrm{kI}}{\sqrt{1+(\mathrm{kI})^{2}}}\left(\mathrm{~A}-\alpha \mathrm{I}^{2}\right) \\
\text { avec } \mathrm{k}=12,5 ; \mathrm{A}=1,05 \text { et } \alpha=0,76 \text {. }
\end{gathered}
$$

valeur que l'on peut calculer (Ik $=2,2 \mathrm{cal} . / \mathrm{cm}^{2} / \mathrm{h}$ ou $0,08 \mathrm{I}^{\prime} \mathrm{o}$ ) en admettant que la relation entre $p$ et I suit l'équation de SмrтH (1936) : $\mathrm{KI}=\mathrm{p}\left(1-\mathrm{p}^{2}\right)^{-\frac{1}{2}}$ dans laquelle $1 / \mathrm{K}=\mathrm{Ik}$, intensité à laquelle $p=0,71$ (TAlling $1957 \mathrm{a}$ ). Rophe (1965) indique que Ik varie généralement entre $18 \%$ et $25 \%$ de I'o à la longueur d'onde dont la transmission est la plus élevée : par rapport à la lumière verte, $\mathbf{I}_{\mathrm{k}}$ est de l'ordre de $\mathbf{0 , 2 5} \mathrm{I}^{\prime} \mathrm{o}$ dans le lac de Port-Bielh.

- pour des intensités comprises entre 10 et $30 \mathrm{cal} . / \mathrm{cm}^{2} / \mathrm{h}$, il existe une corrélation négative hautement significative $(r=-0,825)$ entre l'énergie lumineuse et le taux de photosynthèse qui décroît de façon pratiquement linéaire lorsque I augmente. Un phénomène d'inhibition identique est connu dans la majorité des milieux aquatiques. Ryther (1956) a montré que le taux de photosynthèse du phytoplancton marin est réduit d'environ cinq fois lorsque l'intensité d'éclairement augmente de 10 à $30 \mathrm{cal} . / \mathrm{cm}^{2} / \mathrm{h}$. TALLing (1957 a) observe que la diminution du taux de photosynthèse des populations d'Asterionella formosa commence pour une intensité de 9 à $13 \mathrm{cal} . / \mathrm{cm}^{2} / \mathrm{h}$. Dans le lac de Port-Bielh l'effet inhibiteur se manifeste également au-dessus de $10 \mathrm{cal} . / \mathrm{cm}^{2} / \mathrm{h}$ c'est-à-dire, en moyenne, dans une zone où l'intensité d'éclairement est supérieure à 0,25 I'o. Compte tenu de la forte transmission des rayonnements 
lumineux et de la profondeur relativement faible de ce lac, l'inhibition y est proportionnellement plus importante que dans les lacs de plaine.

Pendant l'isothermie, l'activité photosynthétique du phytoplancton peut ainsi être décrite comme une fonction de l'énergie lumineuse. Les résultats obtenus pour le lac de Port-Bielh sont tout à fait semblables aux données expérimentales correspondant à des conditions très diverses (Ryther 1956, Talling 1957 a, SteemannNiELSEN 1962, Goldman et al. 1963, RodHe 1965) et conformes à la formulation mathématique proposée par TALLING (1957 a et $1957 \mathrm{~b}$ ) et Vollenweider (1965) (fig. 31). Lorsque le phytoplancton est uniformément réparti, les conditions d'éclairement déterminent dans tous les milieux aquatiques une réponse identique de la photosynthèse pélagique. Sur ce point, le phytoplancton du lac de Port-Bielh ne présente aucune différenre fondamentale avec ceux des lacs tempérés ou de la mer.

$3^{\circ}$ Nous avons vu (§ II 3.3.) que l'évolution journalière de la photosynthèse se caractérise par une forte dépression de l'activité photosynthétique en surface au milieu de la journée. Ce phénomène peut être défini par la relation photosynthèse-lumière que nous venons de décrire. Dans la fig. 32, est représentée l'évolution de la photosynthèse relative à quatre profondeurs différentes au cours de deux journées solaires. $\mathrm{p} / \mathrm{p}_{\text {opt }}$ a été évalué à partir des courbes d'ensoleillement (fig. 24) et de la fig. 30. Etant donné que les valeurs expérimentales donnent le taux d'assimilation horaire moyen pendant la durée de l'expérience ( 3 à $5 \mathrm{~h}$ ) et que les valeurs calculées ne rendent pas compte de la diminution de la photosynthèse l'après-midi, la similitude entre les deux séries de courbes (fig. 24 et 32) est assez bonne. La réponse du phytoplancton aux variations de l'intensité lumineuse paraît être sensiblement identique pendant tout l'été, même lorsque les algues, la température et les composantes chimiques n'ont pas une répartition homogène (courbes du 4-8-1971).

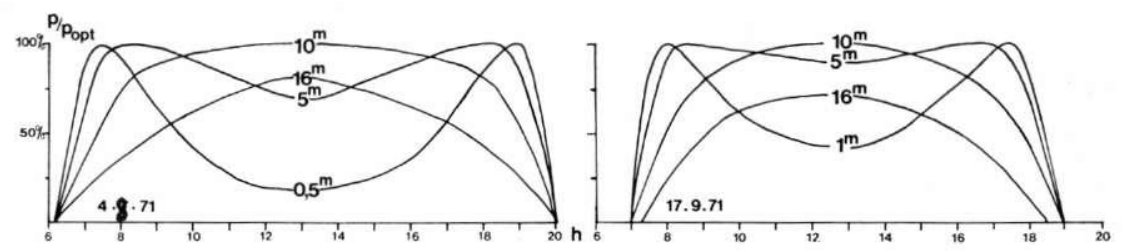

Fig. 32. - Évolution journalière des taux de photosynthèse $\left(\mathrm{p} / \mathrm{p}_{\text {opt }}\right)$ à différentes profondeurs du lac de Port-Bielh, calculée d'après la courbe moyenne de la figure 30 et les courbes d'ensoleillement (fig. 24). 
Le point le plus important qui ressort de l'analyse de ces courbes est que la quantité maximale de carbone assimilé en une journée (c'est-à-dire la plus grande quantité de matières organiques synthétisées) correspond pendant tout l'été à une profondeur comprise entre 5 et $10 \mathrm{~m}$ (fig. 24). Les mesures effectuées pendant l'isothermic d'automne montrent que celte zone correspond bien aux conditions optimales d'éclairement (fig. 30) pour lesquelles les processus de photosynthèse sont saturés par la lumière. Pendant la stratification d'été, cette zone ne correspond cependant pas aux biomasses maximales de phytoplancton. Pour interpréter cette différence, on peut supposer que le taux de respiration du phytoplancton et la prédation par le zooplancton diminuent en profondeur en même temps que la lempérature et la lumière. Dans ces conditions, des taux de photosynthèse légèrement plus faibles peuvent aboulir à la formation de biomasses plus importantes en zone profonde.

Ainsi l'énergie lumineuse disponible apparaît comme la cause essenticlle de la distribution des taux d'assimilation photosynthétiques suivant la profondeur. Dans le lac de Port-Bielh, Ia corrélation entre la lımière et la production est sensiblement identique à celle des milieux aquatiques aux propriétés optiques différentes. Les profils verticaux semblent simplement déplacés vers la profondeur par suite de la forle pénélration des radiations et de la diminution, aux faibles tempéralures, du taux de photosynthèse à saturation ('TAling $1957 \mathrm{~b}$ ). PEChlaner (1971) souligne qu'une corrélation entre la production et la lumière est rarement observée dans les lacs clairs d'altitude. Il l'attribuc au fait que le phyloplancton compense les variations saisonnières et journalières de l'intensité lumineuse par une migration verlicale, qu'il a observéc pour l'espèce dominante du Vorderer Finsterlaler See (Gymnodinium uberrimum). Il n'existe apparemment aucun phénomène identique dans le lac de Port-Bielh.

Dans les lacs peu profonds du vallon de Port-Bielh, le développement de biomasses algales relativement importantes et les taux de photosynthèse élevés sont en contradiction avec l'hypothèse d'un effet inhibiteur des rayonnements ultra-violets dans les lacs Iransparents d'altitude. Ils révèlent, par ailleurs, que les relations entre la lumière et le métabolisme du phytoplancton ne sont pas totalement indépendantes des paramètres chimiques. Dans ces lacs homothermes, la circulation des caux renouvelle constamment les substances nutritives en favorisant les échanges au niveau de la vase. La biomasse algale et l'activité photosynthétique y sont nettement plus élevées que dans la zone superficielle du lac de PortBielh $(0-5 \mathrm{~m})$ pourtant soumise à des conditions d'éclairement identiques. La réduction de la photosynthèse près de la surface est 
également peu prononcée. Il est alors permis de supposer avec Lind (1965) et Prchlaner (1971) que l'effet inhibiteur des fortes intensités lumineuses devient d'autant plus important que la disponibilité en sels nutritifs diminue. Dans ces conditions, l'évolution de la production en fonction de la profondeur et ses variations au cours de l'été résulterait de l'action combinée de la lumière ct des composantes chimiques.

\section{COMPOSANTES CHIMIQUES}

La figure 33 représente l'évolution comparée de la productivité primaire, du $\mathrm{pH}$ et de la teneur en $\mathrm{PO}_{4}-\mathrm{P}$ et $\mathrm{NO}_{3}-\mathrm{N}$.

La diminution des taux de photosynthèse à la fin de la période de stratification correspond à une diminution de la quantité d'éléments dissous, principalement du $\mathrm{CO}_{2}$ libre (qui se traduit par l'augmentation du $\mathrm{pH}$ ) et du $\mathrm{PO}_{4}-\mathrm{P}$. Les diagrammes des fig. 6 et 7 montrent par ailleurs que celte diminution affecte surtout la zone profonde. Elle résulte du développement des biomasses relativement importantes au début de l'été.

L'amplitude des variations de la teneur en $\mathrm{PO}_{4}-\mathrm{P}$ et $\mathrm{NO}_{3}-\mathrm{N}$, généralement considérés comme facteurs limitants, est assez faible. Le rôle de ces éléments a été étudié par plusieurs auteurs (par exemple CHU 1942 et 1943, Rodne 1948) sur des cultures d'algues. Les résultats expérimentaux sont cependant difficilement utilisables lorsqu'il s'agit de définir les concentrations inféricures limites pour le phytoplancton lacustre. D'une part, le nombre d'espèces étudiées est relativement restreint et les exigences varient selon les espèces. On sait par exemple (Rodre 1948) que les Chrysomonadines (Dinobryon, Uroglena) ont les besoins les plus faibles, propriété qui peut être rapprochée de l'abondance de ce groupe dans les lacs de montagne. D'autre part, la régénération du phosphore dans l'eau à partir de la phase solide, des algues et du zooplancton est relativement rapide (Hutchinson 1957 page 744, Rigler 1961 a el 1964, Overbeck 1962). De plus le phosphore el l'azote peuvent être ulilisés sous des formes diverses par les algues (VollenweIder 1968). Enfin, une concentration donnée d'un élément nutritif peut avoir un effet différent selon les conditions de lempérature el d'éclairement (Lund 1965, Fogg 1965).

Comme tous les lacs de montagne, les lacs du vallon de PortBielh sont pauvres en phosphore et en azote. Dans les lacs de faible profondeur, la concentration de ces éléments est du même ordre de grandeur que dans le lac de Port-Bielh (Capblanco et Lavilue 1969). Cependant, la quantité de $\mathrm{PO}_{4}-\mathrm{P}$ augmente légèrement au cours de l'été et présente un maximum (4 à $5 \mu \mathrm{g} / 1$ ) en 

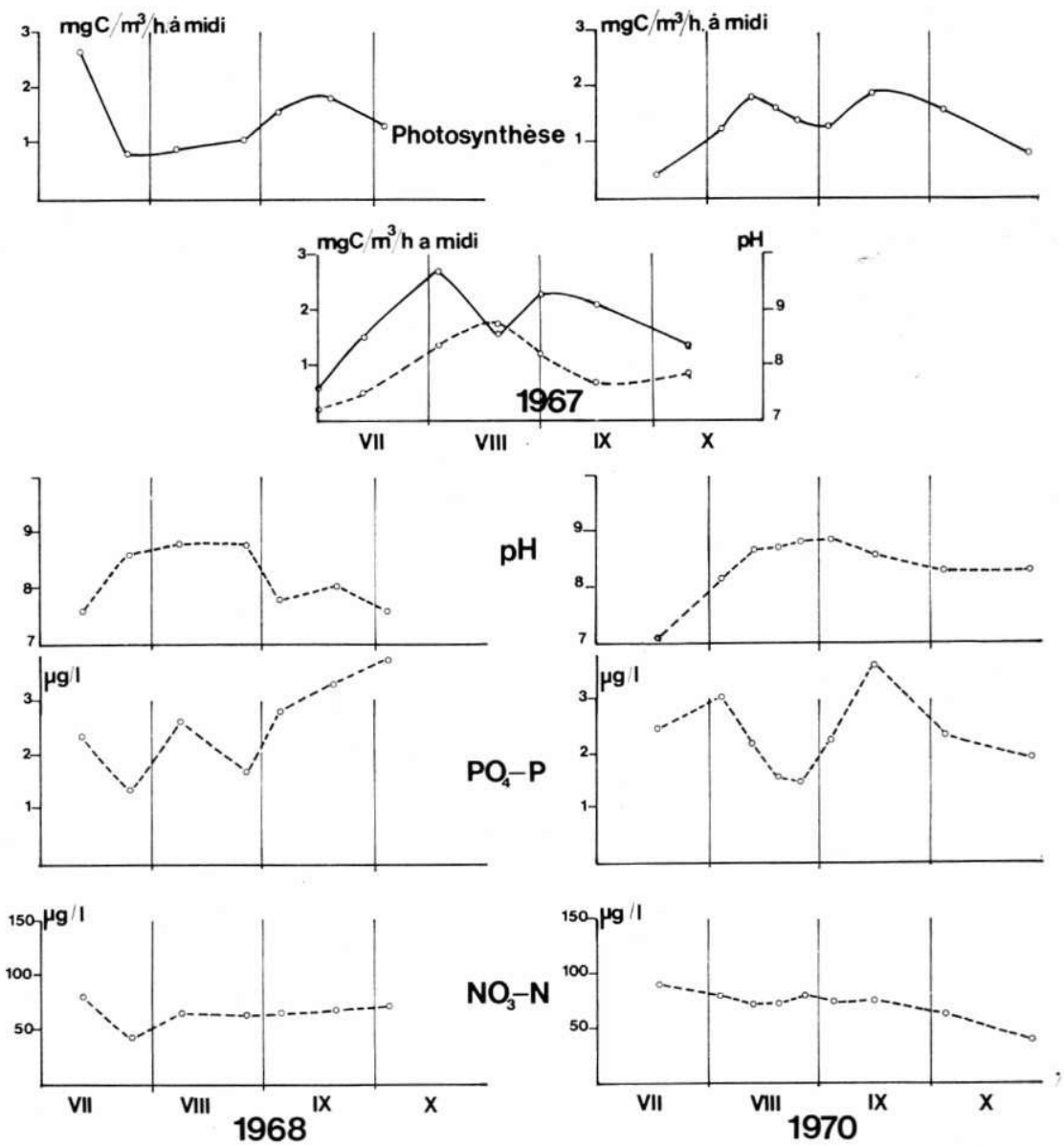

Fig. 33. - Évolution comparée des taux d'assimilation photosynthétique (mg $\mathrm{C} / \mathrm{m}^{3} / \mathrm{h}$ à midi), du $\mathrm{pH}$ et de la teneur en $\mathrm{PO}_{4}-\mathrm{P}$ et $\mathrm{NO}_{3}-\mathrm{N}$ au lac de PortBielh, en été (valeurs moyennes entre $0 \mathrm{~m}$ et $18 \mathrm{~m}$ ).

septembre qui correspond aux plus fortes productivités. La comparaison de ces lacs montre que pour des teneurs en $\mathrm{PO}_{4}-\mathrm{P}$ et $\mathrm{NO}_{3}-\mathrm{N}$ sensiblement identiques, la productivité du phytoplancton est différente. Le taux de renouvellement de cet élément joue vraisemblablement un rôle plus important que sa teneur à un moment donné.

Le $\mathrm{CO}_{2}$ est rarement signalé comme facteur limitant de la photosynthèse dans les milieux aquatiques. Quelques exemples (Steemann-Nielsen 1955, Wright 1960) indiquent que sa diminution peut entraîner une baisse de la productivité. Dans le lac de Port-Bielh, il existe chaque année une correspondance frappante entre la diminution de l'assimilation photosynthétique au mois 
d'août et les valeurs maximales du $\mathrm{pH}$. La comparaison des quatre lacs (tableau XI) indique, d'autre part, que la productivité augmente en même temps que la quantité de $\mathrm{CO}_{2}$ libre disponible. Les lacs du Gourguet et du Gourg Nère Moyen montrent les taux d'assimilation photosynthétique les plus élevés; le $\mathrm{pH}$ y dépasse rarement 8,3 et, corrélativement, la quantité de $\mathrm{CO}_{2}$ libre y est en moyenne plus élevée que dans les lacs de Port-Bielh et du Gourg Nère Inférieur II. Dans ce dernier, les taux de photosynthèse sont sensiblement plus faibles qu'au Gourguet malgré des températures, une teneur en $\mathrm{CO}_{2}$ total et une biomasse algale nettement plus élevées.

Dans ces lacs peu minéralisés, la quantité de $\mathrm{CO}_{2}$ dissous, principalement sous forme de $\mathrm{CO}_{2}$ libre, apparaît donc comme un facteur limitant de la productivité primaire.

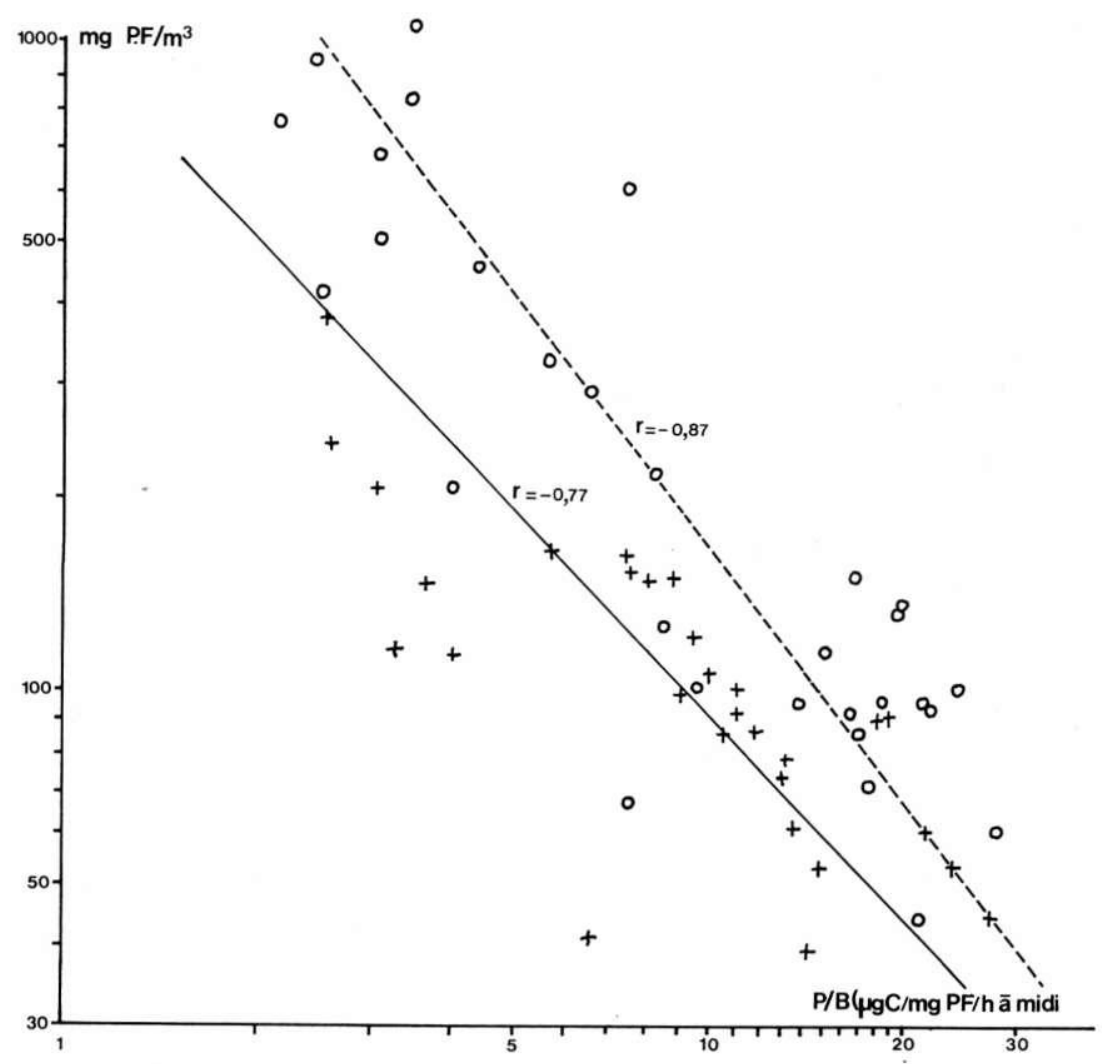

FIG. 34. - Relation entre la biomasse (mg de poids frais $/ \mathrm{m}^{3}$ ) et le coefficient d'activité du phytoplancton ( $\mathrm{P} / \mathrm{B} \mu \mathrm{g} \mathrm{C} / \mathrm{mg}$ poids frais/h à midi) au lac de Port-Bielh en été ( + et trait plein : valeurs moyennes entre 0 et $3 \mathrm{~m}$; o et trait pointillé : valeurs moyennes entre 8 et $16 \mathrm{~m}$ ). 


\section{COMPOSANTES BIOTIQUES}

\subsection{Biomasse algale.}

Dans les lacs du vallon de Port-Bielh, le taux d'assimilation relative $(\mathrm{P} / \mathrm{B})$ ou « coefficient d'activité » du phytoplancton (NAUWERcK 1963) varie en fonction inverse de la densité algale. Cette relation, signalée dans d'autres lacs par plusieurs auteurs (FINDENEgG 1965, Elster 1965, Pechlaner et al. 1972, Goldman et al. 1968 par exemple) a été représentée pour deux zones différentes du lac de Port-Bielh (fig. 34). Dans les lacs de faible profondeur, la corrélation est moins nette (fig. 35), sans doute par suite de l'évolution des paramètres chimiques au cours de l'été.

L'analyse des résultats permet de dégager les points suivants : - pour une biomasse algale identique, le coefficient d'activité est environ deux fois plus élevé dans la zone profonde du lac de Port-Bielh $(12-16 \mathrm{~m})$ que dans la zone superficielle $(0-3 \mathrm{~m})$;

- le rapport $\mathrm{P} / \mathrm{B}$ est plus élevé dans les lacs de faible profondeur (fig. 35) ; pour une quantité d'algues et des conditions d'éclairement identiques, il est en moyenne quatre à six fois plus élevé que dans la zone superficielle du lac de Port-Bielh;

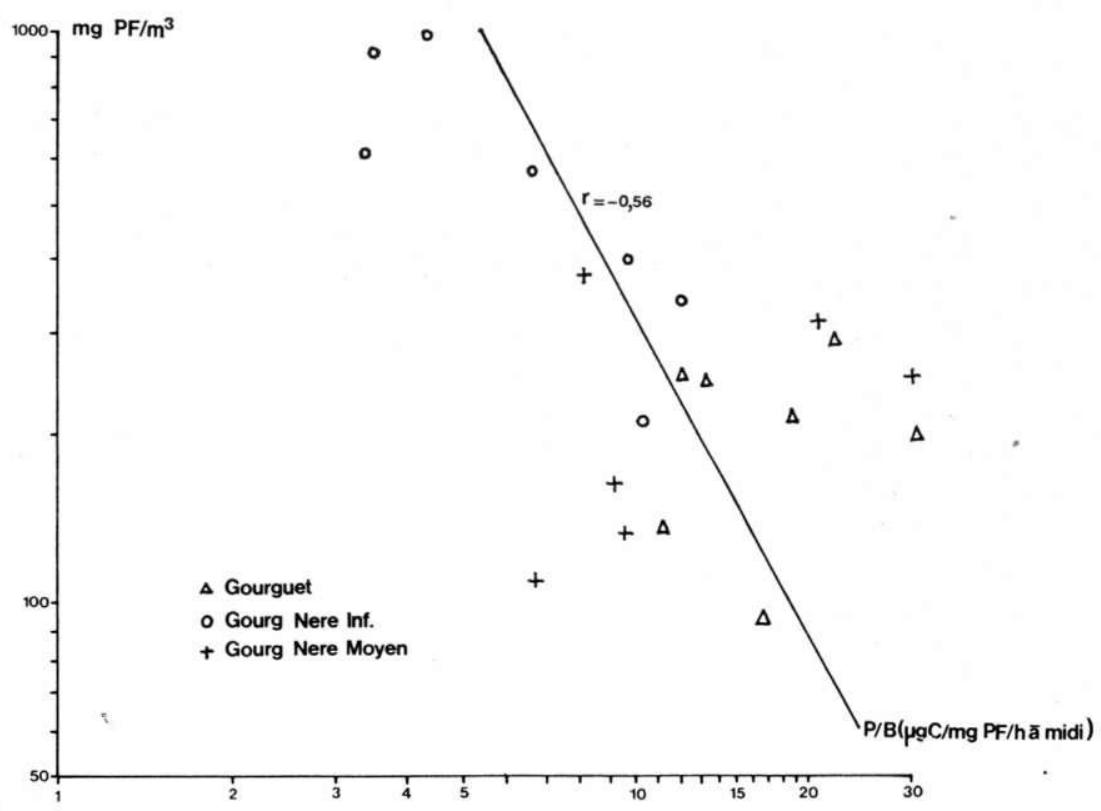

FIG. 35. - Relation entre la biomasse ( $\mathrm{mg}$ de poids frais $/ \mathrm{m}^{3}$ ) et le coefficient d'activité du phytoplancton $(\mathrm{P} / \mathrm{B} \mu \mathrm{g} \mathrm{C} / \mathrm{mg}$ poids frais/h à midi) dans les lacs de faible profondeur. 
dans tous les lacs, les valeurs maximales du taux d'assimilation relative se situent en septembre. Pour le lac de Port-Bielh, elles coïncident avec le début de la période d'isothermie automnale c'est-à-dire avec les températures les plus chaudes. La comparaison des quatre lacs montre cependant qu'il n'existe aucune relation entre la valeur de $\mathrm{P} / \mathrm{B}$ et la température de l'eau;

- le coefficient d'activité est d'autant plus élevé que le volume moyen des éléments du phytoplancton est faible (fig. 36).

Ces résultats peuvent être interprétés par le fait que les formes de petite taille, en raison d'un rapport surface/volume élevé, sont capables d'assimiler les substances nutritives d'une manière plus active que les espèces plus grosses. La dominance des formes nannoplanctoniques dans les lacs oligotrophes est sans doute liée à ce phénomène. L'efficacité de l'assimilation est d'autant plus réduite que la concentration en éléments dissous est faible et que la

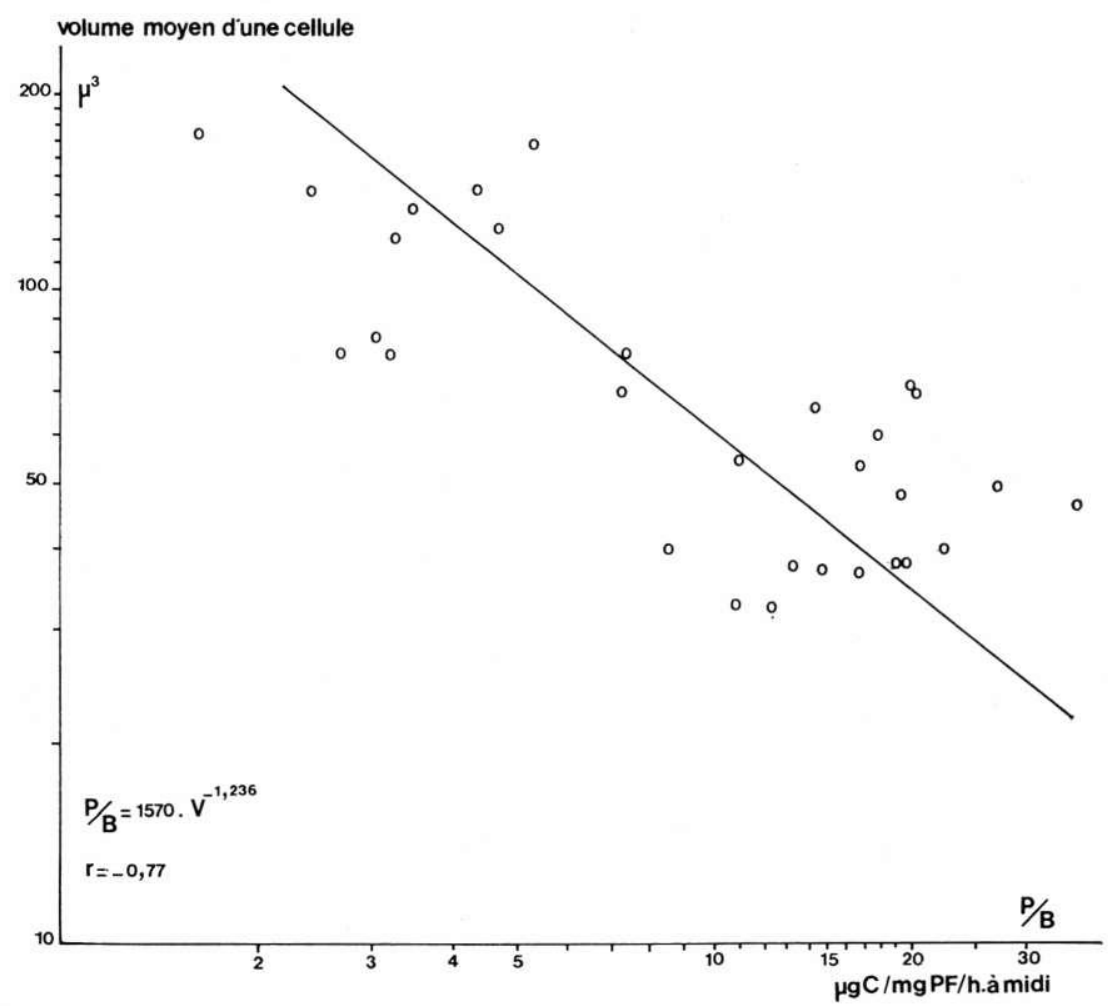

F IG. 36. - Relation entre le volume moyen des algues $(\mu 3)$ et le coefficient d'activité du phytoplancton ( $\mu \mathrm{g} \mathrm{C} / \mathrm{mg}$ poids frais/h à midi) au lac de PortBielh, en été. 
lumière est intense. Sous des condilions d'éclairement identiques, la diminution du rapport $\mathrm{P} / \mathrm{B}$, corrélatif à une augmentation de la densité algale, peut ainsi résulter du processus de compétilion entre les algues planctoniques pour un élément nutritif. Il peut être également la conséquence d'une inhibition de la pholosynthèse par les produils extracellulaires rejetés par les algues. Les expériences de Fogic et WaTt (1965) sur Chlorella pyrenoüdosa tendent à montrer que la quantité de produits exerétés augmente lorsque la photosynthèse est inhibée par les fortes intensités lumineuses et limitée par le $\mathrm{CO}_{2}$ disponible.

\subsection{Diversité spécifique.}

Le cocfficient d'activité (P/B) mesure le taux d'accroissement des communautés algales. On peut admeltre que, dans une communauté plurispécifique, les potentialités d'accroissements et les vitesses de multiplication diffèrent sclon les espèces. En conséquence toute variation de la productivité doit être liée à une modification de la structure de la communauté. Par exemple, une augmentation de $\mathrm{P} / \mathrm{B}$ devrait se traduire par la dominance des quelques espèces dont la vitesse de multiplication est la plus élevée. Inversement, la diminution de $\mathbf{P} / \mathbf{B}$ devrait entraîner une atténuation de la dominance. Margalef (1965) considère ainsi que «la production est une fonction, au sens mathémalique du terme, de la structure de la communauté ».

Les indices de diversité sont une expression quantilative de l'organisation des communautés. L'expression que nous avons utilisée donne la diversité moyenne par individu en unités binaires d'information.

$$
\overline{\mathbf{D}}=-\sum_{\mathbf{i}=1}^{\mathbf{n}} \mathrm{pi} \log _{2} p \mathbf{i}
$$

pi est la probabilité de présence d'un individu de l'espèce i dans l'échantillon (pi $=\frac{n i}{\mathrm{~N}}-=$ nombre d'individus de l'espèce $\mathrm{i} /$ nombre total d'individus dans l'échantillon ).

$\overline{\mathrm{D}}$ est égal à $O$ (lorsque tous les individus appartiennent à la même espèce) et $\rightarrow \infty$ (lorsque chaque individu appartient à une espèce différente).

Nous avons calculé cet indice pour chaque prélèvement. Ses varialions et celles du cocfficient d'activité du phyloplancton sont représentées par les diagrammes de la figure 37. Pendant lout le début de l'été, il existe une relation inverse entre la diversité spécifique et le rapport $\mathrm{P} / \mathrm{B}$; aux fortes valeurs du coefficiont d'acti- 

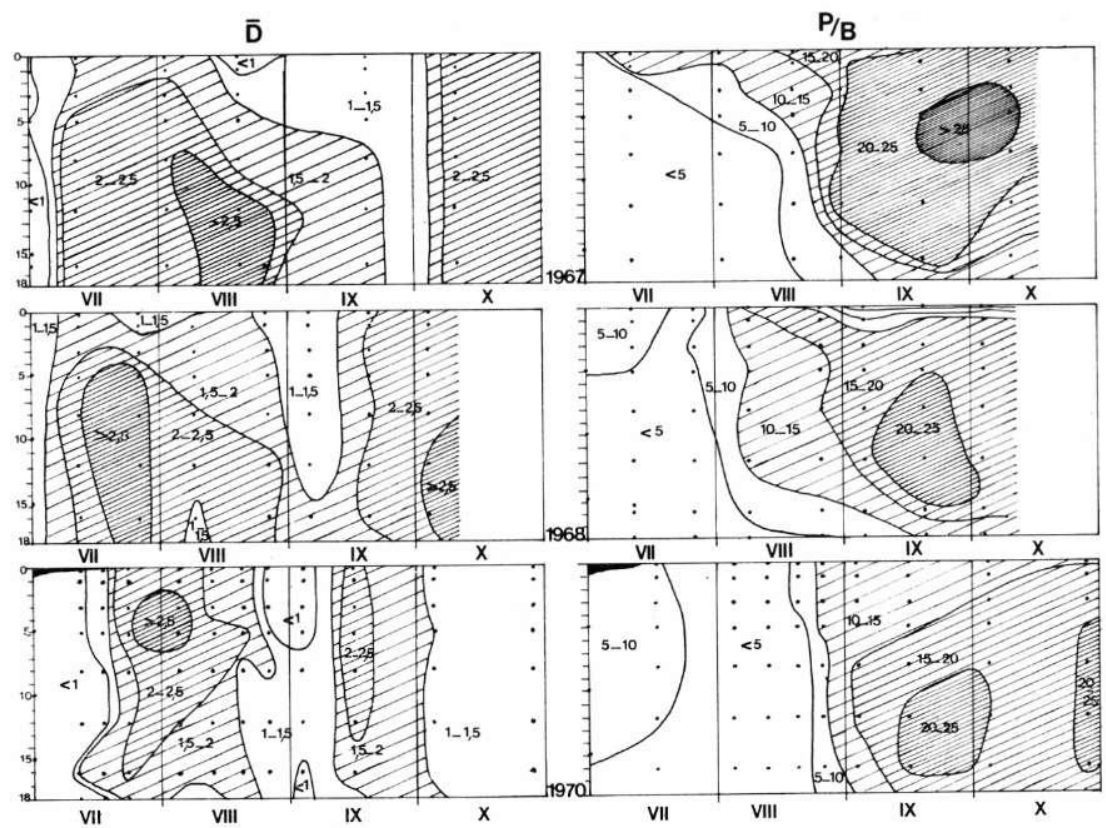

FIg. 37. - Evolution comparée de la diversité spécifique ( $\bar{D})$ et du coefficient d'activité du phytoplancton $\mathrm{P} / \mathrm{B}(\mu \mathrm{g} \mathrm{C} / \mathrm{mg}$ poids frais/h à midi) au lac de Port-Bielh, en été.

vité (zone superficielle du lac pendant la stratification d'été, début de l'isothermie de septembre) correspond généralement une faible diversité spécifique. Cependant, cette relation s'inverse à la fin du mois de septembre où apparaît, chaque année, une augmentation de $\mathrm{D}$ pour des valeurs élevées du rapport $\mathrm{P} / \mathrm{B}$. L'augmentation de la diversité spécifique s'accompagne alors d'une diminution de la densité algale, conséquence vraisemblable de l'intensification de la prédation par le zooplancton. La taille des éléments du phytoplancton étant sensiblement identique, on peut supposer que la quantité d'algues ingérées par les organismes filtreurs dépend uniquement de leur densité dans l'eau. En conséquence, la prédation affecte davantage les espèces dont le taux de multiplication est le plus élevé. Ceci a pour effet d'atténuer la dominance qui devrait normalement résulter d'une augmentation de la productivité.

\subsection{Zooplancton.}

Par suite des migrations verticales du zooplancton et de l'absence de données précises sur la nutrition des diverses espèces, il est difficile de définir clairement le rôle du zooplancton sur le peuple- 
ment phytoplanctonique. Plusieurs résultats (Marshall et Orr 1955, Nauwerck 1959, Rigler 1961 b, Mc Mahon 1965, Richman 1966) indiquent cependant que le taux de nutrition des organismes filtreurs augmente avec la concentration de nourriture, la température et la taille de ces organismes. On peut admettre, d'autre part, que les espèces du phytoplancton du lac de Port-Bielh, de taille peu différente, sont filtrées pratiquement sans sélection.

L'évolution comparée des populations zooplanctoniques et phytoplanctoniques du lac de Port-Bielh montre que :

-- en juillet, lorsque le lac est stratifié, le zooplancton (stades naupliens de Mixodiaptomus laciniatus essenticllement) est plus dense dans les couches superficielles plus chaudes. Ces dernières sont moins riches en phytoplancton que les couches profondes où les taux de photosynthèse journaliers sont cependant plus faibles;

-- en septembre, malgré des taux de production élevés, la quantité d'algues reste relativement faible. Cette période correspond aux densités optimales de zooplancton (tableau IV), alors composé de formes de plus grande taille (copépodites de Mixodiaptomus laciniatus, Daphnia longispina). L'augmentation de la biomasse de zooplancton jointe à l'élévation de la température entrainent une intensification du taux de filtration qui limite le développement des populations algales.

\section{V. -- PROductivite JOURNALIÑe DU LAC DE PORT-BIELH}

Pour nos mesures de productivité, nous avons généralement adopté un temps d'exposition des échantillons d'une duréc de 4 heures $(11 \mathrm{~h}-15 \mathrm{~h})$, plus rarement de 6 heures $(10 \mathrm{~h}-16 \mathrm{~h})$. Le problème consiste à convertir les taux de photosynthèse, mesurés pendant ces expériences, en taux journaliers.

Dans un travail précédent (CAPBLANce et Laville 1972) nous avions, à l'exemple de nombreux auteurs, estimé la production journalière au moyen d'un coefficient calculé à partir des courbes d'ensoleillement (Energie radiante pendant la journée d'expérience/ Energic radiante pendant la période d'exposition). Cette méthode suppose en fait que l'assimilation est proportionnelle à l'énergie lumineuse disponible; cette hypothèse n'est approximativement vérifiée que dans la zone profonde du lac. En surface, dans la zone d'inhibition, le taux de photosynthèse mesuré au milicu de la journéc correspond à une assimilation relativement faible par rapport à la valeur journalière (fig. 24). Le facteur de conversion journalier varie donc en fonction de la profondeur, c'est-à-dire de l'énergie lumineuse disponible. 
Les résultats obtenus dans les quatre séries d'expériences réalisées sur l'ensemble de la journée solaire (cf. § II 3.3. et fig. 24) ont servi de base au calcul de la production journalière. La somme des taux d'assimilation, mesurés entre le lever et le coucher du soleil à une profondeur donnée $(z)$, représente la production journalière $\left(\mathrm{P}_{\mathrm{z}} /\right.$ jour $)$ à cette profondeur. $\mathrm{P}_{\mathrm{z}} /$ jour, exprimé par rapport au taux d'assimilation horaire moyen mesuré au milieu de la journée ( $\mathrm{p}_{z}$ à midi), donne le facteur de conversion journalier $\left(K_{\mathrm{z}}\right)$ pour la profondeur considérée. Les valeurs de $\mathbf{K}_{\mathrm{z}}$ ont été ainsi calculées pour différentes profondeurs à partir des données expérimentales correspondant à deux journées sans nuages (4-8-1971 et 17-9-1971) et à deux journées avec brouillard en fin d'après-midi (12-8-1970 et 3-8-1971). Les résultats (fig. 38) ont été représentés en fonction de l'énergie lumineuse moyenne $I_{z}$ cal./ $\mathrm{cm}^{2} / \mathrm{h}$ à midi) disponible à la profondeur considérée entre $11 \mathrm{~h}$ et $15 \mathrm{~h}$ (temps d'exposition standard). La figure montre l'existence d'une forte corrélation $(\mathrm{r}=0,942)$ entre $\mathrm{I}_{\mathrm{z}}$ à midi et le facteur de conversion journalier $\mathbf{K}_{\mathrm{z}}$. Ce dernier augmente en même temps que $\mathrm{I}_{\mathrm{z}}$; cela traduit le fait que les mesures effectuées près de la surface au milieu de la journée correspondent à l'inhibition la plus forte.

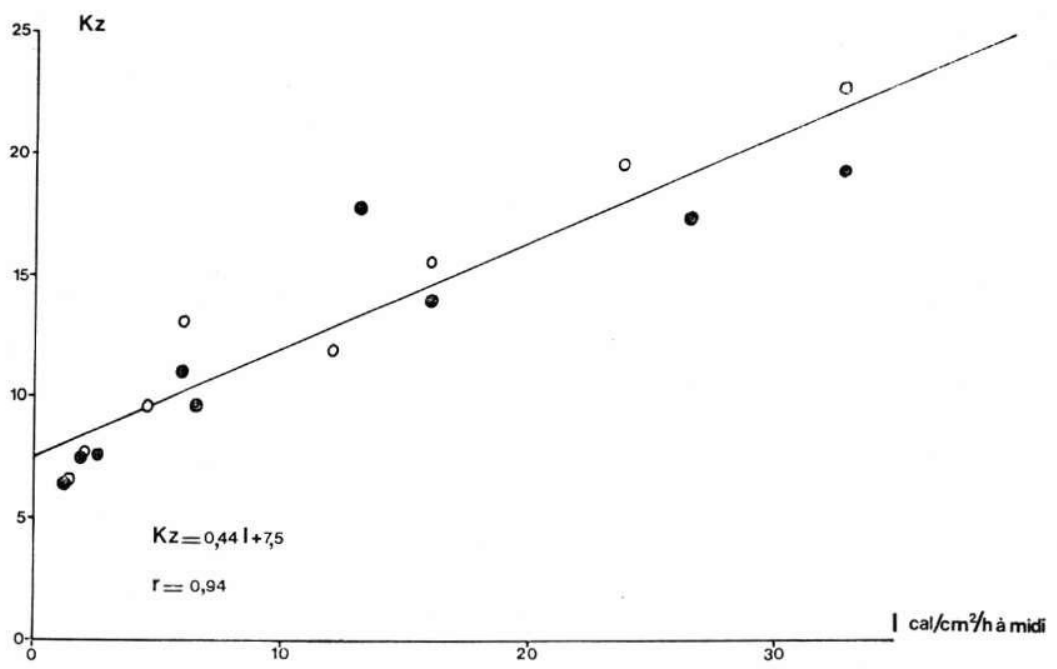

FIG 38. - Relation entre le facteur de conversion journalier

$$
\left(\mathrm{K}_{\mathrm{z}}=\frac{\mathrm{p} \mathrm{mg} \mathrm{C/ \textrm {m } ^ { 3 } / \text { jour }}}{\mathrm{p} \mathrm{mg} \mathrm{C} / \mathrm{m}^{3} / \mathrm{h} \text { à midi }}\right)
$$

et l'énergie lumineuse moyenne (I $\mathrm{cal} / \mathrm{cm}^{2} / \mathrm{h}$ à midi) reçue à la profondeur (z) pendant la période standard d'exposition $(11 \mathrm{~h}-13 \mathrm{~h})$.

0 : mesures réalisées un jour clair;

- : mesures réalisées un jour partiellement nuageux. 


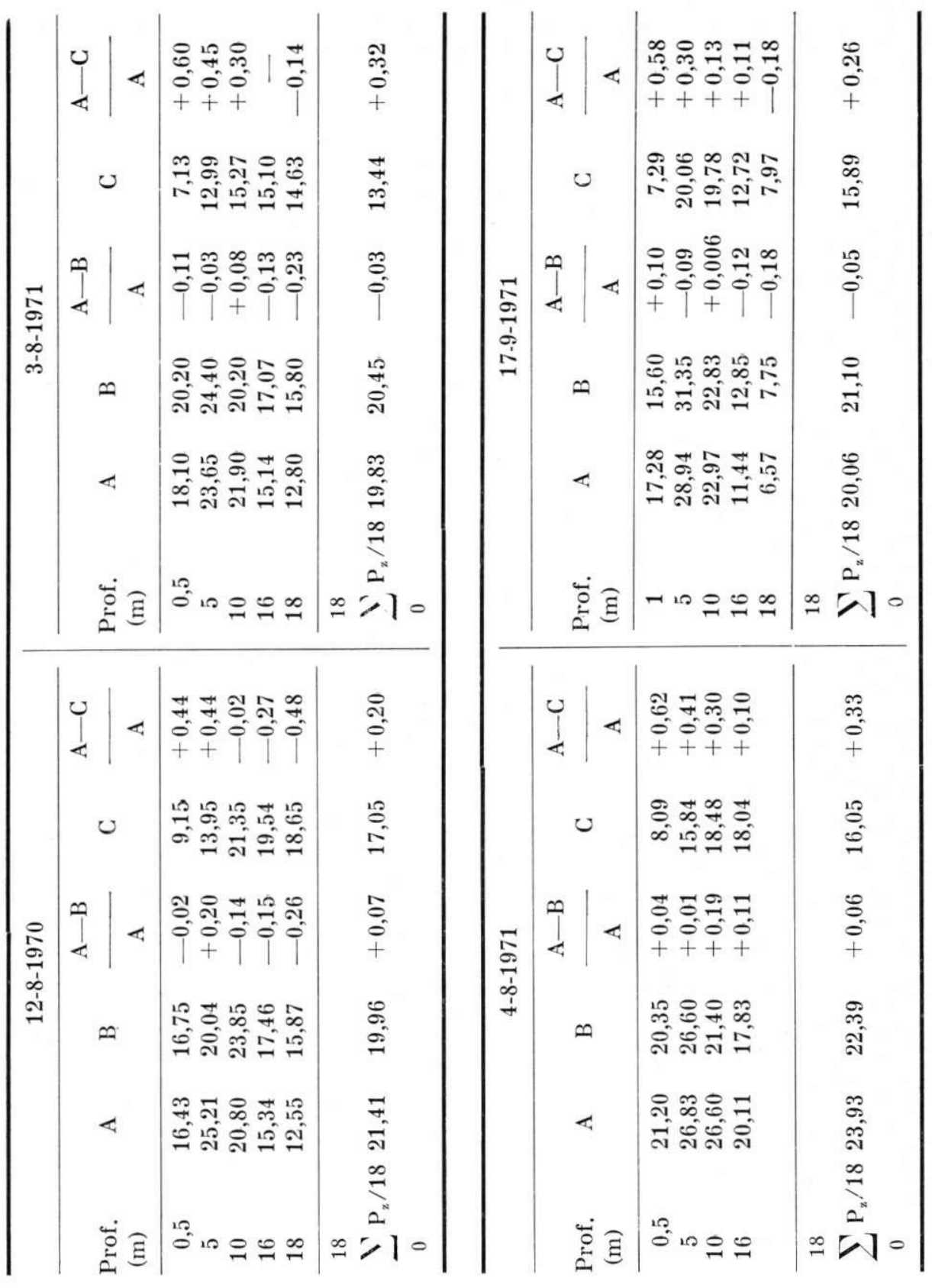

Tableau XII. - Productivité journalière $\left(\mathrm{P}_{\mathrm{z}} \mathrm{mg} \mathrm{C} / \mathrm{m}^{3 /} /\right.$ jour $)$ aux différentes 18 profondeurs et valeur moyenne pour la colonne d'eau $\left(\sum_{Z=0}^{\sum_{x}} P_{x} / 18\right)$ au lac de Port-Bielh.

A : somme des expériences de courte durée réalisées entre le lever et le coucher du soleil;

$\mathrm{B}$ : calculée par la relation, $\mathrm{P}_{\mathrm{z}} /$ jour $=\mathrm{p}_{\mathrm{z}}$ à midi $\cdot\left(0,44 \mathrm{I}_{0}^{\prime} \cdot \mathrm{e}^{-0 \mathrm{z}}+7,5\right)$;

$\mathrm{C}$ : calculée par la relation, $\mathrm{P}_{\mathrm{z}} /$ jour $=\mathrm{p}_{\mathrm{z}}$ à midi $\frac{\mathrm{I}^{\prime} \mathrm{o} \mathrm{cal} / \mathrm{cm}^{2} / \mathrm{jour}}{\mathrm{I}^{\prime} \mathrm{o} \mathrm{cal} / \mathrm{cm}^{2} / \mathrm{h} \text { à midi }}$. 
$K_{*}$ peut être estimé à partir de l'équation de la droite de régression par l'expression :

$$
\mathrm{K}_{7 .}=0,44 \quad \mathrm{I}^{\prime} 0 . \mathrm{e}^{-\mathrm{x}_{\mathrm{z}}}+7,5
$$

où $I^{\prime} 0=$ intensité moyenne de la lumière immédiatement sous la surface pendant le temps d'exposition standard en $\mathrm{cal} . / \mathrm{cm}^{2} / \mathrm{h}$. $\alpha$ - coefficient d'extinction.

Ic tableau XII récapitule, a titre de comparaison, les taux de production journaliers calculés pour quatre journées différentes : -... par sommation des mesures réalisées entre le lever el le coucher du soleil (colonne A);

- en u!ilisant la relation précédente (colonne $\mathbf{B}$ );

- d'après le rapporl Énergic radiante pendant la journée/Ênergie radiante pendant le temps d'exposition (colonne $\mathrm{C}$ ).

Les écarts entre les valeurs calculées (B et $C_{\text {) }}$ ) et les valeurs expérimentales (A), exprimés par rapport à ces dernières, sont indiqués. La productivité moyenne de la colonne d'eau $\sum_{Z=0}^{18} P_{\% / 18}$ est également donnée.

Les valeurs estimées au moyen de la relation $P_{z} /$ jour $=\mathbf{P}_{z}$ a midi $\times K_{\%}$ sont en général assez proches des valeurs expérimentales. Les écarts dépassent rarement $20 \%$; souvent plus importants dans la zone profonde du lac, ils s'amoindrissent dans les couches supérieures $(0-10 \mathrm{~m})$ où leur valeur absolue se situe en moyenne au-dessous de $10 \%$. L'erreur dans l'estimation de la productivité moyenne enlre $0 \mathrm{~m}$ et $18 \mathrm{~m}$ ne dépasse jamais $10 \%$. Inversement, les taux de production journaliers caleulés à partir des courbes d'ensoleillement (colonne C) sont très éloignés des valeurs mesurées; près de la surface $(0-5 \mathrm{~m})$ les écarts dépassent tonjours $\mathbf{4 0} \%$.

Productivité et biomasse sont généralement exprimées par $m_{\text {? }}$ de plan d'eau par intégration des courbes obtenues en portant les différentes valcurs en fonction de la profondeur. Dans le cas du lac de Port-Bielh, celte méthode conduirait à surestimer l'imporlance de la zone profonde puisque le volume décroît avec la profondenr. Pour lenir comple de ce fait, nous avons adopté la méthode de calcul suivante :

- les différentes valeurs de $P_{\%}$ ont étć multipliées par la surface $A_{z}$ du lac à la profondeur correspondante. La somme

$$
\sum_{Z=0}^{18} \frac{\left(\mathbf{P}_{z_{1}} \cdot \mathbf{A}_{Z_{1}}\right)+\left(\mathbf{P}_{z_{2}} \cdot \mathbf{A}_{z_{20}}\right)}{2} \quad\left(Z_{2}-Z_{1}\right)
$$

correspond à la productivité journalière pour la totalité du lac. En divisant par la superficie du lac (A) on oblient la productivité 


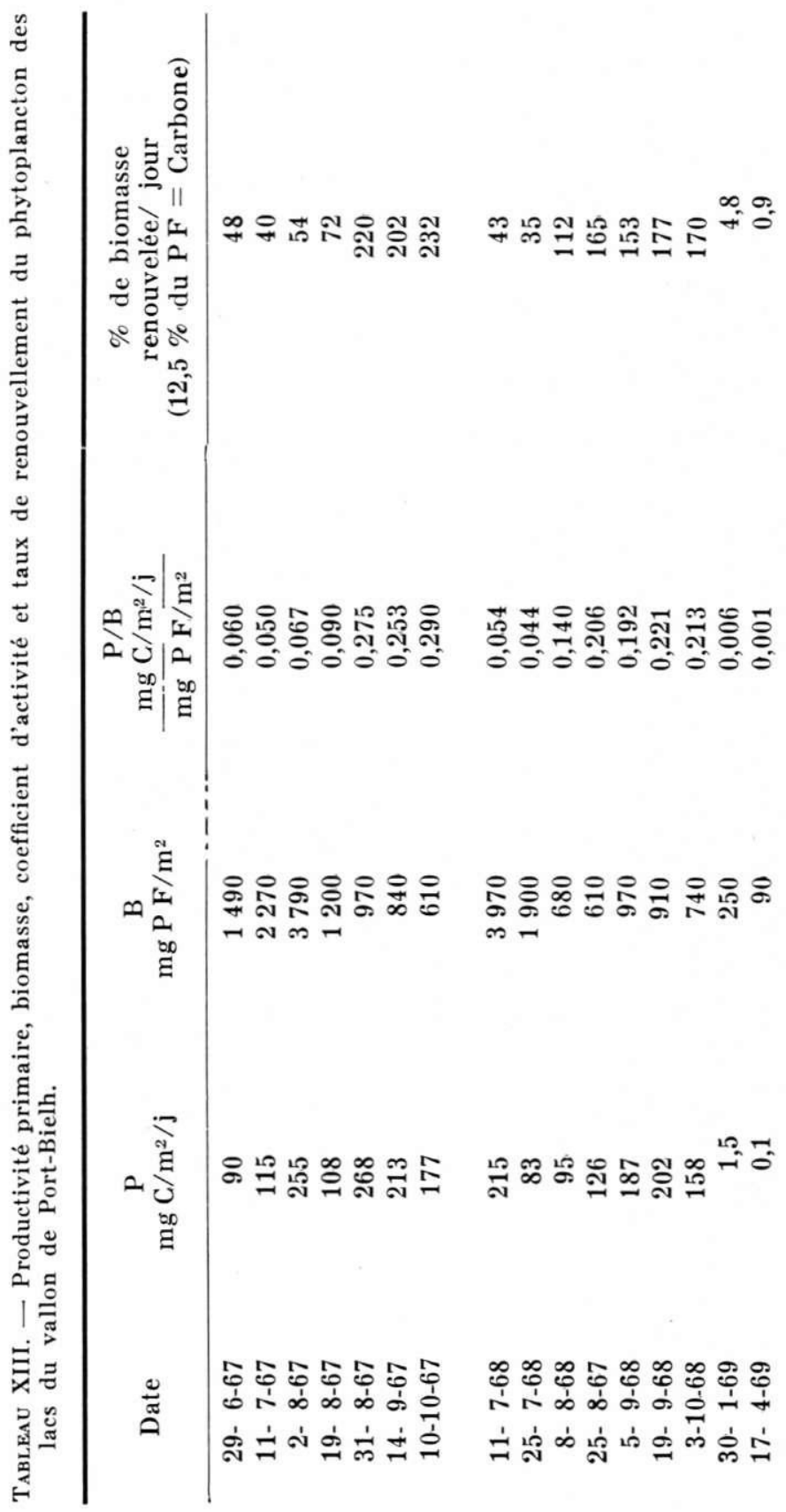




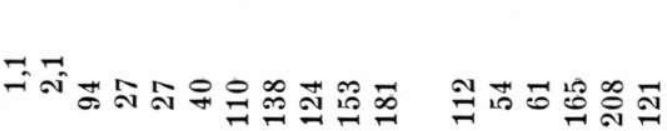

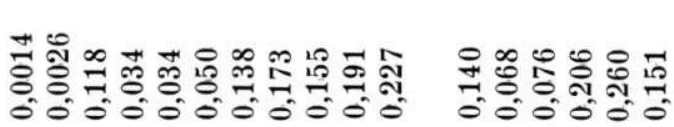

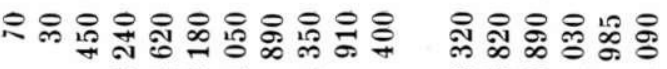
$n+\infty-1$ ब $\mathrm{N}=$

$7 \stackrel{\infty}{\circ}$

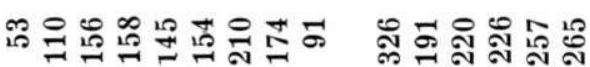

유유유유유유유유유

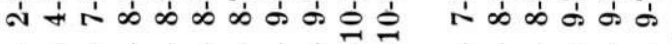

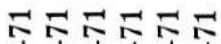

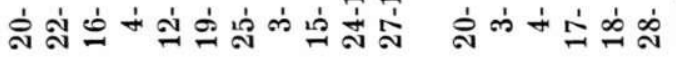

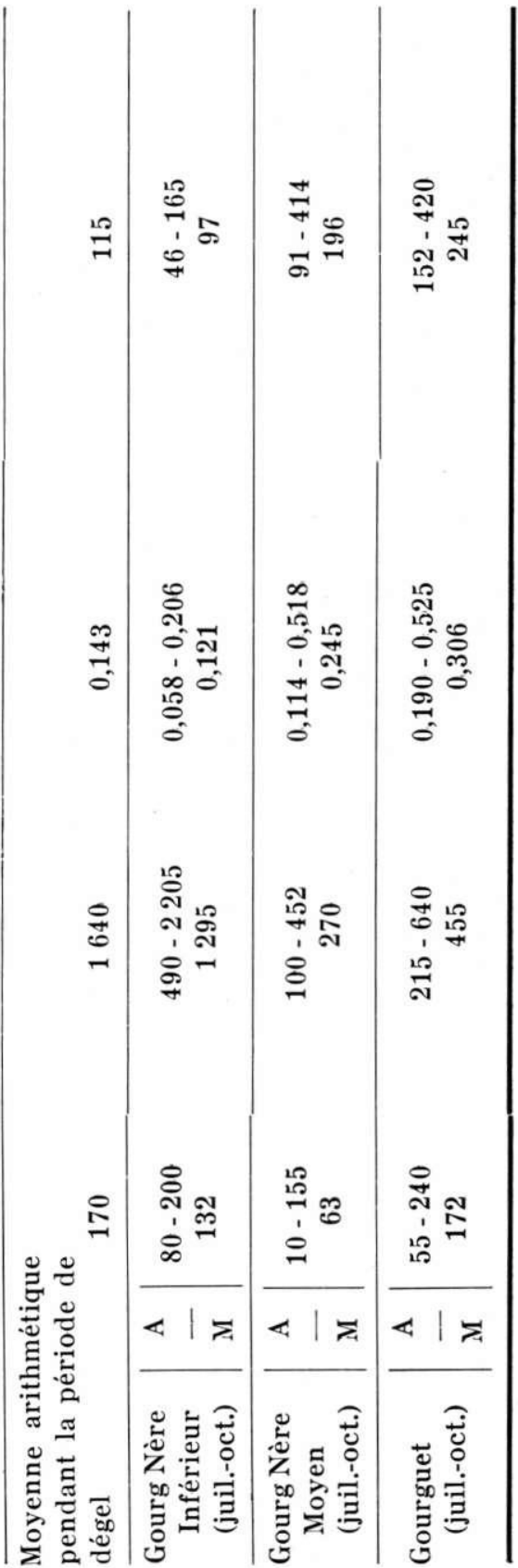


moyenne par $\mathrm{m}^{2}$ de surface; en divisant par le volume (V) on obtient la produclivité moyenne par $\mathrm{m}^{3}$ d'cau. Une méthode de calcul identique a été utilisée pour la biomasse algale.

Les résultats de 33 séries de mesures (4 mesures d'hiver, 29 mesures d'été), réalisées entre 1967 et 1971 dans le lac de Port-Bielh, sont récapitulés dans le tableau XIII. A titre indicatif, figurent ćgalement les valeurs moyennes et extrêmes correspondant aux lacs de faible profondeur; il est admis que dans ces lacs, le rapport entre $\mathbf{P} /$ jour et $\overrightarrow{\mathbf{p}}$ à midi est le même que dans la zone superficielle $(0-5 \mathrm{~m})$ du lac de Port-Bielh.

La productivité moyenne annuclle de la zone pélagique du lac de Port-Biclh est de l'ordre de $65 \mathrm{mg} \mathrm{C} / \mathrm{m}^{2} /$ jour, valeur sensiblement identique à celle d'un lac d'altilude autrichion ('Inzzer 1972). Très réduite pendant l'hiver (moins de $0,5 \mathrm{mg} \mathrm{C} / \mathrm{m}^{2} / \mathrm{jour}$ en moyenne), elle atteint des taux relativement élevés dans tous les lacs du vallon pendant la période estivale. En comparaison, la productivité du phytoplancton est supérieure à celle des lacs arctiques ou d'altitude ćtudiés à ce jour avec des méthodes semblables (tablcau XIV). Elle dépasse même les valeurs indiquées par Findenegg (1964) pour des lacs oligotrophes ou mésotrophes de moyenne altitude en Autriche.

Il faut souligner que cette productivité estivale correspond à de faibles biomasses algales, le plus souvent inféricures à $0,25 \mathrm{~g}$ de poids frais $/ \mathrm{m}^{3}$ d'eau. En conséquence, le rapport $P / B$ atleint dans les quatre lacs des taux élevés; ils sont la preuve du renouvellement rapide de la biomasse phytoplanctonique.

Quelques chiffres donneront une idée de la vitesse de renouvellement. On peut admettre tout d'abord que la méthode du ${ }^{14} \mathrm{C}$ mesure approximativement la production nette du phytoplancton; les pertes de carbone par respiration, de l'ordre de $10 \%$ du taux de photosynthèse à saturation par la lumière (STEEMaNo-Nielsen $1960 \mathrm{~b}$ ), sont sans doute négligeables par rapport aux erreurs d'évaluation de la production journalière. Il faut rappeler ici que cette valeur correspond uniquement à la journée solaire et qu'clle ne tient pas comple de la respira!ion noclurne. Par ailleurs, plusieurs résultats (PARsons et al. 1961, LuNd 1961, Nalewajko 1966, Strathman 1967, Winherg et collaboraleurs 1972) indiquent que $10 \%$ à $15 \%$ du poids frais de phytoplancton sont composés de carbone. Ainsi peut-on tenter quelques estimations. En été, une journéc de pholosynthèse renouvelle en moyenne $115 \%$ de la biomasse dans le lac de Port-Biclh, $97 \%$ dans le Gourg Nère Inférieur II, $196 \%$ dans le Gourg Nère moyen et $245 \%$ dans le Gourguet.

Des taux de renouvellement aussi élevés ont été signalés dans d'autres lacs; Golduan el al. (1968) estiment par exemple à $151 \%$ 


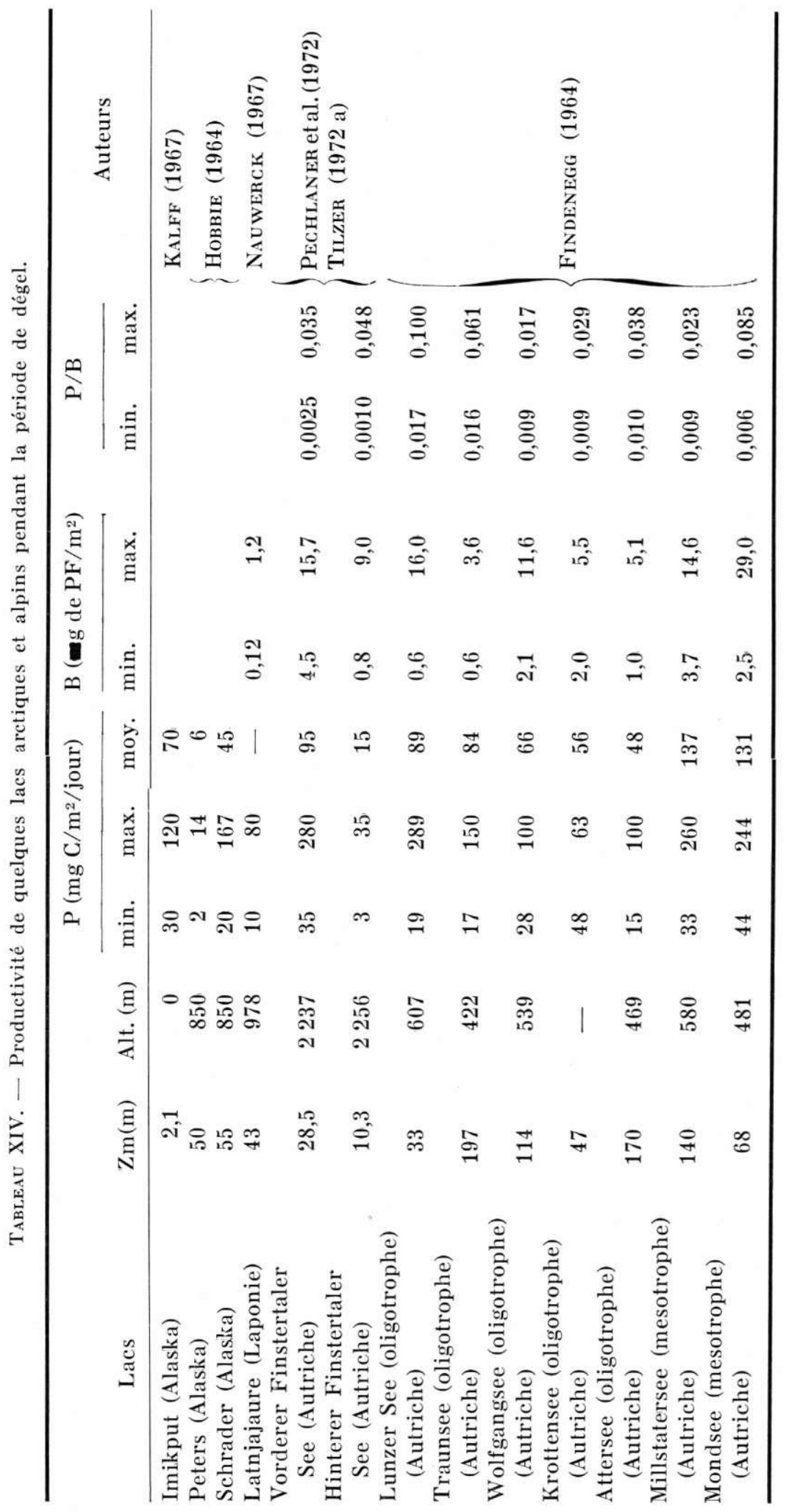


la part de biomasse algale renouvelée en moyenne par jour d'été dans le lac Majeur. Un maximum de $411 \%$ a été atteint en juillet. Mais, d'une manière générale, le rapporl $\mathrm{P} / \mathrm{B}$ reste le plus souvent inféricur à 0,1 (100\% de renouvellement journalier) dans la majorité des lacs étudiés. Sur 237 valeurs calculées par RodHe (1958) et Findenecig $(1964,1965$ et 1966) pour des lacs oligotrophes à eutrophes, $68 \%$ sont inférieures à $0,05,84 \%$ sont inféricures à 0,1 et $7 \%$ seulement supérieures à 0,2 .

Dans deux lacs de haute montagne des Alpes autrichiennes le coefficient d'activité du phytoplancton ne dépasse jamais 0,05 en été (Pechlaner et al. 1972, Tilzer 1972 a). La biomasse algale de ces lacs, comparable à celle des lacs de moyenne allitude étudiés par Findenegg (tableau XIV) est deux à trois fois plus élevée que dans les lacs du vallon de Port-Bielh, Gourg Nère Inférieur II excepté. Son taux de renouvellement estival est en moyenne quinze fois moindre qu'au lac de Port-Bielh, trente fois moindre qu'au Gourguet. Pour une densité algale à peu près identique, l'aclivité photosynthéliq̨ue du phytoplancton du Gourg Nère Inférieur Il est environ dix fois supérieure à celle des laes alpins.

La relation inverse entre biomasse et productivité ne suffit pas à expliquer ces différences. La composition spécifique du phytoplancton, la taille moyenne des éléments et l'état physiologique des cellules sont autant de facteurs susceptibles d'influer sur le rendement pholosynthétique des communautés algales (Findenegg 1971). La dominance des Péridiniens dans les lacs d'altitude des Alpes et leur absence dans les lacs pyrénéens étudiés est peut-être une des causes des différences de rendement photosynthétique. Cet exemple souligne en tout cas lá complexité des lois qui régissent les rapports entre la productivité et la hiomasse. Sans doute faudra-t- il rechercher des paramètres plus précis que le volume global ou la quantité de pigments chlorophylliens pour définir un peuplement phytoplanctonique et prévoir sa capacité productive. Cette voie permet'rait peut être d'utiliser les organismes comme indicateurs de productivité.

\section{IV. - CONCLUSION}

La persistance d'une épaisse couche de glace et de neige pendant plus de six mois réduit considérablement la productivité primaire des lacs de montagne. Au lac de Port-Bielh, quelques espèces d'algues plancloniques estivales subsistent sous cet écran lumineux. Lcur activité photosynthétique, à peine décelable à partir du mois de janvier, ne parvient pas à équilibrer les pertes par respiration et par sédimentation. Contrairement aux lacs alpins, il n'existe pas 
de populations de Dinoflagellés aptes à compenser l'alténuation de la lumière par une migration verticale et assurer ainsi la persistance de la photosynthèse sous la glace en hiver. Les processus de décomposition prédominent; plus intenses au contacl du fond, ils aboutissent à la formation de biomasses importantes de bacléries, associées à des algues hétérotrophes (Cyanophycées, Astasia), el se traduisent par une augmentation de l'assimilation obscure de ${ }^{14} \mathrm{C}$ et par une consommation d'oxygène. Fin l'absence d'( $)_{2}$ et aux faibles températures hivernales, ces processus de décomposition sont cependant très ralentis : pour l'ensemble du lac, la consommation d'oxygène sous la glace est inférieure à $0,01 \mathrm{mg} / \mathrm{litre} / 24 \mathrm{~h}$. Il en résulte une accumulation de matières organiques dans les sédiments dont la teneur $(25$ à $35 \%$ du poids sec) est comparable à celle de certains lacs culrophes.

Les taux de production du phytoplanclon des lacs du vallon de Port-Bielh sont relativement élevés en été. Ils sont sous la dépendance d'un complexe de facteurs, agissant en étroite interaction, et que l'on peut regrouper en trois composantes principales: la pénétration de l'énergie lumineuse, la circulation des caux et la prídalion par le zooplancton.

Dans ces lacs peu profonds el très transparents, l'activité photosynthétique se manifeste au sein de toute la masse d'cau. Aux forles intensités lumineuses de surface correspond une inhibition de la photosynthèse. Ce phénomène est réversible et paraît d'autant plus imporlant que la disponibilité en substances nutritives est faible. Au lac de Port-Bielh, il est probable que la dis!ribution des algues planctoniques, en période de stratification thermique, résulte de celle inhibition de surface. Toutefois, les biomasses les plus importantes ne correspondent pas à la zone de pholosynthèse optimale; les pertes par respiration, exerétion de produits extracellulaires et prédation par le zooplancton sont sans doute plus importantes dans les couches supérieures, plus chaudes et plus éclairées.

Cette distribution du phytoplancton en période de stagnation, jointe au développement important d'algues benthiques (Nitella flexilis, Diatomées et Chlorophycées périphyliques el épipćliques) se traduit par l'appauvrissement de l'hypolimnion en éléments dissous $\left(\mathrm{CO}_{2}, \mathrm{PO}_{4}-\mathrm{P}, \mathrm{NO}_{3}-\mathrm{N}, \mathrm{SiO}_{2}\right)$. Parmi ces éléments, la faible teneur en $\mathrm{CO}_{2}$ libre de ces eaux peu tamponnécs paraît être un facteur limitanl la productivité primaire. Il existe probablement un phénomène de concurrence entre les deux communautés, l'absorption des substances nutritives au niveau des sédiments par les algues benthiques contribuant à la diminution de la densité de phyloplanclon dans la zone pélagique. Lorsque le gradient ther. mique s'atténue et qu'augmente, en conséquence, la masse d'eau soumise à unc circulation, le renouvellement des substances nutri- 
tives à partir des sédiments est aceru. L'augmentation des taux de photosynthèse à l'isothermie d'automne ainsi que leurs valeurs, toujours plus élevées, dans les lacs peu profonds de même altitude montrent que les échanges entre l'eau et les sédiments favorisent la produclivité primaire. L'effet inhibiteur des radiations U.V. ne semble pas jouer, par contre, un rôle important sur le développement du phytoplancton des lacs de haute montagne. L'activité photosynthétique du phytoplancton dépend davantage de la proximité des sédiments et des possibilités d'enrichissement de l'eau à leur contact que d'une distance par rapport à la surface du lac.

Le zooplancton limite la formation de biomasses phytoplanctoniques importantes. Les fortes densités d'organismes filtreurs qui peuplent la zone pélagique du lac de Port-Bielh et, corrélativement, les faibles quantités de phytoplancton présentes en été, malgré un taux de renouvellement élevé, permettant de supposer que la majeure partie des algues planctoniques est consomméc avant leur sédimentation. Ce processus accélère le recyclage des éléments nutritifs et assure une produclivilé relativement élevée et à peu près constante en été.

Par suite de son renouvellement rapide, le phytoplancton suffit vraisemblablement à assurer la nutrition des consommateurs pélagiques; son rôle est sans doute minime pour la nulrition des organismes benthiques. Ceux-ci ont à leur disposition des biomasses importantes d'algues benthiques sur la totalité du fond, avec une production dépassant probablement celle du phytoplancton.

\section{RÉSUME}

Le pliytoplancton et la productivité primaire ont été étudiés au lac de Port-Bielh (2 $285 \mathrm{~m}$ ), de juin 1967 à octobre 1971 , ainsi que dans trois lacs voisins de plus faibles dimensions, en 1968. L'évolution du peuplement phytoplanctonique et de la productivité primaire et ses relations avec les composantes physiques, chimiques et biologiques de ces milieux Iacustres de haute montagne sont analysées dans ce travail.

Le phytoplancton se compose d'espèces de petite taille (nannoplancton) où dominent des formes flagellées (Chrysomonadines et Cryptomonadines) et des Diatomées (Cyclotella). Les ChIorophycées sont peu abondantes, les Péridinjens pratiquement absents. Si ces groupes ce succèdent au cours de l'été de façon à peu près identique, le peuplement des quatre laces différe, tant sur lc plan qualitatif que quantitatif.

Le cycle annuel du phytoplancton du lac de Port-[3ielh se caractérise par la suceession de deux périodes distinctes. En hiver, les quantités d'algues sont réduites (3 à $28 \mathrm{mg}$ de l'oids frais $/ \mathrm{m}^{3}$ ); près du fond se développent d'importantes populations de bactéries anaérobies, associées à des Cyanophycées et à Astasia sp. En été, la biomasse algale est de $180 \mathrm{mg}$ de Poids frais $/ \mathrm{m}^{3}$ en moyenne, elle atteint un maximum 
(420 a $510 \mathrm{mg}$ de Poids frais $\left./ \mathrm{m}^{33}\right)$ cluaciue annéce trois semaines à un mois après la disparition de la glace. Pour la majorité des espèces, les populations les plus rlenses se développent dans la zone profonde du lac, en période de stratification thermigue. L'isothermic d'automne entraine une répartition homogène des algues dans toute la masse d'eau.

En hiver, la productivité primaire du lac de Port-Bielh, très faible sous la glace, est de l'ordre de $10 \mu \mathrm{g} \mathrm{C} / \mathrm{m}^{3} /$ jour; la fixation de carbone à l'obscurité est relativement importante, notamment dans la zone profoncle. En été, l'assimilation obscure représente généralement moins de $2 \%$ de la photosynthèse; la productivité movinne est de $18,9 \mathrm{mg} \mathrm{C} / \mathrm{m}^{3} /$ jour avec deux maxima $\left(23,5\right.$ à $36,3 \mathrm{mg} \mathrm{C} / \mathrm{m}^{3} /$ jour $)$ qui correspondent, le premier, au pic de plyytoplancton, le second, à l'isothermie d'automne. Lc coefficient d'activitè clu phytoplancton est élevé $(0,143 \mathrm{mg} \mathrm{C} / \mathrm{mg}$ de Poids frais/jour en movenne); il augmente progressivement au cours de l'été, corrélativement à la diminution de la bjomasse et du volume moyen des éléments llu phytoplancton.

Ial productivite des lacs de faible profondeur est deux a quatre fois supéricure à celle du lac de Port-Bjells. Cotle différence peut-être attribuée à leur constante homothermic cui favorise les echanges permanents entre la vase et l'eau. Ia composition et la densité du peuplement phytoplanctonique et sa productivité paraissent lices an régime hydrologique qui détermine l'évolution des composantes chimiques.

Ia lumière joue un rôle important dans la dynamique du phytoplaneton de ces lacs d'altitucle. Son atténuation par la slace et la neige empêche pratiquement tout processus d'assimilitation photosynthétique penclant les six mois rl'hiver. Durant la période estivale, et par suite de la forte transparcnee des caux, les phénomènes d'inhibition réduisent la photosynthèse. Dans le lac de l'ort-Biclh, cet effet est sensible jusqu'à 8 à 10 mètres de profondeur. L'analyse des profils verticaux de photosynthèse pendant l'isothermic d'automne et au cours d'une journée montre que Ia relation photosynthèse-lumière peut être décrite par une Joi générale communc à tous les milieux aquaticues. La comparaison avec les lacs de faible profondeur et les relations entre la biomasse algale et le rapport $P / B$ incliquent cependant que la lumière n'agit pas inclépendamment des paramèlres chimiques; son effet inhibiteur parait d'autant plus prononcè que la disponibilité en sels dissous est faible. La productivité tes laes de montagne résulle sans doute de laction conjustuce de ces deux facteurs, la température intervenant apparamment peu sur l'activité photosynthétique des algues.

Dans le lac de Port-Bielh, après Ja disparition de la glace, le développement du phytoplancton entraîne un appauvrissement en substances dissoutes. Les teneurs minimales, à la fin de la périorle de stratification thermique, correspondent à une diminution de la biomasse algale et de la producfivitc. Parmi les facteurs responsables de cette diminution, la faible teneur en CO2 libre paraît jouer un rôle important.

Il n'existe pas de correspondance étroite entre l'évolution de la pro. ductivité et celle de la biomasse algale. Dans le lac de Port-Biclh, la poussée de photosynthèse automnale n'entraine pas une augmentation de la biomasse ou une diminution de l'indice de diversité. Pendant la stratification d'été, les fortes biomasses algales se forment à une profondeur supéricure à celle de l'optimum re photosynthèse journalier. Ces différences peuvent être attribuées à l'action du zooplancton dont la répartition verticale, la composition et la densité varient au cours de l'été.

Comparés avec d'autres laces d'altitude et des lacs arctiques, les lacs du vallon de Port-Bielh se distinguent par une forte productivité estivale, 
voisine de celle de certains lacs mesotrophes alpins. Malgré une activité photosynthétique intense, la biomasse de phytoplancton reste cependant assez faible du fait de la courte durée de vie des organismes nannoplanctoniques qui la composent et de la prédation par le zooplancton.

\section{PHYTOPLANCTON AND PRIMAKY PRODUCTION OF SEVERAL HIGH ALTITUde LAKES IN THE PYRENGes.}

Phytoplankton and primary production has been studied in Lake Port-Bielh $(2285 \mathrm{~m})$ from June 1967 to October 1971, and also in three neighbouring lakes of smaller size in 1968. This investigation describes the changes in the phytoplankton population and in primary production, and exumines the relationships of these changes to physical, chemical and biological components of the environment of high, moutain lakes.

The phytoplankton is composed of species of small size (nannoplankton) with flagellates (Chrysomonads and Cryptomonads) and diatoms (Cyclotella) predominant. The Chlorophyceae are less abundant and the Peridiniaceae are virtually absent. Although these groups succeed one another in an almost identical way throughout the summer, the population of the four lakes differ, both on the qualitative and quantitative plane.

The annual cycle of phytoplankton in Lake Port-Bielh is characterised by the succession of two distinct periods. In winter, the quantity of algae is greatly reduced (3-28 $\mathrm{mg}$ fresh weight $\left./ \mathrm{m}^{3}\right)$; and important populations of anacrobic bacteria associated with Cyanophyceae and Astasia sp. develop near to the bottom. In sumner, the algal biomass has a mean value of about $180 \mathrm{mg}$ fresh weight $/ \mathrm{m}^{3}$; and reaches its annual $\left(420-510 \mathrm{mg}\right.$ fresh weight $\left./ \mathrm{m}^{3}\right)$ three to four weeks after the disappearance of the ice. For most species, the most dense populations develop in the profundal zone of the lake during the period of thermal stratification. The isothermy of autumn produces a homogenous distribution of algae in all the water mass.

In winter, the prinary production of Lake Port-Bielh is very weak beneath the ice and is of the order of $10 \mu \mathrm{g} \mathrm{c} / \mathrm{m}^{3} / \mathrm{day}$; the fixation of carbon in the dark is relatively important, notably in the profundal zone. In summer, the dark assimilation generally represents less than $2 \%$ of the photosynthesis; the mean productivity is $18.9 \mathrm{mg} \mathrm{C} / \mathrm{m}^{3} /$ day with two maxima $\left(23.5-36.3 \mathrm{mg} \mathrm{C} / \mathrm{m}^{3} / \mathrm{day}\right)$, the first of which corresponds with the peak in the phytoplankton and the second if which corresponds with the autumn period of isothermy. The coefficient of phytoplankton activily is high (average value $0.143 \mathrm{mg} \mathrm{C} / \mathrm{mg}$ fresh weight/day); it inereases progressively throughout the summer and correlatively with the decrease in the biomass and mean volume of clements of the phytoplankton.

The productivity of shallower lakes is two to four times higher than that of Lake Port-Biclh. This difference is perhaps due to their constant homothermy which favours constant exchanges between the mud and the water. The composition and the density of the phytoplankton population and its productivity appears to be linked to the hydirological regime which determines the evolution of chemical components.

light plays an important role in the dynamics of the phytoplankton of these high lakes. Its attenuation by ice and snow impedes practically 
all processes of photosynthetic assimilation during the six winter months. During the summer period, as a result of the high transparency of the water, the phenomena of inhibition reduce photosynthesis. In Lake Port-Bielh, this effect is noticeable dow to a depht of 8 to 10 metres. Analysis of vertical profiles of photosynthesis during the autumnal isothermy and in the course of a day shows that the relationship of photosynthesis to light is possibly described by a general law common to all aquatic environments. Comparison with the shallower lakes and the relationships between algal biomass and the $P / B$ ratio indicates however that light does not act independently from chemical factors; its inhibitory effect appears to be more marked when availability of dissolved salts is low. The productivity of mountain lakes is without loubt the consequence of the joint action of these two factors, the temperature intervening apparently less on the photosynthetic activity of the algae.

In Lake Port-Bielh, after the disappearance of the ice, the development of phytoplankton produces an impoverishment of dissolved substances. 'The minimum values, at the end of the period of thermal stratification, correspond to a decrease in algal biomass and productivity. Amongst the factors responsible for this decrease, the poor content of free $\mathrm{CO}_{2}$ appears to play an important role.

There is not a close agreement between changes in productivity and algal biomass. In Lake Port-Bielh, the increased photosynthesis in autumn does not produce an increase in biomass or a decrease in the diversity index. During the summer period of stratiflcation, the greatest algal biomass appears at a depth higher than that for optimum daily photosynthesis. These differences can be attributed to the activity of zooplankton whose vertical distribution, composition and density varies throughout the summer.

Compared with other high altitude lakes and arctic lakes, the lakes of the valley of Port-Bielh are distinguished by a high summer productivity which is close to that of some mesotrophic alpine lakes. In spite of intense photosynthetic activity, the phytoplankton biomass remains fairly low because of the short life-span of nannoplanktonic organisms which form the biomass, and because of predation by zooplankton.

\section{TRAVAUX CITÉS}

Ambach (W.) eт Habicht (H. L.). 1962, - Untersuchungen der Extinktionseigenschaften des Gletschereises und Schnees. Arch. Meteorol., Geophys. Bioklimatol., sér. B., 11 : 512-532.

Arthun (C. R.) et Riglen (F. A.). 1967. - A possible source of error in the $\mathrm{C}_{14}$ method of measuring primary productivity. Limnol. Oceanogr. 12, 1 : 121-124.

BeEtox (A. M.). 1957. - Relationship between Secchi disk readings and light penetration in Lake Huron. Trans. Am. Fish. Soc., $87: 73-79$.

Besch (W. K.), Backhaus (D.), Capblance (J.) et Lavandieh (P.). 1972. Données écologiques sur les algues benthiques de haute montagne dlans les Pyrénées. I. Diatomées. Annls Limnol., 8 (2) : 103-118.

Bourreis.y (P.). 1954. - Recherches sur les Chrysophycées : morphologie, phylogénie, systématique. Thèse Fac. Sciences Paris, Série A $2704 N^{\circ}$ 3576. Mémoire Hors série I in- $8^{\circ}(1957): 412 \mathrm{p}$. 
Brouardel (J.) Et RiNck (F.). 1963. --- Mesure de la production organique en Méditerranée dans les parages de Monaco, à l'aide du ${ }^{14} \mathrm{C}$. Ann. Inst. Océanogr., $40(2): 109-164$.

Capblance (J.) et Lavilje (H.). 1969. -- Etude morphométrique et physico-chimique de ncuf lacs du massif de Néouvielle (HautesPyrénées). Annls Limnol., (1968), 4 (3) : 275-324.

Capblance (J.) ET Lavilie (H.). 1972 - Etude de la productivité du lac de Port-Bielh (Pyrénées-Centrales). Proc. UNESCO-IBP Symposium on Productivity Problems of Freshuaters, Kazimierz-Dolny. Poland. May 6-12 1970: 73-88.

Capbiance (J.), Décamps (H.) et Laville (H.). 1972. . Sauver d'euxmêmes les lacs de montagne. Sciences Progrès Découvertes, $\mathrm{N}^{\circ} \mathbf{3 4 5 0}$, Déc. 72 : 31-38.

Chouako (P.). 1949. - Caractères généraux des Pyrénées Centrales entre Gaves et Nestes. Bull. Soc. bol. Fr. 96 (10) : 7-15.

CHu (S.P.). 1942, - The influence of the mineral composition of the medium on the growth of planktonic algae. I. Methods and culture media. J. Ecol., 30 (284-325).

$\mathrm{CHU}$ (S. P.). 1943. - The influence of the mineral composition of the medium on the growth of planktonic: algae. II. The influence of the concentration of inorganic nitrogen and phosphate phosphorus. J. Ecol., 31 : 109-148.

Doty (M. S.) ET Oguni (M.). 1957. - Evidence for a photosynthefic daily périodicity, Limnol. Oceanogr., $2: 37-40$.

Edmonson (W. T.) ET Winklerg (G. G.). 1971. A manual on methods for the Assessemenf of secondary Productivity in fresh waters. $I B P$. Handbook $n^{\prime \prime}$ 17. Blackwell Scientific Publications, Oxford et Edimburg : 358 p.

Elster (H.J.). 1965. - Absolute and relative assimilation rates in relation to phytoplankton populations. Mem. Ist. ital. Idrobiol. (suppl.) $18: 77-103$.

FindenegG (I.). 1943. - Untersuchungen über dic ökologie und die Produktionsverhältniss des Planktons im Kärntner Seengebiete. Int. Revue ges. Hydrobiol. Hydrogr., 43 : 368-429.

Findenegiti (I.). 1964. - Produktionsbiologie, Planktonuntersuchungen an ostalpenseen. Int. Revue ges. Hydrobiol. Hydrogr., 49 (3) : $381-416$.

Findenegi (I.). 1965. - Relationship between standing crop and primary proluctivity. $\mathrm{Mem}$. Ist, ilal. Idrobiol. (suppl.) 18 : 271-289.

Findenefig (I.). 1966. - Phytoplankton und Primärproduktion einiger ostschweizerischer Seen und des Bodenses. Schweiz. Z. Hydrol., 28 (2) : 148-171.

Findenegg (I.). 1971. - Die Produktionsleistungen einiger planktischer Algenarten in ihrem natürlichen Milicu. Arch. Hydrobiol., 69 : 273-293.

FogG (G. E.). 1965. - Algal cultures and phytoplankton ecology. Univ. of Wisconsin Press. Madison : $126 \mathrm{p}$.

Fogg (G. E.). 1971. - Extracellular products of algae in Freshwater. Arch. Hydrobiol. Beih. Ergebn. Limnol., 5 : 1-25.

FogG (G. E.), Natewajko (C.) FT WaTT (W. D.). 1965 - Extracellular products of phytoplankton photosynthesis. Proc. R. Soc. B, 162 : 517-534.

Fogg (G. E.) ET Watt (W. D.), 1965, - The kineties of release of extracellular products of photosynthesis by phytoplankton. Mem, Ist. ilal. Idrobiol. (suppl.) $18: 165-174$. 
Goldman (C. R.). 1968. - The use of absolute activity for eliminating serious errors in the measurement of primary productivity with C1.1. J. Cotss. perm. int. Explor. Mer, 32 (2) : 172-179.

Goldman (C. R.), Mason (D. T.) ET Wood (B. J.). 1963. - Light injury and inhibition in antarctic fresh water phytoplankton. Limnol. Oceanogr., 8 : 313-322.

Goldmin (C. R.), Gehietti (M.), Javornicky (P.), Melchiori-Santolini (U.) ET De Ambzaga (E.). 1968. - Primary productivity, bacteria, phyto. and zooplankton in lake Maggiore : Correlations and relationships with ecological factors. Mem. Ist. ital. Idrobiol., 23 : 49-127.

Hatida. (P.). 1967. - Ultraviolet action spectra in algology. A review. photochem. photobiol., 6: 445-460.

Hoвbie (J. E.). 1964. - ${ }^{14} \mathrm{C}$ measurements of primary production in two arctic alaskan lakes. Verh. internat. Verein. Limnol., $15: 360-364$.

Hobrie (J. E.) ET WRIGHT (R. T.) 1965. - Compctition between planktonic bacteria and algae for organic solutes. Mem. Ist. ital. Idrobiol. (suppl.) $18: 175-185$.

Hutchinsov (G. E.). 1957. - A treatise on limnology. I. Geography, physics and chemistry. John Wiley and Sons, Inc. New York, Chapman and Hall, Ltd. London : $1015 \mathrm{p}$.

Javornicky (P.). 1958. - The revision of some quantitative methods for phytoplankton research, Sci. Pap. Inst. Chem. Techn. Prague, 1 : 283-367.

Jorgensen (E. G.). 1964. - Adaptation to different light intensities in the Diatom Cyclotella meneghiniana (Kutz). Physiologia Pl, 17 : $136-145$.

KAsFF (J.). 1967. - Phytoplankton dynamies in an aretic lake. J. Fish. Res. Bd. Can., 24 (9) : 1861-1871.

IAville (H.). 1972 a. - Recherches sur les Chironomidles (Diptera) lacustres du massif de Néouvielle (Hautes-Pyrénées). I. Systémattique, écologie, phénologie. Annls Limnol., (1971), 7 (2) : 173-332.

Lavirde (H.). 1972 b. - Recherches sur les Chironomides (Diptera) lacustres du massif de Néonvielle (Hautes-Pyrénées). II. Communautés et production. Annls Limnol. (1971), 7 (3):335-414.

LCND (J. W. G.) 1949. - Studies on isterionella. I The origin and nature of the cells producing seasonal maxima. $J$. Ecol., $37: 389-419$.

Lind (J. W. G.). 1964. - Primary production and periodicity of Phytoplankton. Verh. internat. Verein. Limnol., 15 : 37-56.

LuND (J. W. (x.). 1965. - - The ecology of the fresh-water phytoplankton. Biol. Rev., 40 (2) : 231-293.

Lund (J. W. G.) Kipling (C.) ET Le CRex (E. D.). 1958. - The inverted microscope method of estimating algal numbers and the statistical basis of estimation by counting. Mydrobiologia, 11 : 143-170.

Margatef (R.). 1965. - Ecological correlations and the relationship between primary productivity and community structure, Mem. Ist. ital. Idrobiol. (suppl.), 18 : 355-364.

Makshim. (S. M.) Er ORR (A.P.). 1955. - Experimental feedings of the Copepod Calamas finmarchicus (Gunner) on phytoplankton cultures labelled with Cit. Deep Sea Res., 3 : 110-114.

Montrmer (C. H.). 1941-42. - The exchange of dissolved substances between mud and water in lakes. J. Ecol., $29: 280-329 ; 30: 147-$ 201.

McMahon (J. W.). 1965. - Some physical factors influencing the feeding behavior of Daphnia magna Straus. Can. J. Zool., $43: 603-611$. 
NALEwaJko (C.), 1966. -- Dry weight, ash and volume data for some freshwater planktonic algae. J. Fish. Res. Bd. Can., 23 : 1 285-1 287.

NAUwERcK (A.), 1959. - Zur Bestimmung der Filtrierrate limnischer Planktontiere. Arch. Hydrobiol. (suppl.) 25 : 83-101.

Nauwerck (A.). 1963. - Dic Beziehungen zwischen Zooplankton und Phytoplankton im See Erken. Symb. bot. upsal., 17 (5) : 163 p.

Nauwerck (A.). 1966, --. Beobachtungen über das Phytoplankton klarer Hochgebirgsseen. Schweiz Z. Hydrol., 28 (1) : 4-28.

Natwerck (A.). 1967. - Das Iatnjajaureprojekt. Rep. Inst. Freshwat. Res, Droltningholm, $47: 56-75$.

NAuwerck (A.). 1968 -. Das Phytoplankton des Latnjajaure 1954-1965. Schweiz Z. Hydrol., 30 (1) : 188-216.

OHIE (W.). 1958. - Diurnal production and destruction rates of phytoplankton in lakes. Rapp. Cons. Explor. Mer, 144 : $129-131$.

Osmera (S.). 1966. - Zur Methode der Festsetzung der Biomasse einiger Planktonk rebstiere. Zool. lisiy, $15: 79-83$.

Ovlirbeck (J.), 1962 - Untersuchungen zum Phosphathaushalt von Grünalgen. III. Das Verhalten der Zellfraktionen von Scenedesmus quadricauda (Turp) Breb. im Tageszyklus unter verschiedenen Belichtungsbedingungen und bei verschiedenen Phosphatverbindungen. Arch. Mikrobiol., $41: 11-26$.

Parsons (T. R.), Stephens (K.) et Strickland) (J. D. H.). 1961. -..- On the chemical composition of eleven species of marine phytoplankters. J. Fish. Res. Bd. Can., 18 (6) : 1001-1016.

Pavoni (M.). 1963. -- Die Bedeutung des Nannoplanktons im Vergleich zum Netzplankton. Schweiz. Z. Hydrobiol., 25 : 219-341.

Pechiankr (R.). 1964 - Planktonproduction in natural lakes and hydroelectric water basins in the alpine region of the Austrian Alps, Verh, internat. Verein. Limnol., $15: 375-383$.

Pechlanir (R.). 1966. - Die Finstertaler Seen (Kühtai, österreich). I. Morphometrie, Hydrographie, Limnophysik und Limnochemie. Arch. IIydrobiol., 62 : $165-230$.

Pechlaner (R.). 1967. - Die Finsterialer Seen (Kühtaj, österreich). II. Das Phytoplankton. Arch. Hydrobiol., $63: 145-193$.

Pechlaner (R.). 1971. - Factors that control production rates and biomass of phytoplankton in high-mountain lakes. Mitt. internat. Verein. Limnol., $19:$ 125-145.

Pechlaner (R.), Bretschko (G.), Goldmand (P.), Pfeifer (H.), Tilzer (M.) ET Weissenbach (H, P.). 1972. - The production processes in two high mountain lakes (Vorderer and Hinterer Finstertaler See, Kühtai, Austria). Proc. UNESCO-IBP Symposium on Productivity Problems of Freshwalers. Kazimierz-Dolny, Poland. May 6-12 $1970: 237-267$.

Rey (J.). 1969. - Ecologie des Cladocères du massif de Néouvielle (Hautes-Pyrénées). Annls Limnol. (1968), 4 (3) : 325-356.

Rey (J.) HT Capbiance (J.). (en prép.). - Peuplement zooplanctonique d'un lac d'altitude des Pyrénées.

Ricumas (S.). 1966. --- The effect of phytoplankton concentration on the feeding rate of Diaptomus oregonensis. Verh. Internat. Verein. Limnol., 16 : 392-398.

Rigien (F. H.). 1961 a. --.- The uptake and release of inorganic phosphorus by Daphnia magna Straus. Limnol. Oceanogr., 6 : 165-174.

Rigi.er (F. H.). 1961 b. -. The relation between concentration of food and feeding rate of Daphnia magna. Can. J. Zool., 39 (6) : 857-868. 
Rigler (F. H.). 1964. - The phosphorus fractions and turnover time of inorganic phosphorus in different types of lakes. Limnol. Oceanogr., 9 : 511-518.

Romanenko (W.I.). 1964. - Heterotrophic assimilation of $\mathrm{CO}_{2}$ by the aquatic microflora. Microbiologia, 33 (4) : 679-683.

Ronhe (W.). 1948. - Environmental requirements of Fresh-water plankton algae. Experimental studies in the ecology of phytoplankton. Symb. bot, upsal., 10 (1) : 1-149.

Rodнe (W.). 1958. - Primärproduktion und Seetypen. Verh. Internat. Verein, Limnol., $13: 121-141$.

RoDHE (W.). 1962. - Sulla produzione di fitoplancton in laghi transparenti di alta montagna. Mem. Ist. ilal. Idrobiol, 15 : 21-28.

RodHe (W.). 1965. - Standard correlations between pelagic photosynthesis and light. Mem. Ist. ital. Idrobiol., (suppl.) 18 : 365-381.

Rodhe (W.), Vollenweidfr (R. A.) re Nauwerck (A.). 1958. - 'The primary production and standing crop of phytoplankton. In : Perspectives in Marine Biology (édité par A. A. Buzzati-Traverso), University of California Press : 299-322.

Rodne (W.), Hobrie (J. E.) eT WRIGHT (R. T.). 1966. - Phototrophy and heterotrophy in high mountain lakes. Verh. Internat. Verein. Limnol., 16 (1) : 302-313.

Rutrner (F.), 1937. - Jimnologische Studien an einigen Seen der Oslalpen. Arch. Hydrobiol., 32 : 167-319.

Ruttner (F.). 1953. - Fundamentals of limnology. Univ. of Toronto Press : 242 p.

Ryther (J.). 1956. -- Photosynthesis in the ocean as a function of light intensity. Limnol. Oceanogr., $1: 61-70$.

SARUiASHI (K.). 1955. - On the equilibrium concentration of carbonic acid substances dissolved in natural water, Pap. Met. Geophys. Tokyo, 6 : $39-55$.

SAUbrerer (F.). 1962, - Empfehlungen für Durchführung von Strahlungs. messungen an und in Gewässern. Mill. int. Verein. theor, angew. Limnol., $11: 1-77$.

Sacneers (G. W.), Trama (F. B.) et Bichman (R. W.). 1962. - Fvaluation of a modified $\mathrm{C}^{14}$ technique for shipboard estimation of photosynthesis in large lakes. Gt. Lakes Res. Div. Inst. Sci. Techn. Mich., $8: 1-61$.

Schindere (D. W). 1971. - - Production of phytoplankton and zooplankton in Canadian Shicld lakes. Proceedings of the IBP-UNESCO Symposium on Productivity Problems of Freshwaters, KazimierzDolny, Poland, May 6-12 1970 : 311-331.

Schindere (D. W.) ET Holmgren (S. K.), 1971. - Primary production and phytoplankton in experimental lakes areas, Northwestern Ontario, and other low carbonate waters, and a liquid scintillation method for mcasuring ${ }^{14} \mathrm{C}$ activity in photosynthesis. J.Fish. Res. Bd. Can., $28: 189-201$.

SMith (E. L.). 1936. - Phofosynthesis in relation to light and carbon dioxide. Proc, natn. Acad. Sci., Wash., 22 : 504.

Sonokin (Y.I.). 1965. - On the trophic role of chemosynthesis and bacterial biosynthesis in water bodies. Mem. Ist. ital. Idrobiol., (suppl.) $18: 187-205$.

Sonokin (Y. I.) ET Kadota (H.), 1972.-Techniques for the assessment of microbial production and decomposition in fresh-waters. IBP Handbook $n^{\circ} 23$. Blackwell Scientific Publications, Oxford : 112 p. 
Steemaxi-Nielsfen (E.). 1952. - The use of radioactive carbone $\left(\mathrm{C}_{1 \mathrm{t}}\right.$ ) for measuring organic production in the sea. J. cons. perm. int. Explor. Mer, $18: 117-140$.

SteEmano-Nifisen (E.). 1955. - - The production of organic matter by the phytoplankton in : Danish lake receiving extraordinarily great amounts of nutrient salts. Hydrobiologia, $7: 68-74$

Steeman-Nietser (E.). $1960 \mathrm{a}$. - Dark fixation of $\mathrm{CO}_{2}$ and measurements of organic productivity with remarks on chemosynthesis. Physiologia Pl., 13 : 348-387.

SteEmaNN-Niblsex (E.). $1960 \mathrm{~b}$. - Productivity of the oceans. A, Kev. Pl. Physiol., 11 : 341-362.

StemmanN-Nikisix (E.). 1962. - Inactivation of the photochemical mechanism in photosynthesis as a mean to protect the cells against too high light intensities, Physiologia Pl., 15 : 161-171.

StbemaNo-Nielses (E.). 1965. - On the determination of the activity in $\mathrm{C}^{14}$ ampoules for measuring primary production. Limnol. Océanogr,, (suppl.) $10: 247-253$.

StrathmaNe (R.R.). 1967. Estimating the organic carbon content of phytoplankton from cell volume or plasma volume. Limnol. Oceanogr., 12 (3) : 411-419.

T.uling (J. F.), 1957 a. -... Plotosynthetic characteristics of some freshwater plankton diatoms in relation to underwater radiation. New Phytol., 56 : $29-50$.

Talling (J. F.). 1957 b. - The phytoplankton population as a compound photosynthetic system. New Phylol., 56 : 133-149.

Tilzer (M.). 1972 a. - Dynamik und Jroduktivität von Pliytoplankton und pelagischen Bakterien in einem Hochgebirgssee (Vorderer Finstertaler Sce, österreich). Arch. IIydrobiol. (suppl.) 40 (3) : 201-273.

Tr.J.er (M.). 1972 b. - Bacterial productivity of a high-mountain lake. Verh. Internat. Verein, Limnol., $18: 188-196$.

Uтекмӧнt, (H.). 1958. - Zur Vervollkommung der quantitativen Phytoplankton-Methodjk. Mitt. int. Verein, theor, angew, Limnol., 9 : 1-38.

Volofeswalder (R. A.) it Nauwerck (A.). 1961. -- Some observations on the $C_{11}$ method for measuring primary production. Verh, Inlernat. Verein. Limnol,, 14 : 134-139.

Vot.JeNwionen (R. A.). 1965. - Calculations models of photosynthesis depth curves, and some implications regarding day rate estimates in primary production measurements. Mem. Ist. ital. Idrobiol., (suppl.) $18: 425-4557$.

Voldenweiner (R.A.), 1968. - Recherches sur l'aménagement de l'eau Jes hases scientifiques de l'eutrophisation des lacs et des caux courantes sous l'aspect particulier du phosphore et de l'azote comme facteurs d'eutrophisation. Rappor/ O.C.D.E. DAS/CSI/68.27 : $128 \mathrm{p}$.

Votdexweidfe (R.A.). 1969. - A manual on methods for measuring primary production in aquatic environments. IBP. IIandbook $N^{\circ} 12$, Blackwell Scientific: Publication, Oxford and Edimburg: 244 p.

WATt (W. D.). 1965. - Release of dissolved organic material from the cells of phytoplankton populations. Proc. R. Soc. B., 164 : $\mathbf{2 1 - 5 5 1 .}$

Winberci (G. (i.) ET Collaboratcurs (lio.). 1971. - Symbols, units and conversion factors in studies of freshwater productivity. IBP' Central Office, 7 Marylebone Road, London, $23 \mathrm{p}$. 
Wood (G. K.). 1970. - Effect of the beta spectrum on self-absorption of beta radiation from ${ }^{14} \mathrm{C}$. Int. J. appl. Radiat. Isotopes, 21 : 581-586.

Wood (G. K.). 1971. - Self-absorption corrections for the ${ }^{14} \mathrm{C}$ method with $\mathrm{BaCO}_{3}$ for measurement of primary productivity. Ecology, 52 (3) : 491-498.

Wright (J. G.). 1960. - The limnology of Canyon Ferry Reservoir : III. Some observations on the density dependence of photosynthesis and its cause. Limnol. Oceanogr., 5 : 356-361.

Wright (R. T.). 1964. - Dynamics of a phytoplankton community in an ice covered lake. Limnol. Oceanogr., 9 : 163-178.

Yentsch (C. S.) ET Ryther (J. H.). 1957. - Short-terms variation in phytoplancton chlorophyll and their significance. Limnol. Oceanogr., 2 : 140-142. 
Fig. 20. - Évolution et distribution des populations de Cyclotella au lac de Port-Bielh, en été
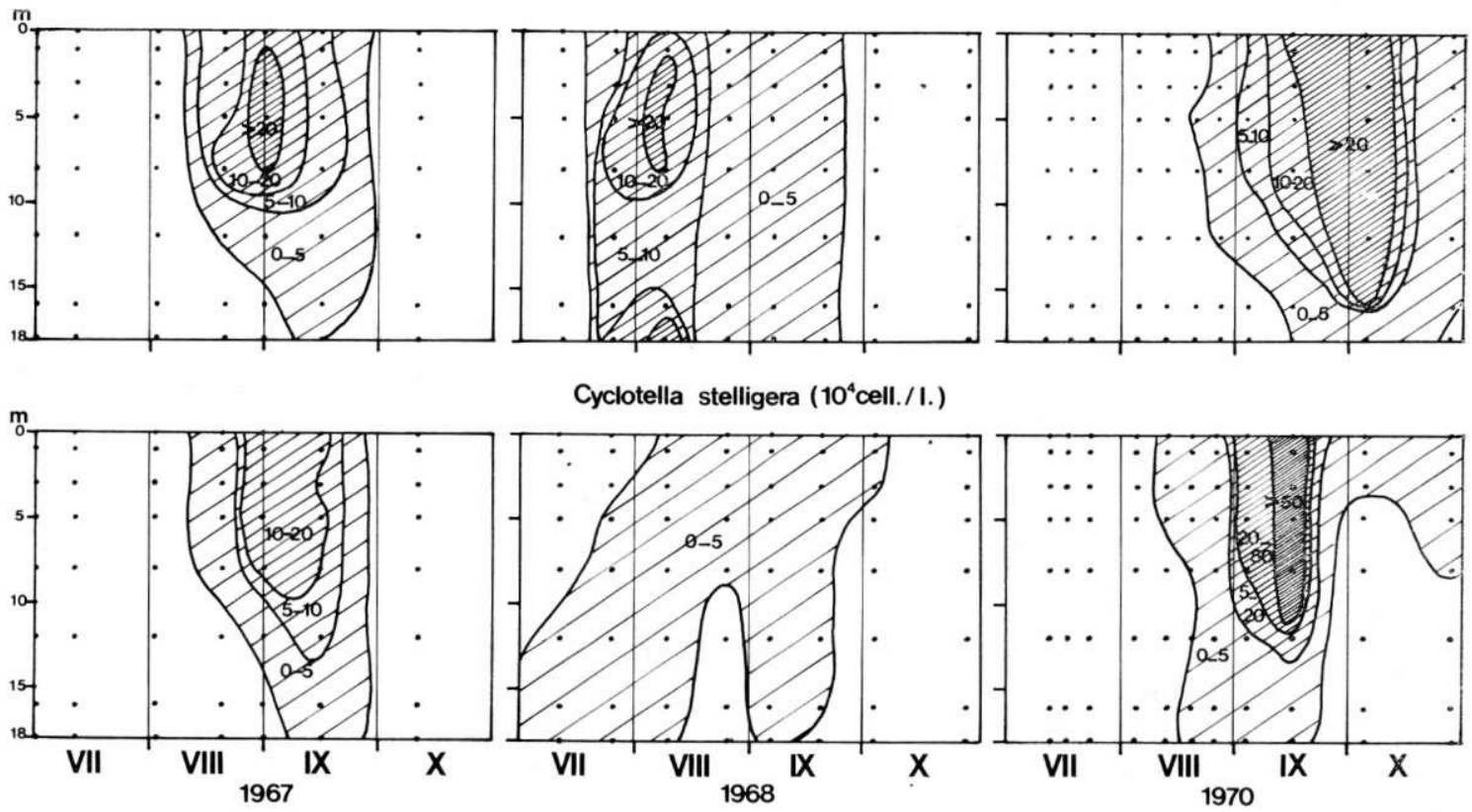

Cyclotella stelligera $\left(10^{4} c e l l . / I.\right)$

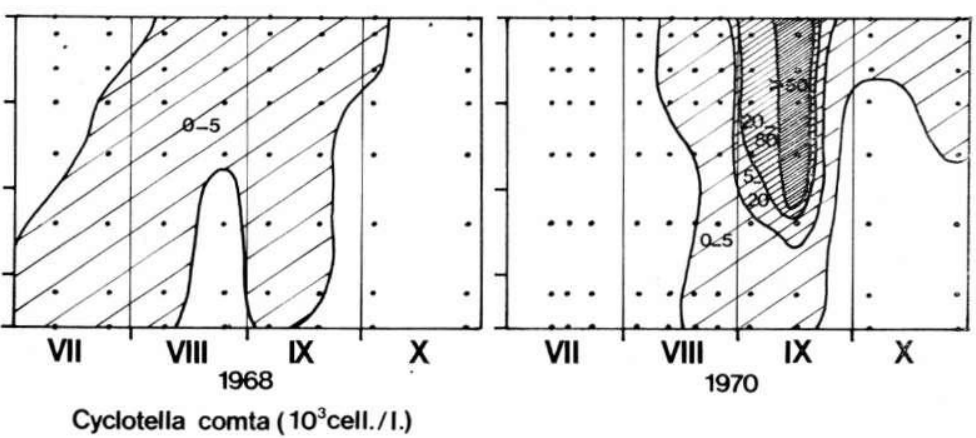

Fig. 21. - Évolution et distribution des populations de Cryptomonadines au lac de Port-Bielh, en été.
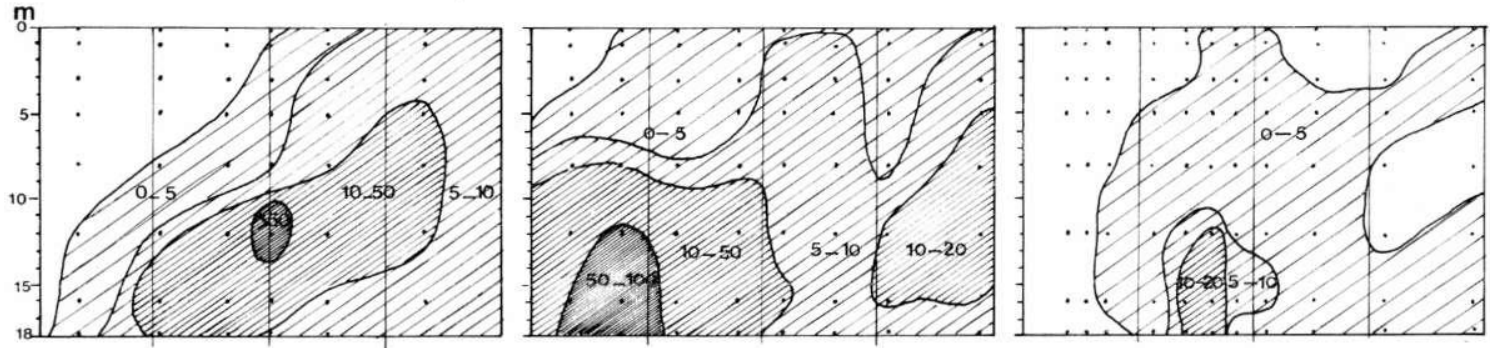

Chroomonas minuta $\left(10^{4}\right.$ cell./I.
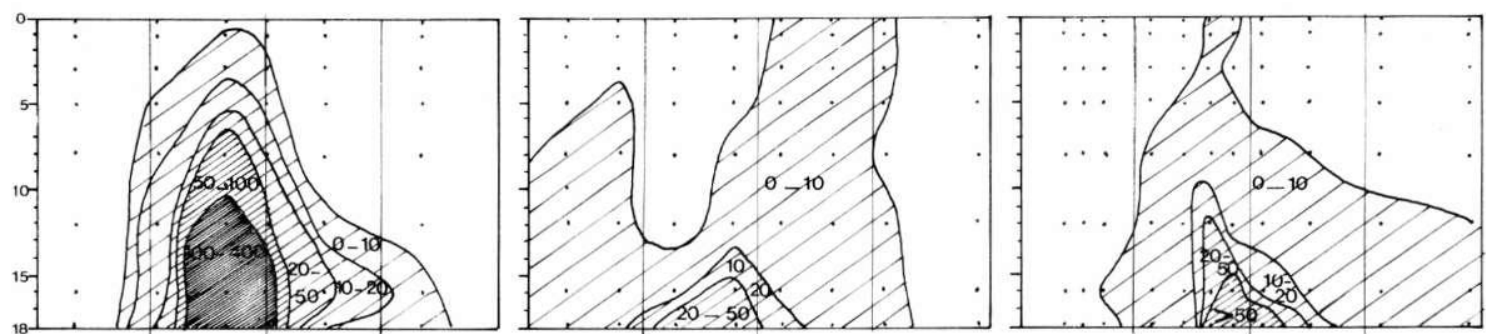

Cryptomonas ovata $\left(10^{3} \mathrm{cell} / \mathrm{l}\right.$. $)$
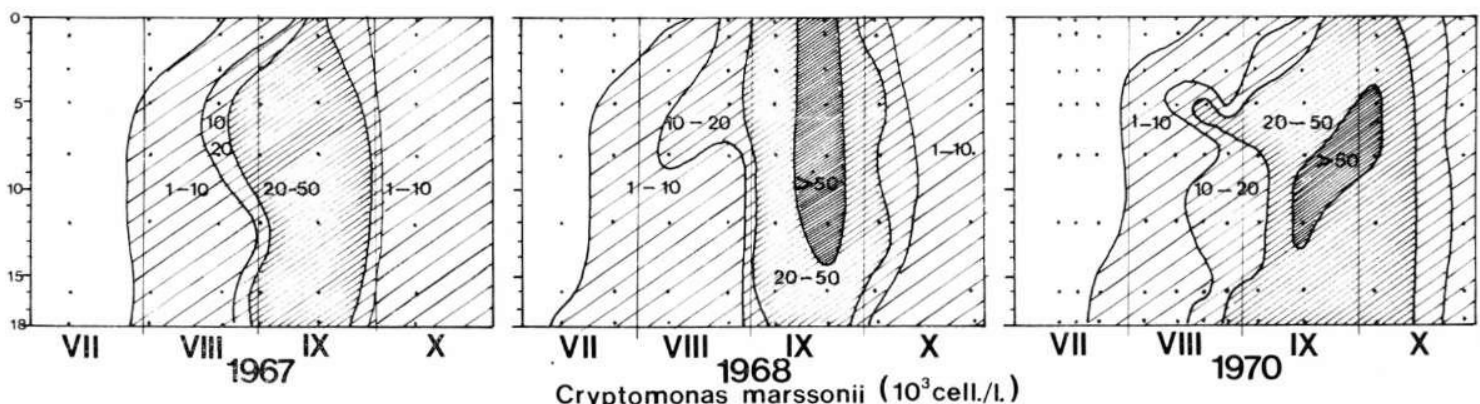
FIG. 18. - Evolution et distribution des populations de trois espèces dominantes de Chlorophycées du lac de Port-Bielh, en été. Hachures horizontales

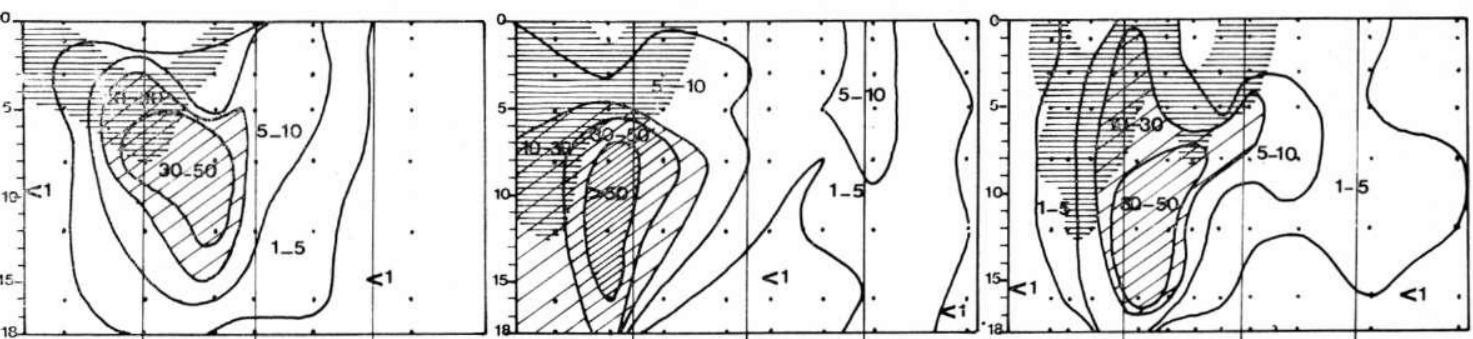

Chlamydomonas spp. ( $\left.10^{4} \mathrm{cell} / \mathrm{I}\right)$

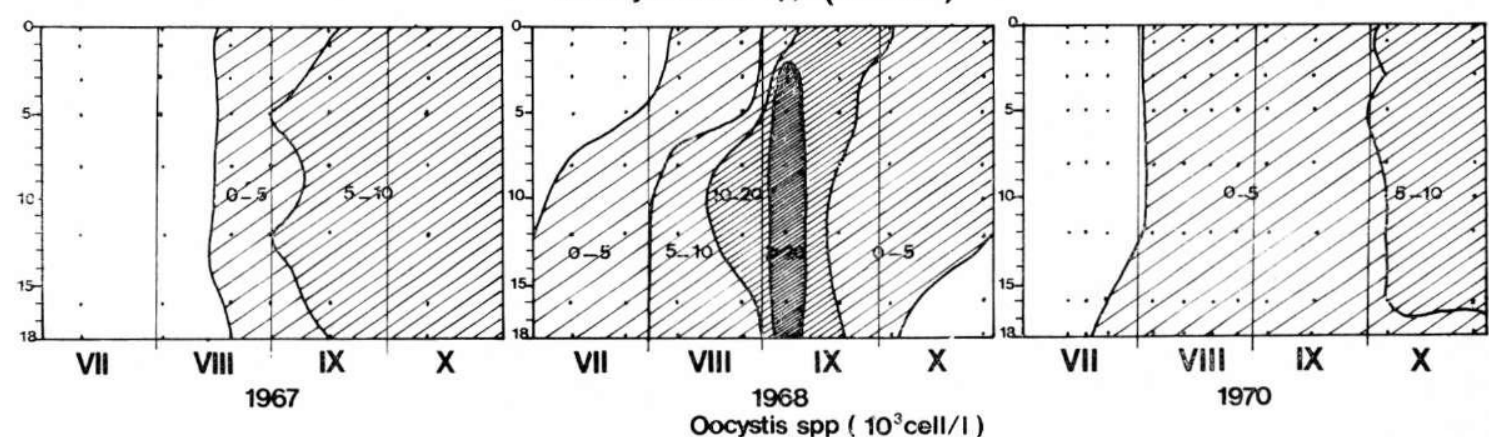

FIG. 19. - Evolution et distribution des populations de Chrysomonadines dominantes au lac de Port-Bielh, en été.
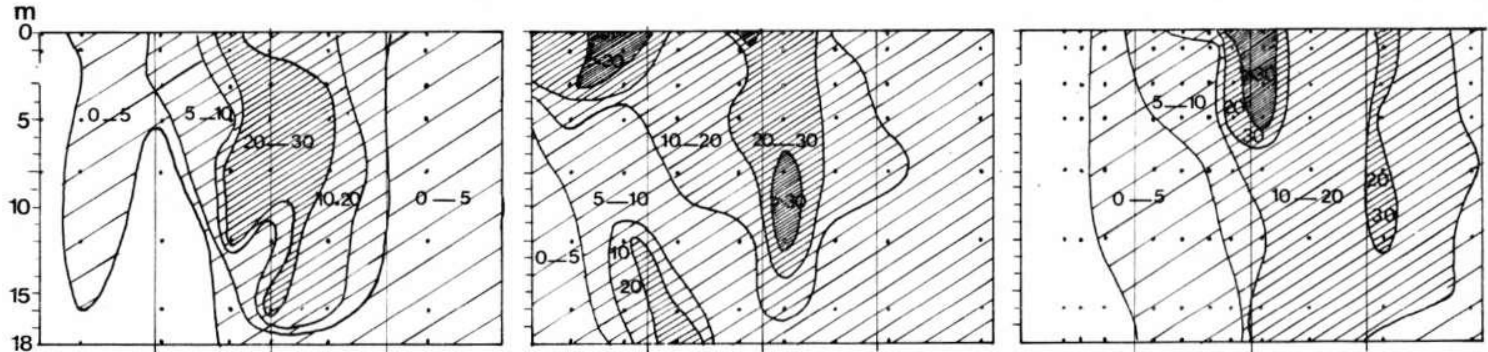

Chromulina cf. minima $\left(10^{5} \mathrm{cell} / 1\right)$
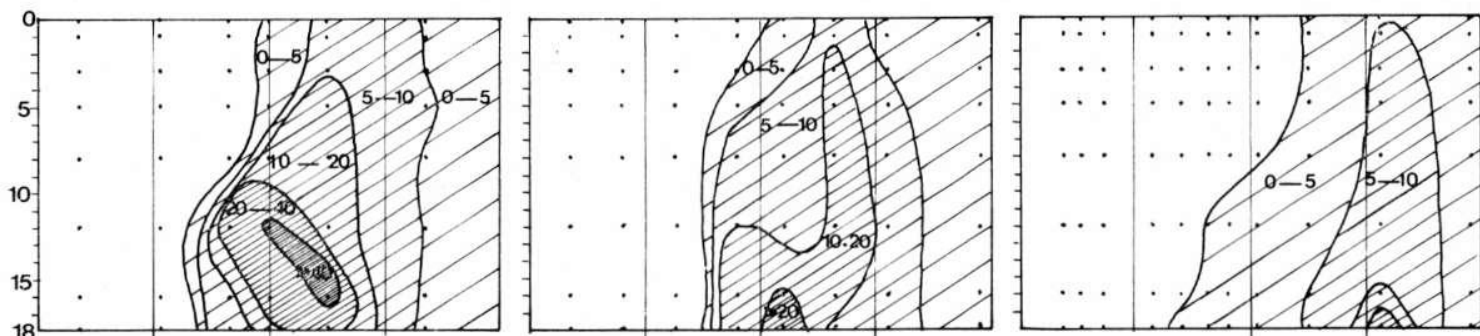

Chromulina cf. glacialis (10 cell/1)
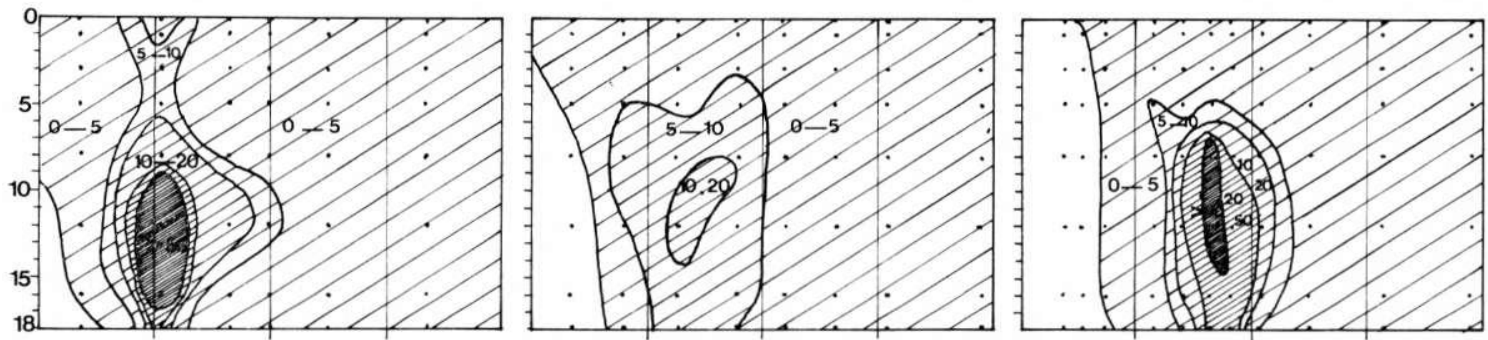

Erkenia subæquiciliata $\left(10^{5} \mathrm{cell} / 1\right)$
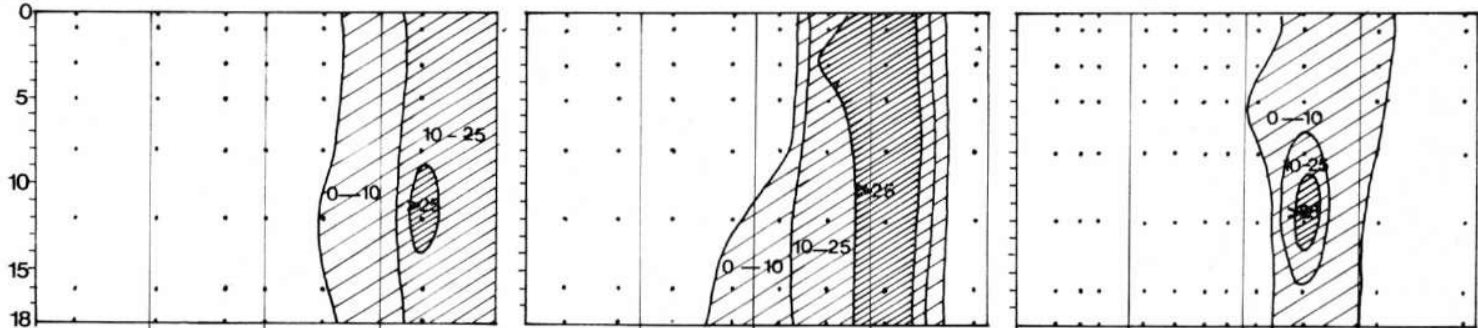

Ochromonas cf. elegans $\left(10^{4} \mathrm{cell} / \mathrm{l}\right)$
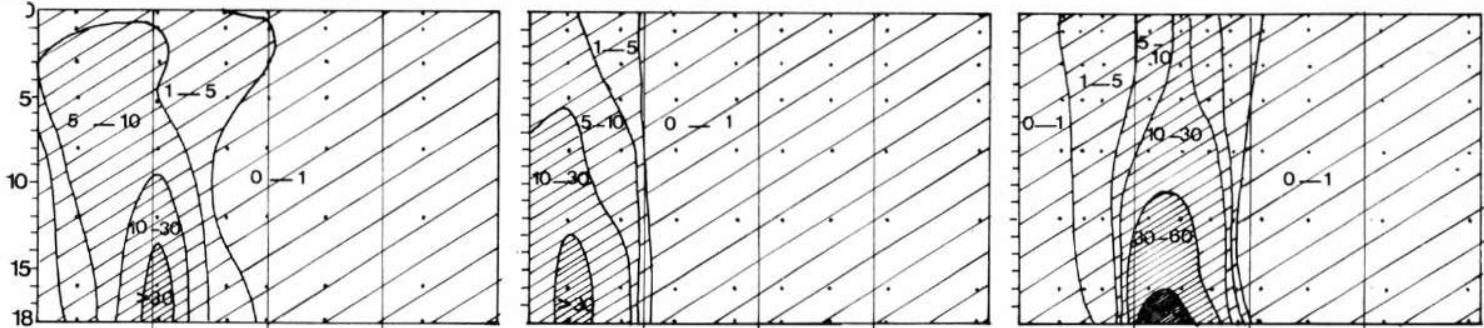

Ochromonas + Chromulina $\left(10^{5} \mathrm{cell} / \mathrm{I}\right)$
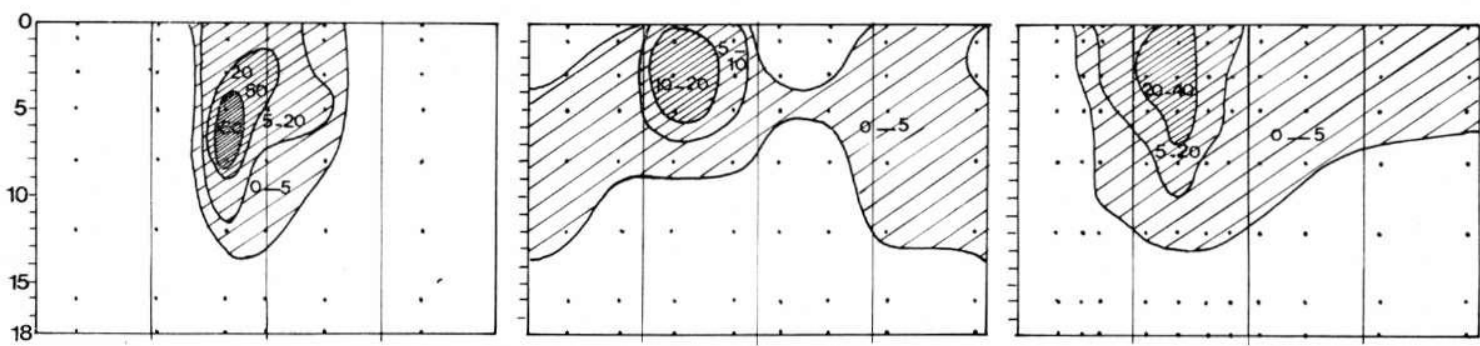

Pseudokephyrion sp $\left(10^{4}\right.$ cell/1)
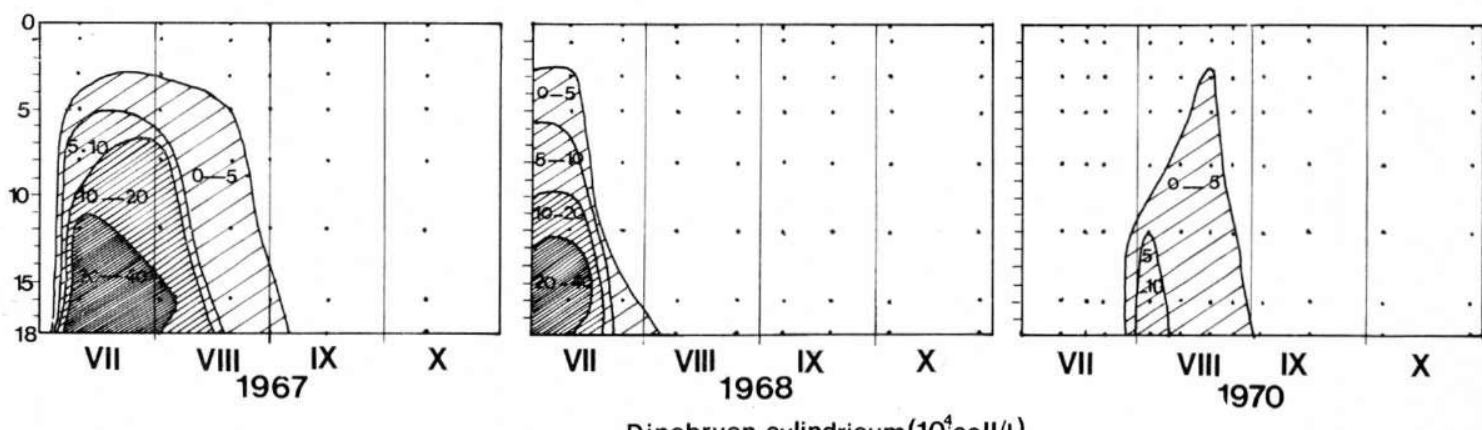